University of Louisville

ThinkIR: The University of Louisville's Institutional Repository

Electronic Theses and Dissertations

8-2004

\title{
The roles of pancreatic beta cell antioxidants in islet transplantation and type 1 diabetes.
}

Xiaoyan Li

University of Louisville

Follow this and additional works at: https://ir.library.louisville.edu/etd

\section{Recommended Citation}

$\mathrm{Li}$, Xiaoyan, "The roles of pancreatic beta cell antioxidants in islet transplantation and type 1 diabetes." (2004). Electronic Theses and Dissertations. Paper 828.

https://doi.org/10.18297/etd/828

This Doctoral Dissertation is brought to you for free and open access by ThinkIR: The University of Louisville's Institutional Repository. It has been accepted for inclusion in Electronic Theses and Dissertations by an authorized administrator of ThinkIR: The University of Louisville's Institutional Repository. This title appears here courtesy of the author, who has retained all other copyrights. For more information, please contact thinkir@louisville.edu. 


\title{
THE ROLES OF PANCREATIC BETA CELL ANTIOXIDANTS IN ISLET TRANSPLANTATION AND TYPE 1 DIABETES
}

\author{
By \\ Xiaoyan Li \\ B.S. Shanghai Medical University, 1992 \\ M.S. Shanghai Medical University 1999 \\ M.S. University of Louisville, 2002

\begin{abstract}
A Dissertation
Submitted to the Faculty of the

Graduate School of the University of Louisville in Partial Fulfillment of the Requirements for the Degree of

Doctor of Philosophy

Department of Pharmacology and Toxicology

University of Louisville

Louisville, Kentucky
\end{abstract}

August 2004 
THE ROLES OF PANCREATIC BETA CELL ANTIOXIDANTS IN ISLET TRANSPLANTATION AND TYPE 1 DIABETES

By

\author{
Xiaoyan Li \\ B.S. Shanghai Medical University, 1992 \\ M.S. Shanghai Medical University 1999 \\ M.S. University of Louisville, 2002
}

A Dissertation Approved on

August 5, 2004

By the following Dissertation Committee:

\author{
Dissertation Director
}




\section{ACKNOWLEDGEMENTS}

My sincere thanks go to the following people for the generous help they offered in many different ways:

To my mentor, Dr. Paul N. Epstein, for his faith in me as a research scientist and his dedication to the furthering of my education in the field of medical research. I also want to thank his ubiquitous support and guidance.

To my committee members Drs. Evelyne Gozal, David W. Hein, Michele M. Kosiewicz, and William M. Pierce, for their valuable suggestion, critical evaluation of this project, and more importantly, their time.

To the faculty and staff in the Department of Pharmacology and Toxicology and the Department of Pediatrics at the University of Louisville for their friendship and help.

To my beloved daughter, Grace, and husband, Hainan Chen, for their understanding, support, patience and valuable discussion and technical assistance throughout the years.

This work was supported by grants from the American Diabetes Association and National Institutes of Health (NIH) grants RO1-DK52309 and RO1-DK58100. 


\title{
ABSTRACT \\ THE ROLES OF PANCREATIC BETA CELL ANTIOXIDANTS IN ISLET TRANSPLANTATION AND TYPE 1 DIABETES
}

\author{
Xiaoyan Li
}

August 5, 2004

Pancreatic beta cells are extremely vulnerable to destruction by Reactive Oxygen Species (ROS). In type 1 diabetes and islet transplantation ROS are thought to be involved in the loss of beta cells. To test the role of antioxidant in islet transplantation. In our lab we have determined that transgenic overexpression of the antioxidant protein metallothionein (MT) in pancreatic beta cells provides broad resistance to oxidative stress by scavenging most kinds of ROS. A direct test of hypoxia/reperfusion sensitivity was shown that MT markedly reduced ROS production and improved islet cell survival. Furthermore, in both syngeneic transplantation and allotransplantation, MT islets preserved high insulin content and extended the duration of euglycemia two-fold longer than nontransgenic islets. The time course of protection suggested that the major mode of MT action may have been protection from hypoxia or hypoxia/reperfusion.

To test the role of antioxidants in type 1 diabetes, three lines of antioxidant transgenic NOD mice were produced with $\beta$-cell specific overexpression of MT, catalase (Cat) or MnSOD. Unexpectedly, the two cytosolic antioxidants, MT and Cat, but not 
mitochondrial MnSOD, dramatically hastened both spontaneous onset diabetes and cyclophosphamide (CYP) induced diabetes in NOD mice. MT and Cat transgenic $\beta$-cells died by apoptosis more rapidly than control $\beta$-cells. These data indicate that cytoplasmic ROS may have some protective role in $\beta$-cells against type 1 diabetes, which is a role that has been recognized in some other cell types.

To elucidate this protective mechanism, we assessed the status of the PI3K/Akt/Foxo1/PDX-1 pathway, one of the most important survival pathways in the $\beta$-cells. Western blots of islets from transgenic and control NOD mice showed that both in vivo after CYP injection and in vitro after cytokine treatment phosphorylation of Akt and Foxo-1, and PDX-1 expression were significantly reduced in transgenic islets. In vitro MT sensitized NOD islets to cytokine induced cell death even though MT efficiently scavenged cytokine induced ROS production. Orthovanadate, a protein tyrosine phosphatase (PTP) inhibitor rescued the sensitizing effect of MT to cytokine toxicity. Our data imply that elevated cytosolic antioxidants may result in higher PTP activity in $\beta$-cells by protecting PTPs from ROS, thereby cause decreased $\beta$-cell survival and accelerating type 1 diabetes in NOD mice.

The data from this project demonstrated that overexpression of antioxidants protects islets from ROS damage produced during early phase islet transplantation but sensitizes $\beta$-cells to diabetes in NOD mice. 


\section{TABLE OF CONTENTS}

PAGE

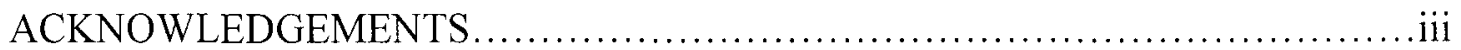

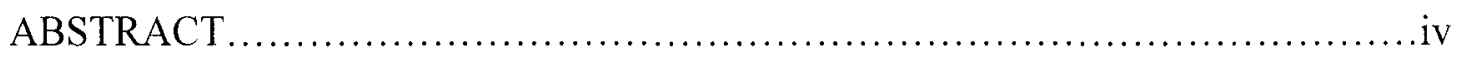

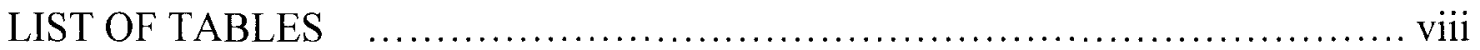

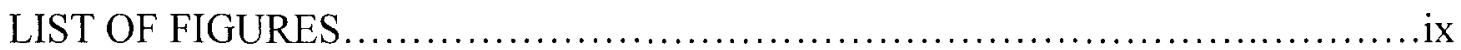

CHAPTER

I. THE ROLE OF MT IN ISLET TRANSPLANTATION $\ldots \ldots \ldots \ldots \ldots . . . . \quad 1$

Introduction ..............................................

Materials and Methods .......................................... 6

Results................................................... 14

Discussion .................................................... 17

II. THE ROLE OF ANTIOXIDANTS IN TYPE 1 DIABETES

Introduction................................................ 28

Materials and Methods ............................................ 68

Results...................................................... 84

Discussion...................................................... 91

Limitations for this study ..................................... 97

REFERENCES .......................................................... 124 
CURRICULUM VITAE . 


\section{LIST OF TABLES}

TABLE

PAGE

2-1. Characteristics of FVB control and MT transgenic islets. 103 


\section{LIST OF FIGURES}

Figure

PAGE

1-1. ROS production in dispersed FVB control and transgenic MT islet cells 20

1-2. Nitric oxide induced damage in FVB and MT transgenic islets exposed to SNAP for $24 \mathrm{hrs}$ 21

1-3. ROS production in FVB and MT islets exposed to hypoxia for $7 \mathrm{hrs}$

1-4. Cell viability in MT transgenic and FVB control islets after hypoxia exposure

1-5. Graft insulin content of FVB and MT islets after syngeneic transplantation

1-6. Percentage of euglycemic recipients after receiving FVB or MT transgenic islets after transplantation 25

1-7. Nitrotyrosine production in FVB and MT allografts 6 days after transplantation 26

2-1. The breeding program for generation of consgenic NOD mice with beta cell antioxidant overexpression 98

2-2. PCR-based genotyping of diabetic susceptible alleles in congenic NOD mice with beta cell specific expression of MnSOD transgene 90

2-3. Catalase transgenes overexpressed in pancreatic islet 100 
2-4. Immunostaining for MT, Catalase and MnSOD in transgenic and control NOD mice

2-5. MT overexpression reduced STZ induced diabetes on NOD background ..... 102

2-6. No alteration of Glutathione peroxidase activity in transgenic islets 104

2-7. Insulitis and pancreatic insulin level in transgenic and control NOD mice 105

2-8. Cumulative diabetes incidence in control NOD, transgenic MTNOD ......... 106

2-9. Preserved pancreatic insulin levels after CYP injection

2-10. Accelerated spontaneous diabetes onset in MTNOD and CatNOD male mice 108

2-11. Increased pancreatic islet apoptosis in MT transgenic NOD mice after injection of CYP

2-12 The effect of MT and catalase transgenes on islet-brain protein-1 (IB-1) expression in NOD mice before and after CYP administration

2-13. Insulitis in MT transgenic and nontransgenic NOD mice before and after CYP administration

2-14. Cell viability in MTNOD transgenic and NOD control islets after cytokines' treatment

2-15. Cell viability in CatNOD transgenic and NOD control islets after cytokines' treatment

2-16. Increased caspase-3 expression in MTNOD islets after cytokine treatment 114

2-17. The effect of MT and catalase transgenes on islet-brain protein-1 (IB-1) expression in NOD islets treated with cytokines 115

2-18. Reduced Akt phosphorylation in MTNOD mice after CYP injection 116 
2-19. Reduced Foxo phosphorylation in MTNOD mice after CYP injection

2-20. Reduced PDX-1 expression in MTNOD mice after CYP injection

2-21. Reduced activity of the pathway from P-Akt through PDX-1 CatNOD islets obtained from the mice treated with CYP

2-22. The PI3K inhibitor wartmanin sensitizes to cytokine toxicity in NOD but not MTNOD islets

2-23. Western blot indicating reduced activity of the pathway from P-Akt through PDX-1 in MTNOD islets treated with cytokines

2-24. Reduced ROS production in MTNOD and CatNOD islets following treatment with cytokines

2-25. The rescue effect of orthovanadate against cytokine induced islet cell death in MTNOD islets 


\section{CHAPTER I}

\section{THE ROLE OF MT IN ISLET TRANSPLANTATION}

\section{INTRODUCTION}

\section{Diabetes mellitus}

Diabetes mellitus has been defined on the basis of disturbed carbohydrate metabolism, specifically, hyperglycaemia. There are two major forms: Type 1 (insulin-dependent) diabetes mellitus (IDDM) and Type 2 (non-insulin-dependent) diabetes mellitus (NIDDM). In the United States, there are 18.3 million people, or $6.3 \%$ of the population, who have diabetes. It is estimated that $5-10 \%$ of Americans who are diagnosed with diabetes have type 1 diabetes. Approximately 90-95\% (17 million) of Americans who are diagnosed with diabetes have type 2 diabetes. In NIDDM, insulin resistant and beta cell dysfunction have been identified as two major defects. However, IDDM develops as a consequence of the selective destruction of insulin-producing beta cells by an autoimmune aggression.

In spite of extensive investigation, the etiology of both Type 1 and Type 2 diabetes is still unknown, although genetic and environmental factors are found to be involved. The evidence for genetic component of diabetes mellitus has come from family studies including monozygotic investigation. Monzygotic twin concordance rates in NIDDM may reach more than $90 \%$, while in IDDM they do not exceed 50\%.(1). Environmental 
factors including diet, exercise and age play very important role in the pathogenesis of NIDDM. Also environmental factors such as hormonal, dietary, viral, climatic, toxic and psychological events are shown to be involved in type 1 diabetes onset. (2-5).

\section{$\underline{\text { Islet transplantation }}$}

Transplantation of pancreatic islets is considered to be one of the most effective treatments for Type 1 diabetes (6). Recently, islet transplantation using the Edmonton protocol (7) achieved insulin independence in 12 out of 15 diabetic patients for one year. However wide spread application of transplantation therapy is still limited by the need for more than one donor pancreas per recipient and difficulties in maintaining long-term euglycemia (8). One obstacle has been that many islets are lost during the initial stages of transplantation $(9 ; 10)$. Shortly after implantation islet grafts function poorly and many transplanted beta cells undergo apoptosis prior to stable engraftment. This increases the mass of islets needed to achieve euglycemia (11). Unfortunately there is an extreme shortage of human pancreatic islet donors. Therefore instead of increasing the number of islets implanted, a more desirable strategy is to improve islet graft survival during the early stages of transplantation. However, to date no impressive regimen has been devised to prevent early graft damage.

Reactive oxygen species (ROS) are involved in both early islet graft loss and longer term immune rejection. Shortly after implantation, islet grafts are exposed to nonspecific inflammatory events (12) that generate proinflammatory cytokines, nitric oxide and reactive oxygen species (ROS). These local, nonspecific inflammatory 
mediators attack implanted islets. In the rat islet transplant model, grafts are destroyed by high level of nitric oxide released from allogenic (13) or syngenic (14) macrophage. In addition, the graft suffers from an initial period of hypoxic ischemia after transplantation. Oxygen tension measured within the islet graft is initially very low (15). In fact newly transplanted islets are essentially avascular, leaving them with insufficient oxygen and nutrients until the process of revascularization is completed. This ischemic microenvironment, followed by reperfusion as a consequence of revascularization, produces conditions known to induce detrimental ROS in transplanted organs (16-18).

The damaging effects of ROS on pancreatic islets have been widely investigated in diabetes $(19 ; 20)$ as well as in islet transplantation (21-23). Exposure of isolated human islets (24), rodent islets $(25 ; 26)$ or beta cell lines (27) to ROS markedly inhibits beta cell function and results in beta cell death. Compared to other cell types, pancreatic beta cells are particularly susceptible to destruction caused by ROS (28). This is probably because islet cells contain very low levels and activities of several ROS detoxifying systems (29). Recent studies reported that early islet graft loss could be ameliorated by various antioxidant combinations such as $\alpha$-tocopherol (30) and other vitamins (31). Other reports have investigated transgenic overexpression of single, specific antioxidant protein. Protection from mitochondrial superoxide radical by adenoviral mediated expression of MnSOD (32) was sufficient to extend islet graft function by $50 \%$. However, in our laboratory, we found that overexpression of the specific, hydrogen peroxide detoxifying protein catalase failed to prevent insulin loss in syngeneic islet grafts (33). To test whether beta cell protection could be improved by protecting against 
multiple species of ROS several laboratories have expressed more than one antioxidant enzyme. In insulin secreting RINm5F cells, combined expression of $\mathrm{Cu} / \mathrm{Zn}$ SOD plus catalase or $\mathrm{Cu} / \mathrm{Zn}$ SOD plus glutathione peroxidase provided more protection against hydrogen peroxide, superoxide radical, and nitric oxide than expression of either transgene alone $(34 ; 35)$. Co-administration of SOD and catalase in cultured rat islets more effectively prevented alloxan induced destruction than either antioxidant alone (36). These results indicated that enhanced protection was possible by scavenging more than one species of ROS. Therefore, we hypothesized that a significant improvement of islet graft survival could be achieved if the donor islets were protected by a potent antioxidant protein with a broad spectrum of ROS scavenging activity, such as metallothionein (MT).

MT is a low molecular weight, cysteine-rich and highly inducible protein that binds heavy metal with high affinity. MT appears to play an important role in metal metabolism and detoxification. Due to its many cysteine residues MT also functions as a potent antioxidant. Elevated expression of MT in pancreatic beta cells, produced either by zinc induction $(37 ; 38)$ or by transgenic techniques (39), has been shown to protect from streptozotocin (STZ) induced beta cell damage and diabetes. Studies in cell-free system have demonstrated that MT is able to scavenge a wide range of ROS including superoxide, hydrogen peroxide, hydroxyl radical and nitric oxide at higher efficiency than other antioxidants such as GSH (40-42). However, it is not certain that MT will provide such a broad spectrum of antioxidant function in vivo. 


\section{MATERIALS and METHODS}

\section{Animals}

MT transgenic mice were established in our laboratory on the FVB strain with pancreatic beta cell overexpression of the human MT II gene, as described previously (43). In more detail, the MT transgene, designated HMT, was constructed utilizing the plasmid INS.HBS provided by Dr. Timothy Stewart (Genentech, California). This plasmid contained the human insulin promoter and first intron followed by unique BamH I and Hind III sites. A $2.4 \mathrm{~kb}$ Nco I / Hind III fragment containing all introns and exons of the human MT II gene was ligated behind the insulin promoter utilizing the BamH I and Hind III sites of INS.HBS. Prior to ligation the Nco I and BamH I sites were blunt ended with Klenow polymerase. Before microinjection, the 4100 bp HMT transgene was removed from plasmid sequences by cutting with Hind III and EcoRI. The HMT- 1 transgenic line was used in this study since this line has the highest expression of MT. Recipient Balb/c mice were purchased from Jackson Laboratory (Bar Harbor, Maine). All mice were housed in ventilated cages at the University of Louisville Research Resources Center with free access to water and standard mouse diet. All animal procedures were approved by the Institutional Animal Care and Use Committee, which is certified by the American Association of Accreditation of Laboratory Animal Care.

\section{Chemicals}

Streptozotocin, 3-morpholinosydnonimine (SIN-1), S-nitro-N-acetyl-penicillamine (SNAP), hypoxanthine, xanthine oxidase, collagenase (type V), Ficoll and trypsin were 
obtained from Sigma (St. Louis, MO). Hank's balanced salt solution (HBSS), RPMI 1640 medium, and fetal bovine serum (FBS) were supplied by Gibco BRL (Rockville, MD). Rat insulin standard was bought from Linco (St. Charles, MO). Rabbit antiserum to guinea pig insulin, was purchased from BioGenex (San Ramon, CA). Monoclonal anti-nitrotyrosine antibody was supplied by Cayman (Ann Arbor, MI). 5-(6)chloromethyl-2', 7'-dichlorodihydrofluorescein diacetate $\left(\mathrm{CM}-\mathrm{H}_{2} \mathrm{DCFDA}\right)$ was purchased from Molecular Probes (Eugene, OR). Alamar Blue was purchased from Biosource International (Camarillo, CA).

\section{Islet preparation}

The isolation procedure was based on a modification of the method of Gotoh et al (44) and has been described previously(45). Isolated islets were cultured overnight in RPMI1640 medium containing $10 \%$ BSA, 2\% Penicillin-Streptomycin before the transplantation and in vitro studies, which were performed on the second day.

\section{Measurements of ROS production}

To measure ROS production in single islet cells, the overnight cultured islets were first dispersed into individual cells by treatment with trypsin (0.0075\%) in $\mathrm{Ca}^{2+}$ and $\mathrm{Mg}^{2+}$ free Hanks' solution at $37^{\circ} \mathrm{C}$ for $10 \mathrm{~min}$ followed with mechanical dispersal by 50 times of repeat pipetting, as described previously (46). A cell membrane-permeable and oxidant sensitive fluorescent dye 5-(6)-chloromethyl-2', 7'dichlorodihydrofluorescein diacetate (CM- $\mathrm{H}_{2}$ DCFDA) was used to measure ROS. The dispersed islet cells were loaded with $10 \mu \mathrm{M}$ CM- $\mathrm{H}_{2}$ DCFDA for 30 min followed by 
three washes of fresh culture medium without phenol red. The cells were resuspended in culture medium without phenol red. After the cells were counted, the dispersed islet cells containing CM- $\mathrm{H}_{2}$ DCFDA were distributed into a 96-well plate at concentration of 40,000 cells per well in $200 \mu$ islet culture medium without phenol red. The exogenous sources of ROS: $\mathrm{H}_{2} \mathrm{O}_{2}$, SIN-1 or hypoxanthine/xanthine oxidase, were added quickly to the wells. With the addition of ROS, the increase of fluorescence intensity in each well was measured on a fluorescent microplate reader (Tecan, Durham, NC) at an excitation wavelength of $485 \mathrm{~nm}$ and an emission wavelength of $530 \mathrm{~nm}$. The data were expressed as fluorescent intensity per 40,000 cells.

ROS production in whole islets following hypoxia treatment was measured with a method modified from the procedure of Ye, et al (47) in our laboratory. Briefly, the hypoxia treated or untreated FVB control or MT transgenic islets were loaded with 5 $\mu \mathrm{M} \mathrm{CM}-\mathrm{H}_{2} \mathrm{DCFDA}$ for $30 \mathrm{~min}$ followed by three washes of fresh culture medium. The fluorescence of each islet was activated at an excitation wavelength of $485 \mathrm{~nm}$ and recorded at an emission wavelength of $530 \mathrm{~nm}$. ROS was monitored from randomly sampled individual islets using an Olympus IX70 inverted microscope equipped with a digital cooled CCD camera. Images were analysed with ImagePro software (Media Cybernetics, Silver Spring, MD). More than one hundred islets from at least three separate islet isolations were studied for each group. The results were expressed as the mean fluorescence intensity.

\section{Nitric oxide in vitro studies}


Isolated FVB and HMT-1 islets were exposed to different concentrations of a nitric oxide donor, S-nitro-N-acetyl-penicillamine (SNAP) for $24 \mathrm{hrs}$. Apoptotic and necrotic DNA were detected with an anti-histone biotin/anti-DNA POD ELISA ${ }^{\text {plus }}$ kit (Roche, Indianapolis, IN) based on the manufacturer's instructions. Briefly, 40 to 50 islets were cultured for $24 \mathrm{hrs}$ in $500 \mu \mathrm{l}$ fresh culture medium in a $1.5 \mathrm{ml}$ microtube with or without SNAP treatment. After treatment the microtube was centrifuged at $200 \times \mathrm{g}$ for $10 \mathrm{~min}$ at

$4{ }^{\circ} \mathrm{C}$. The supernatant was removed as the necrosis DNA sample. The pellet was lysed with $100 \mu \mathrm{l}$ lysis buffer for $30 \mathrm{~min}$ at room temperature. The microtube was centrifuged again at $200 \times \mathrm{g}$ for 10 minutes at $4^{\circ} \mathrm{C}$. The supernatant was removed as apoptotic DNA sample. To quantify the necrotic and apoptotic DNA, both DNA samples were added to the streptavidin-coated microplate contained in the kit. All values were normalized to islet total DNA measured by picogreen DNA quantification (Molecular Probes, Eugene, OR).

\section{In vitro hypoxia treatment}

Isolated FVB and HMT-1 islets were cultured in a 96-well plate placed in a sealed incubator chamber saturated with $1 \% \mathrm{O}_{2}, 5 \% \mathrm{CO}_{2}$ and $94 \% \mathrm{~N}_{2}$ at $37{ }^{\circ} \mathrm{C}$. After incubation for 24,48 , or $72 \mathrm{hrs,} \mathrm{the} \mathrm{islet} \mathrm{cell} \mathrm{viability} \mathrm{was} \mathrm{assessed} \mathrm{by} \mathrm{measuring} \mathrm{islet}$ metabolism as indicated by alamar blue absorbance. The data for cell viability were calculated as the percentages of viability of control cells that were cultured normally in $95 \%$ air, $5 \% \mathrm{CO}_{2}$. ROS production in islets after hypoxia for $7 \mathrm{hrs}$ was measured with CM-H2DCFDA fluorescence dye, as described above. 


\section{Alamar Blue assay}

The Alamar Blue assay, which incorporates a redox indicator that changes color and fluorescence in response to cell metabolic activity, is a commonly used method to assess cell viability and/or proliferation of mammalian cells (48) and micro-organisms (49). In our studies, 15 overnight-cultured FVB control islets or HMT-1 transgenic islets were hand picked into $200 \mathrm{ul}$ fresh culture medium (no phenol red) containing 1:20 diluted Alamar Blue in a 96-well plate. Islets were cultured for $4 \mathrm{hr}$ and the Alamar Blue fluorescence was measured on a fluorescent microplate reader (Tecan, Durham, NC) at the excitation wavelength of $535 \mathrm{~nm}$ and the emission wavelength of $595 \mathrm{~nm}$. This measurement provided an absorbance value indicating the pretreatment metabolic activity and was used to normalize the post-treatment metabolic activity. After three washes with fresh culture medium, islets were cultured in $200 \mu l$ culture medium under normoxia or hypoxia $\left(1 \% \mathrm{O}_{2}\right)$ conditions for varying time periods. At the end of treatment, $50 \mu \mathrm{l}$ culture medium was replaced with $50 \mu \mathrm{l}$ fresh culture medium containing 1:5 diluted Alamar Blue, for a final dilution of 1:20. The color was developed for another $4 \mathrm{hr}$ and the fluorescence was measured again. Islet cell viability was calculated as the ratio of fluorescence after treatment to the fluorescence before treatment.

\section{Syngeneic transplantation}

50 FVB and HMT-1 islets were transplanted separately under each kidney capsule in a normal FVB mouse according to a modification of the procedure of Montana et al (50). Recipient mice were anesthetized via ip. injection with $10 \mu \mathrm{l} / \mathrm{gram}$ of a solution 
containing $10 \mathrm{mg} / \mathrm{ml}$ ketamine and $3.2 \mathrm{mg} / \mathrm{ml}$ xylazine. The left side kidney was first externalized through a small incision and kept moist with saline. 50 islets were picked into a gel-loading pipette tip ( $0.5 \mathrm{~mm}$ diameter) mounted on a 1-cc Hamilton syringe (Reno, NV) and allowed to settle. The tip was inserted through an incision beneath the kidney capsule and the islets were gently forced out of the tip. The body wall and the skin were closed with sutures. Then the transplantation to the right kidney was performed by the same procedure. Six days later, grafts were recovered by removing a portion of the kidney far exceeding the visualized graft site. This portion of the kidney was homogenized in acid ethanol (23 ethanol: $2 \mathrm{HCl}: 75 \mathrm{H} 2 \mathrm{O}, \mathrm{v} / \mathrm{v} / \mathrm{v}$ ) for insulin extraction. To determine the insulin content we used an anti-insulin antibody coated tube RIA kit (Diagnostic Products, Los Angeles, CA) and rat insulin standards according to the manufacturer's instructions. Briefly, $400 \mu \mathrm{l}$ of diluted sample or rat insulin standard solution was mixed thoroughly with $1 \mathrm{ml}$ of ${ }^{125}$ Iodine labeled insulin in the anti-insulin coated tubes. After overnight incubation at room temperature, tubes were washed three times and the radioactivity for each tube was counted in a gamma counter. The sample insulin values were within the $20 \%$ to $80 \%$ bound capacity of the radioimmunoassay. Insulin content was calculated from a standard curve made with rat insulin standards.

\section{Allotransplantation}

200 FVB or HMT-1 islets were transplanted under each kidney capsules (400 total) with the same protocol described above. Before transplantation, the recipient Balb/c mice, aged 8-12 weeks, were injected with a single dose of STZ (ip. $220 \mathrm{mg} / \mathrm{kg}$ ) to 
induce diabetes. Only mice with blood glucose ranging from $350 \mathrm{mg} / \mathrm{dl}$ to $500 \mathrm{mg} / \mathrm{dl}$ were used as recipients for transplantation surgery. After transplantation the mice were allowed to recover freely without treatment. Tail blood glucose levels of the transplanted mice were monitored every other day with a glucose meter (OneTouch Ultra, Life Scan, Milpitas, CA). Graft failure was defined as a return of hyperglycemia (nonfasting blood glucose $>250 \mathrm{mg} / \mathrm{dl}$ ) on two consecutive measurements. Islet graft survival time was calculated as the number of days from transplantation to the first day of hyperglycemia of two consecutive measurements. Grafts from some recipients were recovered 6 days after transplantation and sectioned for hematoxylin/eosin and nitrotyrosine staining. In separate experiments in which only one kidney was transplanted we verified that removal of the graft containing kidney caused a return to glucose levels over $600 \mathrm{mg} / \mathrm{dl}$.

\section{Immunohistochemistry for nitrotyrosine}

Islet grafts were fixed in $10 \%$ formaldehyde in $0.1 \mathrm{~mol} / \mathrm{L}$ phosphate buffer $(\mathrm{pH} 7.2)$, dehydrated in an ascending graded series of ethanol, and subsequently infiltrated with paraffin. Serial section were cut at $5 \mu \mathrm{m}$, mounted on polylysine-coated slides, and then deparaffinized in xylenes and a descending graded series of ethanol. For nitrotyrosine staining, slides were treated with target retrieval solution (Dako corporation, Carpinteria, CA), followed by M.O.M mouse Ig blocking reagent (Vector Laboratories, Burlingame, CA). Nitrotyrosine monoclonal antibody (Cayman, Ann Arbor, Michigan) was added the slides at a concentration of $10 \mu \mathrm{g} / \mathrm{ml}$ and incubated overnight at $4{ }^{\circ} \mathrm{C}$. After 3 washes in phosphate-buffered saline, slides were incubated with biotinylated anti-mouse IgG 
reagent, followed by $\mathrm{ABC}$ reagent and developed with $\mathrm{DAB}$ as chromagen. Slides without primary antibody treatment were used as negative control. For quantification of nitrotyrosine production, $5 \mathrm{MT}$ graft slides and $5 \mathrm{FVB}$ control graft slides from three independent recipients were scored on a scale from 1 to 5 grades based on the severity of nitrotyrosine staining by two researchers blind to the identity of the section.

\section{Data analysis}

Data are presented as the mean \pm standard error. Statistical significance was performed by one-way or two-way ANOVA and Dunnet's post hoc (2-tailed) test. Kaplan-Meier survival analysis and Mantel-Cox Log-rank test were used to analyze islet graft survival time. Mann-Whitney Rank Sum Test was used to analyze nitrotyrosine staining in islet grafts. Computations were done using statistical programs from SPSS (version 10.0) and Sigmastat (version 2.03). 


\section{RESULTS}

Broad spectrum ROS scavenging by MT: Our previous study (51) demonstrated that the MT transgene protected against ROS released by STZ. To determine if MT could protect against many species of ROS, beta cells were exposed to $\mathrm{H}_{2} \mathrm{O}_{2}$, superoxide radical produced by hypoxanthine and xanthine oxidase, and peroxynitrite radical released from SIN-1. Beta cell ROS production measured with $\mathrm{CM}-\mathrm{H}_{2} \mathrm{DCFDA}$ (Figure 1-1) was dramatically reduced by the MT transgene following exposure to all three sources. Islets were also exposed to nitric oxide by incubation with SNAP, a nitric oxide donor. SNAP did not increase $\mathrm{CM}-\mathrm{H}_{2} \mathrm{DCFDA}$ fluorescence in our assay; consequently we assessed MT induced resistance to nitric oxide by observing changes in islet morphology and quantitating islet cell death. As shown in Figure 1-2, MT islets were resistant to SNAP induced morphological damage and cell death as measured by DNA cleavage. These data demonstrate that MT is able to efficiently scavenge all or most forms of free radicals.

In vitro hypoxia studies: Hypoxia and reoxygenation are known to induce ROS production $(52 ; 53)$. To determine if MT could reduce hypoxia induced ROS production we exposed isolated FVB control and MT transgenic islets to $1 \% \mathrm{O}_{2}$. This is close to the microenvironment that transplanted islets are subject to at the graft site (54). ROS production was measured with $\mathrm{CM}-\mathrm{H}_{2} \mathrm{DCFDA}$ following $7 \mathrm{hrs}$ of hypoxia and return to normoxic media. The data in Figure 1-3 illustrate the effect of the hypoxia incubation on ROS generation. Both FVB and MT islets produced more ROS following exposure 
to hypoxia. However the ROS generation was significantly greater in FVB islets than in MT islets. To determine if this reduction in ROS generation translated into improved islet survival, we assessed islet viability with the metabolism sensitive dye Alamar Blue. MT and FVB islets were exposed to $1 \% \mathrm{O}_{2}$ for 24,48 , and $72 \mathrm{hrs}$ and then assayed with Alamar Blue. As shown in Figure 1-4, islet cell metabolism was markedly decreased by hypoxia treatment. Overexpression of MT provided significant resistance to this effect at all time points analyzed.

Transplantation: Hypoxia and/or hypoxia reoxygenation are toxic stressors that grafted islets must contend with during the early phase of transplantion while revascularization progresses. To determine if the ability of MT to protect against hypoxia and reoxygenation would be beneficial in a real transplantation situation, islets were transplanted into syngeneic, nondiabetic FVB recipients. These grafts are subject to hypoxia but not to immune rejection or glucose toxicity. MT transgenic islets were implanted under one kidney capsule and control FVB islets were implanted under the other kidney capsule of the same recipient. Six days after transplantation the graft was recovered for determination of insulin content. Insulin content is a commonly used indicator of transplanted islet health $(55 ; 56)$. Figure 1-5 illustrates that both FVB and MT islet grafts lost part of their insulin content after transplantation. However, FVB islets were more severely affected. MT islets retained about $60 \%$ of their initial insulin content, whereas FVB islets retained less than $20 \%$ of their initial insulin $(\mathrm{p}<0.01)$. 
We also carried out allotransplantation studies using FVB control islets or MT transgenic islets implanted under the renal capsules of STZ induced diabetic Balb/c mice (Figure 1-6). $400 \mathrm{FVB}$ islets were able to maintain near normal blood glucose levels in recipient mice for an average period of $8.36 \pm 1.67$ days. The same number of MT transgenic islet was more effective. Average euglycemic period for recipients receiving MT islets was almost doubled, to $16.2 \pm 2.52$ days. Mantel-Cox Log-rank analysis of islet graft survival time indicated that MT grafts were significantly $(p<0.01)$ more effective in maintaining euglycemia.

To confirm that the prolonged survival of MT islets was due to protection from ROS nitrotyrosine staining in islet grafts recovered after 6 days of transplantation was measured. Nitrotyrosine is a marker for the presence of peroxynitrite. As shown in Figure 1-7, nitrotyrosine staining in MT grafts was markedly decreased compared to nitrotyrosine staining in control FVB islet grafts. This result was confirmed by blind ranking of nitrotyrosine intensity on $5 \mathrm{MT}$ and $5 \mathrm{FVB}$ graft slides from three different recipients per group $(\mathrm{p}<0.02)$. 


\section{DISCUSSION}

In the present study we demonstrated that overexpression of MT reduced ROS levels in beta cells exposed to many different prooxidant stimuli. Protection from ROS helped preserve islet viability after treatment with an NO donor or prolonged exposure to hypoxia. MT transgenic islets maintained almost three fold higher insulin content than control islets following syngeneic transplantation. Transplantation with MT islets prolonged euglycemia by two fold compared to transplantation with control islets and MT reduced the formation of nitrotyrosine in islet grafts into allogeneic, diabetic recipients. The greatest benefit of MT was probably due to protection from hypoxia rather than due to prevention of immune rejection.

Islets are exposed to many noxious ROS during transplantation and the onset of diabetes. These different ROS can produce additive or synergistic toxicity to beta cells $(57 ; 58)$. Therefore it is important that antioxidant treatment protect against as many different types of ROS as possible. However, most enzymatic antioxidant proteins are specific in their substrate and thus limited in the types of ROS that they can inactivate. Catalase and glutathione peroxidase decompose primarily hydrogen peroxide, and SOD activity is specific to superoxide. An example of the restricted protection provided by a single antioxidant enzyme is the recent demonstration (59) that elevated MnSOD expression protected islets from alloxan but provided no protection from nitric oxide. Unlike enzymatic antioxidants, MT has broad antioxidant activity. In cell-free system MT has been shown to scavenge nitric oxide radical (60) superoxide radical (61), hydroxyl radical (62) and peroxynitrite (63). We confirmed that MT was effective 
against all of these ROS when expressed in transgenic pancreatic islets and also showed that MT reduced apoptosis and necrosis produced by nitric oxide exposure. Nitric oxide is generally considered to be an important mediator of beta cell damage produced by many stressors (64). The efficacy of MT against most ROS means that MT overexpression can provide a general test of the role of ROS in beta cell damage produced during transplantation and diabetes.

MT overexpression was able to extend the duration of euglycemia by two fold in allogenic recipient diabetic mice. This amounted to an increase of 8 days. The relatively short period of improved graft function suggests that $\mathrm{MT}$ protects most effectively against the damage produced in the early phase of transplantation, prior to immune rejection of the graft. Consistent with this we found that MT protected graft insulin content in syngeneic recipients, which is in the complete absence of immune rejection. Although there are many factors that contribute to early graft loss, evidence suggests that hypoxia is one important factor. Islet grafts are initially an essentially avascular tissue. Mean $\mathrm{PO}_{2}$ measured in syngeneic transplanted islets (65) is 5-10 mmHg (about 1\% O2). Low levels of oxygen can impair islet cell function and cell survival. It has been shown that there is a strong correlation between reduced oxygen supply and the occurrence of apoptosis in isolated human and rat islets (66). Islet grafts are particularly prone to destruction caused by hypoxia followed by reoxygenation during the process of revascularization (67). The loss of cell viability produced by in vitro hypoxia in the present study is consistent with this sensitivity. MT was very effective in blocking ROS generation and cell death produced by hypoxia. Because our 
fluorescence detection system was not sealed from air the generation of ROS may have been due to hypoxia or hypoxia/reperfusion.

Several studies have used systemic antioxidants to extend efficacy of islet transplants (68-71) with varying degrees of success. To improve outcome and focus protection on the islet, Bertrea et al (72) transplanted islets with adenoviral mediated overexpression of MnSOD into an NODscid model of immune rejection. This produced a $50 \%$ extension of graft function, possibly due to protection from immune attack. We found that MT produced a similar or modestly greater degree of protection. Since experiments were performed in different models direct comparison are impossible. Clearly neither transgene provided complete protection. MT is cytoplasmic and protected against hypoxia, while MnSOD is mitochondrial and was thought to protect against immune attack. Potentially combination of these two differentially localized antioxidants with different modes of action may produce additive or synergistic benefit.

Successful clinic trials using the Edmonton protocol provide encouraging results for islet transplantation. However, the need for multiple donors hampers successful and efficient clinical islet transplantation. The shortage of organ donors is an intractable problem. Therefore any significant improvement in graft efficiency is worthwhile. MT improved islet function by reducing damage secondary to hypoxia. This demonstrates that powerful ROS scavengers are beneficial for transplanted islet survival and may be useful in combination with other strategies aimed at islet graft protection. 

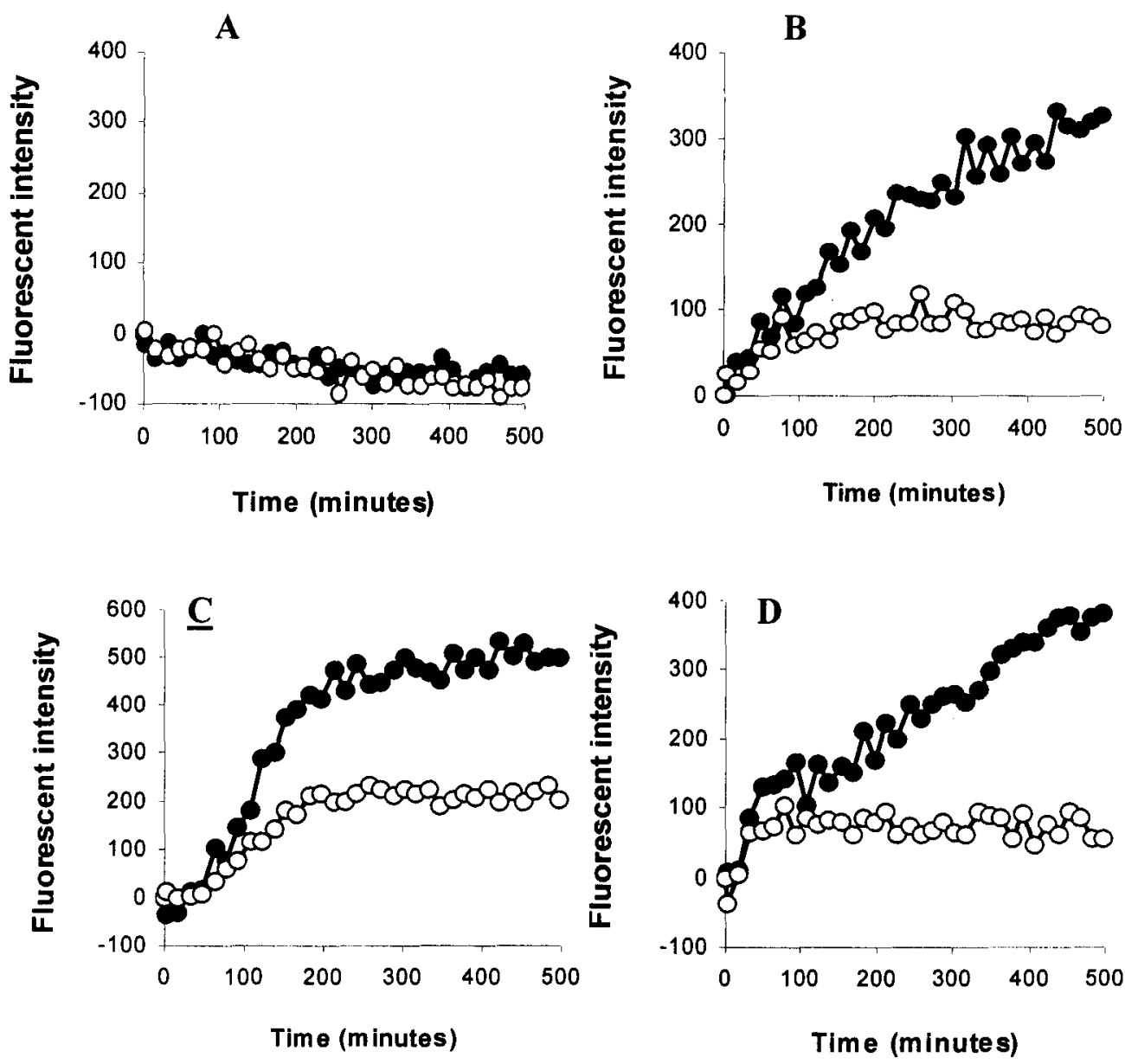

Figure 1-1. ROS production in dispersed FVB control and transgenic MT islet cells. ROS was measured with the fluorescent dye CM- $\mathrm{H}_{2}$ DCFDA as described in Methods. Islet cells were not treated (A), treated with $100 \mu \mathrm{M} \mathrm{H}_{2} \mathrm{O}_{2}$ (B), treated with $30 \mu \mathrm{M} \mathrm{SIN-}$ 1 (C), treated with $1 \mathrm{mM}$ hypoxanthine plus $2 \mathrm{mU}$ xanthine oxidase (D). The solid circles indicate FVB control islet cells. The open circles indicate MT transgenic islet cells. This figure is typical of three independent experiments. 


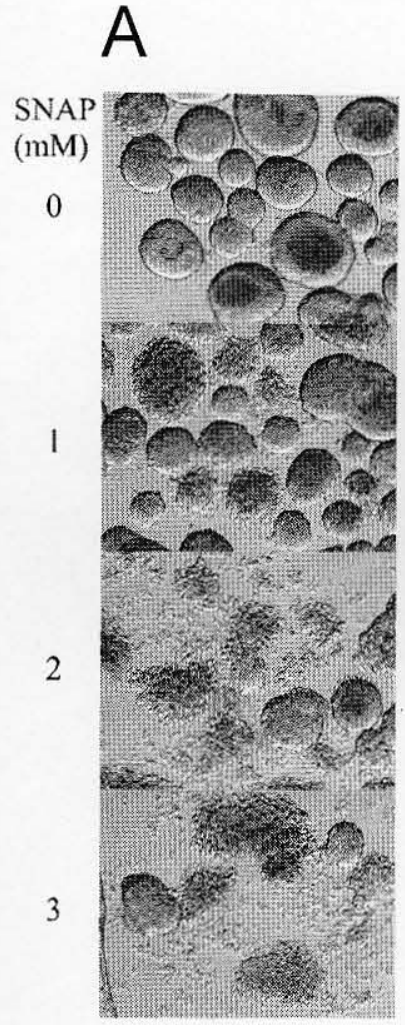

FVB

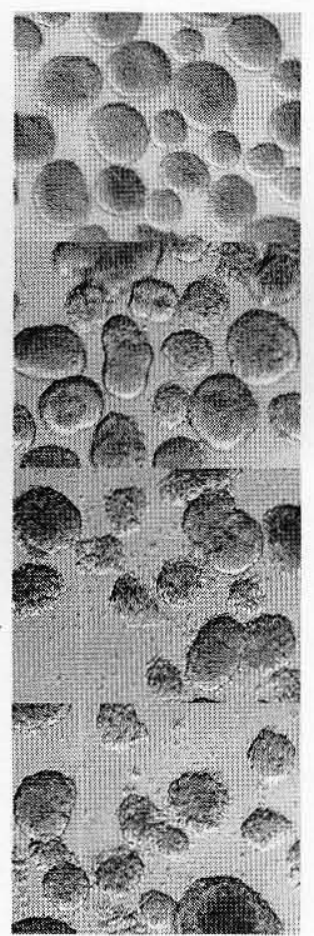

MT
B
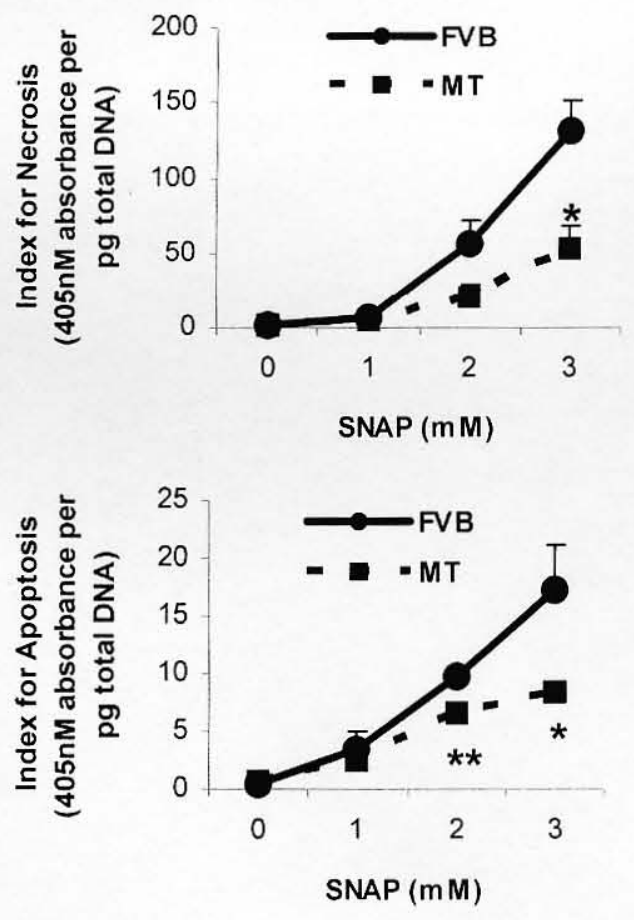

Figure 1-2. Nitric oxide induced damage in FVB and MT transgenic islets exposed to SNAP for 24 hrs. (A) Representative photomicrographs of FVB and MT islets after SNAP treatment. The concentrations of SNAP are shown on the left. Similar results were obtained in four independent experiments. Magnification $\times 100$. (B) Necrosis and apoptosis in SNAP treated islets. Cell death was measured as described in Methods. Data were calculated from four independent experiments. * and ** indicate MT and FVB values were different at the same SNAP concentration $(\mathrm{P}<0.05$ and $\mathrm{P}<0.01$, respectively by one-way ANOVA test). Vertical bars indicate standard error of the mean. 


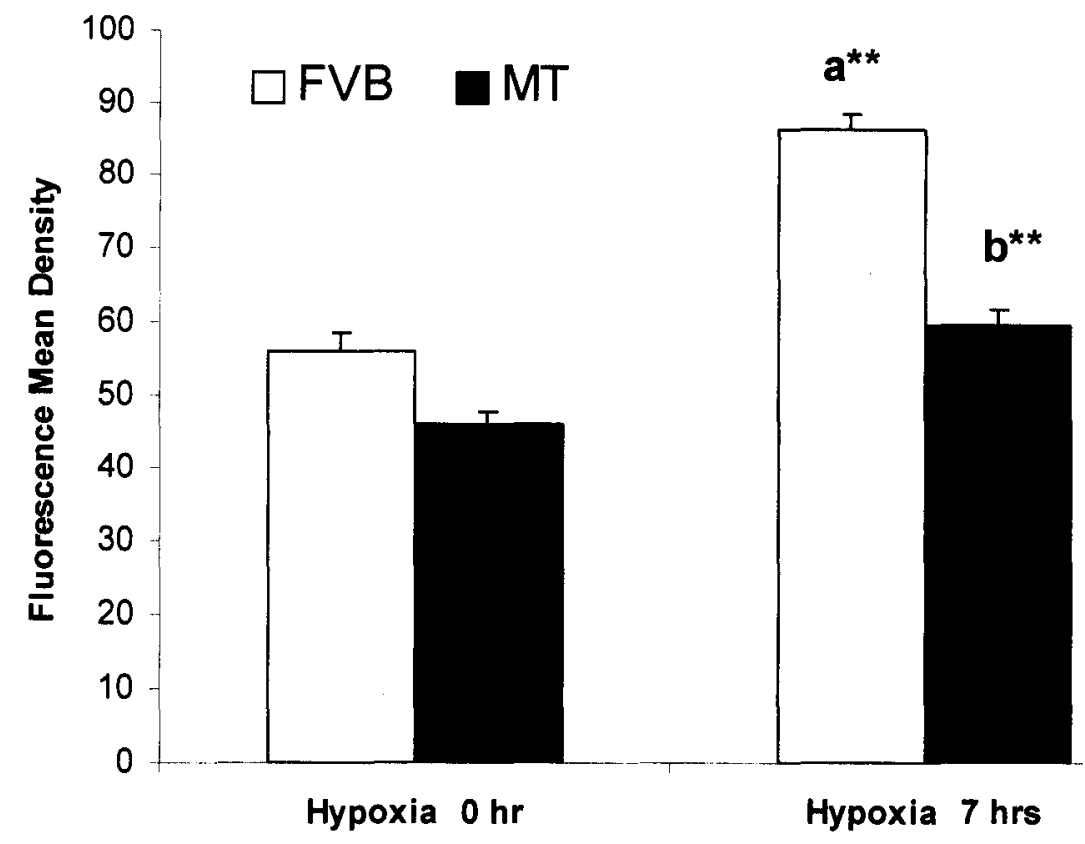

Figure 1-3. ROS production in FVB and MT islets exposed to hypoxia for $7 \mathrm{hrs}$. The MT transgene reduced hypoxia induced ROS production in islet cells. ROS production of whole islets was measured as described in Methods. Data are mean values of more than 100 islets per group. $\mathrm{a}^{* *}$ indicates that hypoxia increased ROS levels in FVB control islets $(\mathrm{P}<0.001) . \mathrm{b}^{* *}$ indicates MT ROS levels were lower than FVB values following 7 hrs of hypoxia $(\mathrm{P}<0.001)$. Statistical significance was measured by two-way ANOVA. Vertical bars indicate the standard error of the mean. 


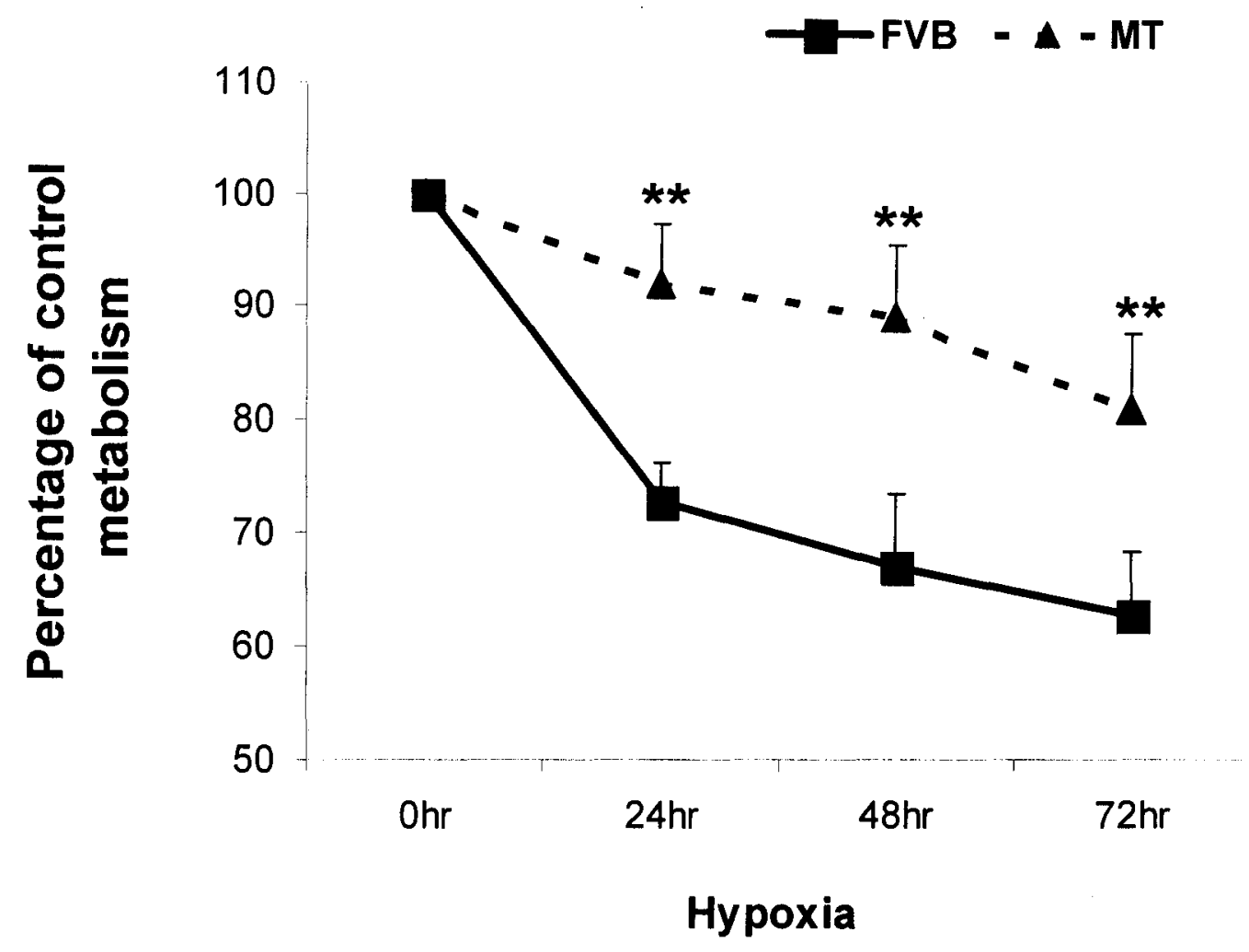

Figure 1-4. Cell viability in MT transgenic and FVB control islets after hypoxia exposure. FVB and MT islets were subject to hypoxia for 24,48 , and $72 \mathrm{hrs}$ and islet cell viability was measured by the Alamar Blue assay. Data were calculated from five independent experiments. ${ }^{* *}$ indicates that MT values are different from the corresponding FVB values $(\mathrm{P}<0.01$ by two-way ANOVA). Vertical bars indicate standard error of the mean. 


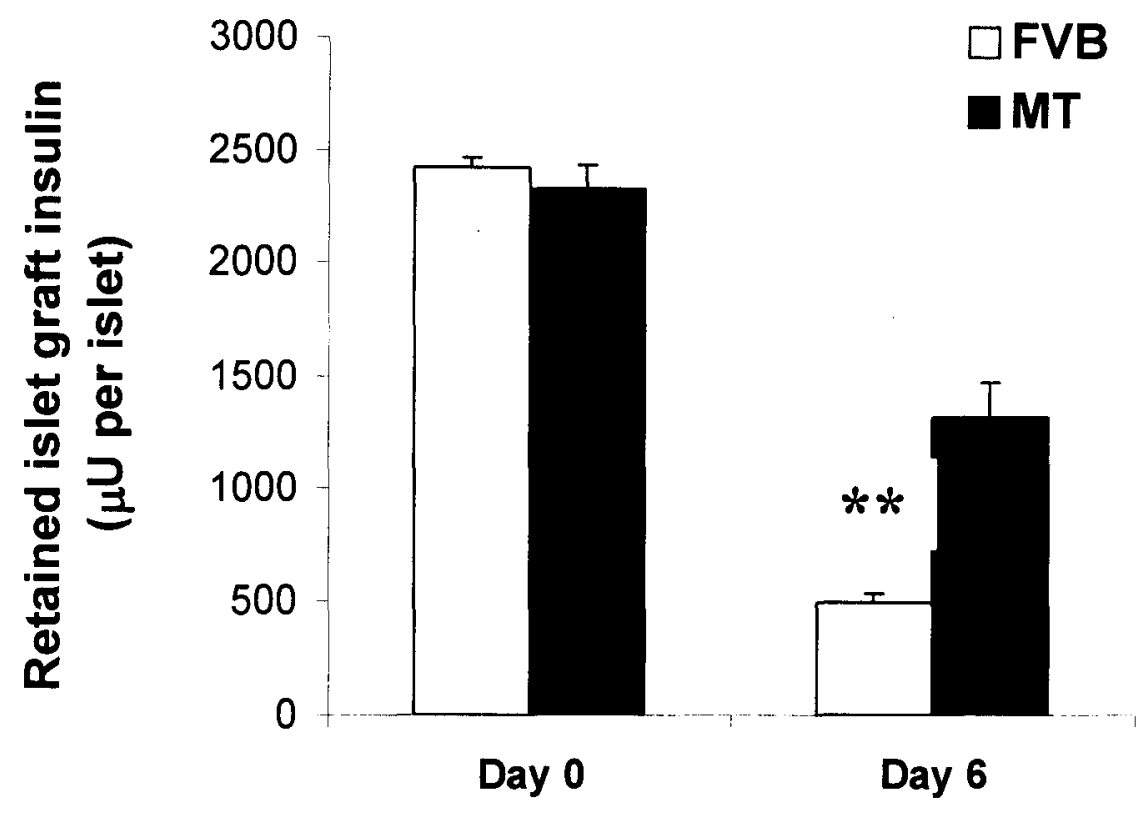

Figure1-5. Graft insulin content of FVB and MT islets after syngeneic transplantation. Each islet type was transplanted into opposite kidneys of normal FVB mice and the insulin content of recovered grafts was measured as described in Methods. Data were collected from 12 recipient FVB mice. ${ }^{* *}$ indicates that the insulin content of MT and FVB grafts are different $(\mathrm{P}<0.001$ by one-way ANOVA). Vertical bars indicate standard error of mean. 


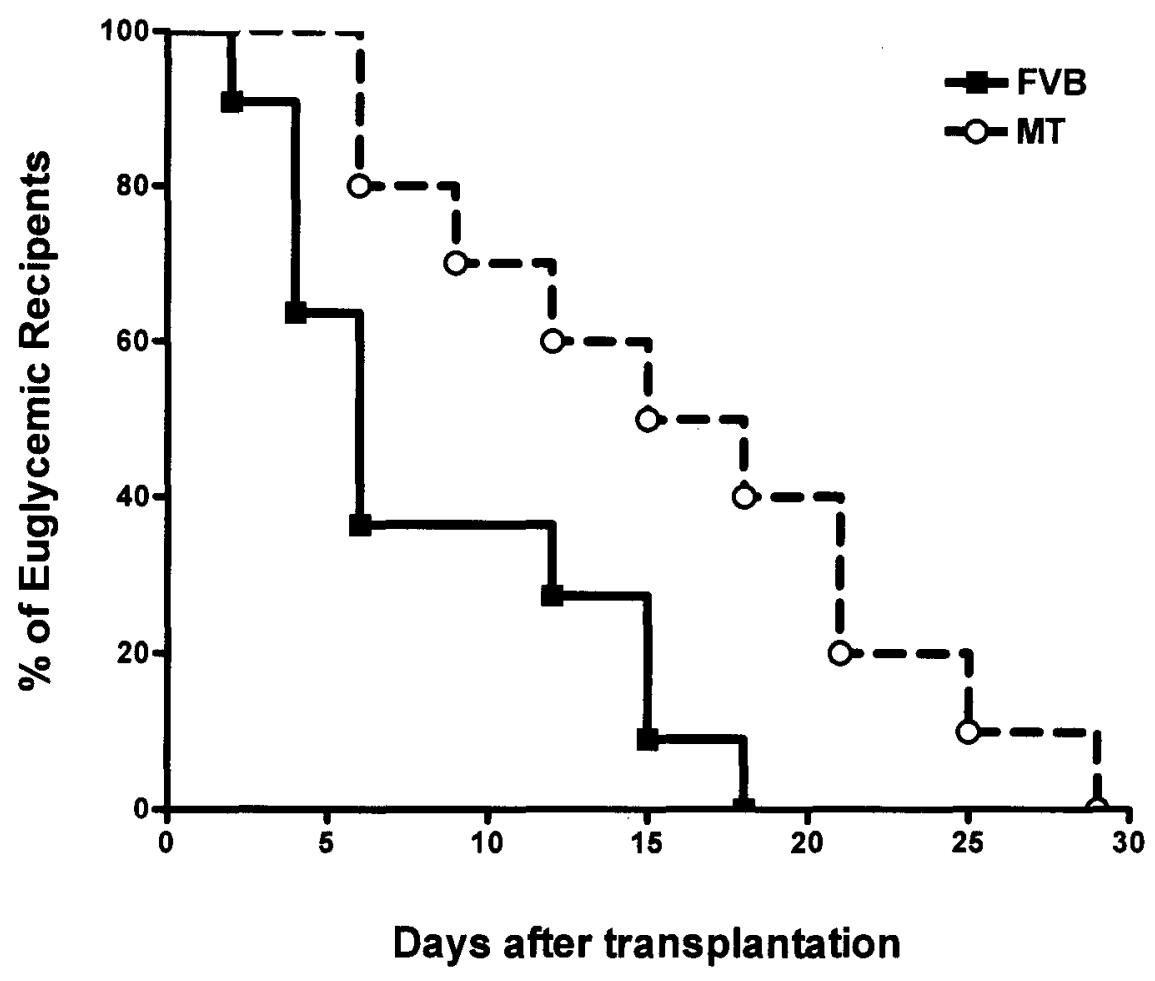

Figure 1-6. Percentage of euglycemic recipients after receiving FVB or MT transgenic islets after transplantation. 400 islets were transplanted under both kidney capsules of STZ induced diabetic Balb/c mice. Loss of euglycemia was defined as two consecutive days of blood glucose over $250 \mathrm{mg} / \mathrm{dl}$. Data were calculated from 11 mice receiving FVB islet grafts and 10 mice receiving MT transgenic islet grafts. The survival time of MT islet grafts was significantly longer than that of FVB grafts $(P<0.01$ by Mantel-Cox Log-rank test). 

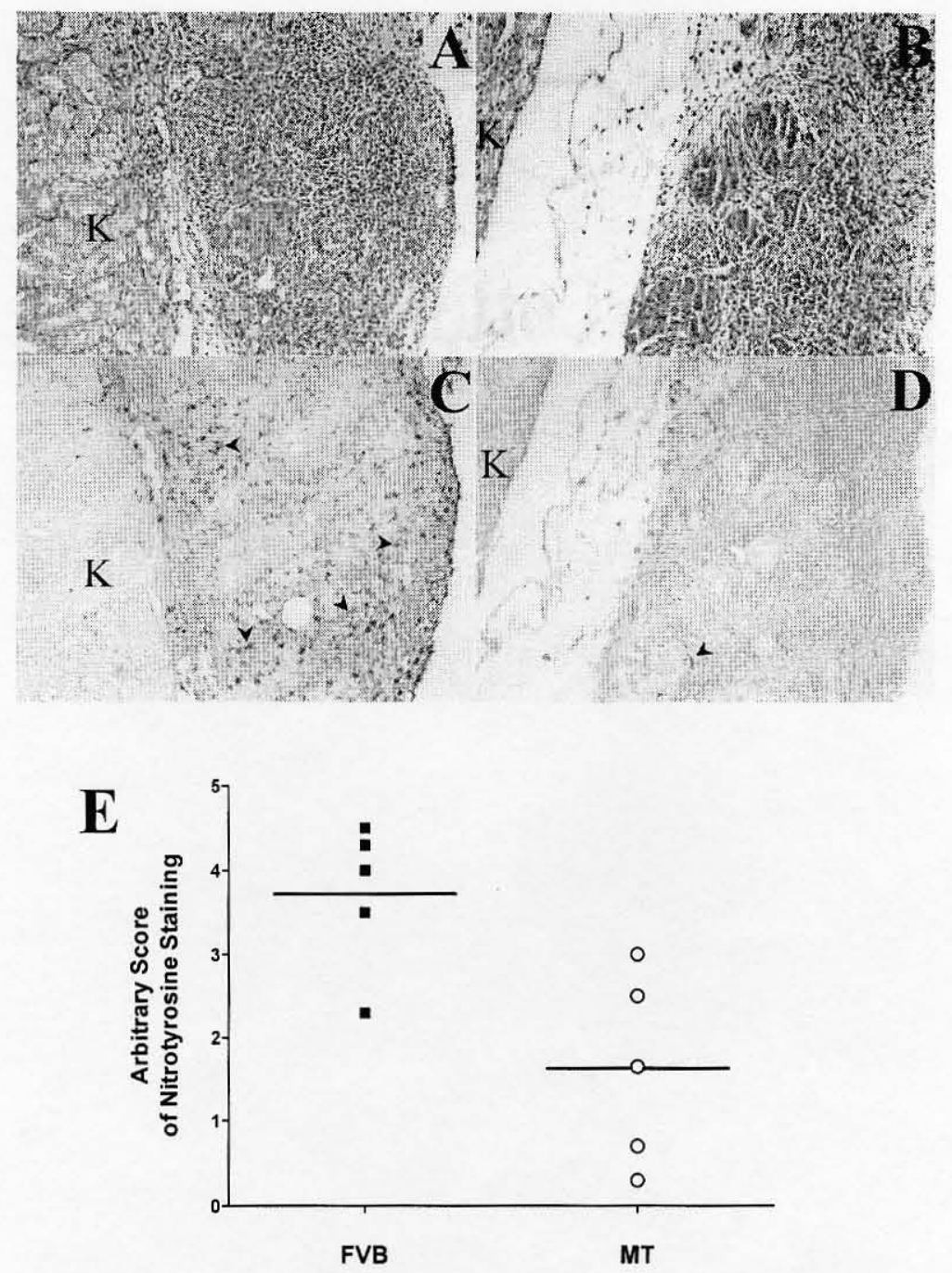

Figure 1-7. Nitrotyrosine production in FVB and MT allografts 6 days after transplantation. A-D: Representative hematoxylin/eosin-stained (A and B) and monoclonal anti-nitrotyrosine stained (C and D) kidney sections with islet transplants from STZ induced diabetic Balb/C recipents. $\mathrm{A}$ and $\mathrm{C}$ are serial sections of FVB allografts. B and D are serial sections of MT allografts. Arrows point to nitrotyrosine staining positive cells. $\mathrm{K}$ indicates kidney tissue. Magnification $\times 200$. E: Scoring of nitrotyrosine in FVB and MT islet grafts. Data were collected from five slides for each type of grafts from three independent recipients and scored blindly by two researchers. 
MT transgene significantly reduces nitrotyrosine production in islet grafts $(\mathrm{P}<0.02$ by Mann-Whitney Rank Sum Test). The horizontal lines indicate the mean score. 


\section{CHAPTER II}

\section{THE ROLE OF ANTIOXIDANTS IN TYPE 1 DIABETES \\ INTRODUCTION}

\section{Autoimmune nature of IDDM}

IDDM is a T-cell mediated autoimmune disease in which the insulin-producing beta cells of the pancreatic islets are destroyed. The involvement of defective regulation of the immune function supports the view that type 1 diabetes is an autoimmune disease . The key evidence for the autoimmune nature of type 1 diabetes includes the importance of the major histocompatibility complex (MHC) genetic background, the presence of mononuclear cells infiltrating pancreatic islet (insulitis), autoantibodies to various islet antigens (including beta cell specific and non-specific antigens), abnormal cellular immunity, and beneficial effect of immunosuppressive therapy.

In humans, genetic susceptibility to IDDM is mainly associated with two chromosomal gene regions: the IDDM1 locus containing the genes for MHC (IDD1 in NOD mouse), which contributes to $42 \%$ of familial inheritance of the disease, and the IDDM2 locus, which accounts for $10 \%$ of inheritance(73). Both in the NOD mouse and in humans, specific MHC genes are necessary but not sufficient for diabetes development(74). MHC genes are thought to control autoimmune susceptibility through class I and II molecules in the selection of the peripheral T-cell repertoire within the thymus and 
through the restricted presentation of autoantigen-derived peptides to $T$ lymphocytes (75).

In both human and animal models, the onset of type 1 diabetes is preceded by a long phase of clinically latent islet-cell-specific infiltration by lymphocytes, called insulitis. A key finding in IDDM patients that die early in the course of their disease is insulitis. Studies in spontaneous model of NOD mouse have shown that around 3 weeks of age, swollen vessels resembling high endothelial venules are first seen adjacent to islets, followed by an increase in the number of dendritic-like cells and macrophages, APC within the vessel wall and at the side of the islet near the vessel. From 4 to 6 weeks of age, periinsulitis occurs, which is composed of an accumulation of APC, B and T lymphocytes around the outside of the islets (76). Insulitis increases with age and there is a change in distribution with increasing intra-islet insulitis compared with periinsulitis .

However, in spite of extensive and active insulitis, intact beta cells persist for long periods of time and no diabetes occurs. Eventually, this balance is lost and insulitis becomes terminally aggressive. It has been shown that all NOD mice develop insulitis; however, in many cases this inflammation is "benign" in that it does not result in the destruction of the insulin-producing beta cells, causing hyperglycemia (77-79). Only in a proportion of mice does the inflammatory process become "malignant" and result in death of the beta cells and consequent hyperglycemia. The data suggested that development of disease is correlated with a switch from a benign to malignant state of 
autoimmunity. However, the mechanisms which precipitate this change from benign to malignant inflammation are not well understood.

IDDM is also characterized by the presence of a variety of antibodies. Several IDDMrelated candidate autoantigens have already been identified in humans and /or animal models, such as glutamic acid decarboxylase (GAD 65 and 67), insulin, proinsulin, ICA 512/IA-2 and IA-2b/phogrin ( two different tyrosine phosphatase antibodies), 38 $\mathrm{kDa}$ antibodies such as imogen 38 and glima 38, peripherin, heat-shock protein (hsp) 60, ICA 69 carboxypetidase $\mathrm{H}$, and bovine serum albumin (80-88). Although it has never been demonstrated that autoantibodies play a pathogenic role, their predictive values make them invaluable markers for identification of preclinical diabetes (88-92). Some autoantibodies are stongly associated with rapid progression to overt diabetes. For example: Cytoplasmic islet cell antibody (ICA) was the first autoantibody described. ICA are detected in $60-90 \%$ of patients with newly diagnosed IDDM and in 1 to $9 \%$ of non-diabetic first degree relatives (88). Islet cell surface antibodies (ICSA) are present in almost all recent-onset IDDM patients (93). Beta cell specific antibodies insulin (IAA) and proinsulin autoantibodies (PAA) are also present in 16 to $69 \%$ of new diagnosed IDDM patients and in 2 to $4 \%$ of first-degree relatives (88). Anti-GAD and anti-IA-2, which are not specific to beta cells but are also expressed in neurons and various endocrine cells (94), are also shown to be highly relevant to overt diabetes (88). Several other antibodies have been described in IDDM such as anti-carboxypeptidase $\mathrm{H}$ and antibodies to BSA, which appear to be less relevant for the prediction of the disease either because of their low frequency or because of their lack of diabetes specificity (88). 
However, as stated above, the presence of autoantibodies in patient sera is not evidence of their pathogenic potential(95). Autoantibodies may be a result of cellular destruction, such as that of cardiac muscle cells after myocardial infarction which give rise to antiheart cell antibodies (96).

In both animal model and human patient, immunosuppressive drugs can benefit the disease. T-cell-targeting agents such as anti-CD4, CD8, CD3 or cyclosporine and induction of immune tolerance or islet autoantigens can prevent type 1 diabetes in animal models. Treatment with immunosuppressive drugs e.g. azathioprine, steroids, cyclosporine increases the remission rate in newly-diagnosed patients (97).

\section{Type 1 diabetes animal model-----NOD mice}

Although the number of type 1 diabetes patients has been projected to increase in the next ten years, analysis of the pathogenesis of diabetes in humans has been limited to the study of autopsy specimens from diabetic patients, or of in vitro effects using isolated islets. Also the symptoms of diabetes appear late, once patients are diagnosed as type 1 diabetes patients, most beta cells have been destroyed. Therefore it is difficult to study the early phases of the disease in humans. Our understanding of the pathophysiological events that precede diabetes development has benefited largely from the accessibility of relevant models of IDDM in the mouse. Animal models for type 1 diabetes fall into two main groups. In the first group, IDDM is induced following an external intervention such as the low-dose multiple streptozotocin model or virus- 
induced diabetes. The second group consists of two rodent models that spontaneously develop type 1 diabetes, the NOD (non-obese diabetic) mouse and the BB (BioBreeding) rat. These have been the most extensively studied animal models over the past 10 years. Both models show striking similarities with human IDDM such as insulitis and antoantibodies. The NOD mouse has proven to be the most informative and has contributed substantially to clarifying the pathogenesis of autoimmune diabetes. Since the NOD mouse has a better-defined genome, costs less, and also has more monoclonal reagents available for the analysis of immune system components, the NOD mouse has been regarded as the favored model for investigations into the pathogenesis of human type 1 diabetes, ever since it was reported in Japan 20 years ago. In this strain, both female and male NOD mice develop diabetes spontaneously, but the females are more susceptible. In the female mice the incidence of diabetes is $90-100 \%$ by 30 weeks of age. Male mice develop diabetes at a frequency of 40 to $60 \%$ by $30-40$ weeks of age (98). Similar to human type 1 diabetes patients, before becoming overtly diabetic, with nonfasting plasma glucose higher than $250 \mathrm{mg} / \mathrm{dl}$, NOD mice go through a long, clinically silent period characterized by a leukocytic infiltrate of the pancreatic islets, referred to as insulitis.

Susceptibility to Type 1 diabetes in NOD mice is polygenic. Currently at least 20 diabetic susceptible alleles have been identified that are associated with the onset and development of diabetes in the NOD mouse (99). These alleles are highly polymorphic. This makes it possible to identify the diabetic susceptible alleles with the aid of microsatellite markers, a group of variable DNA sequences closely linked to the 
diabetic susceptibility loci. By genotyping these diabetic susceptiblity alleles, Serreze et al. (100) established a successful protocol for producing "speed congenic NOD mice" from other strains of mice. Since our antioxidant transgenic mice were established and maintained on the FVB background strain, we utilized Serreze's procedure to more rapidly generate new NOD strains homozygous for all NOD susceptibility alleles which were congenic for our pancreatic beta cell antioxidant transgenes. The susceptibility to Type 1 diabetes in NOD mice is also significantly affected by environmental factors, including housing conditions, health status, diet and chemical or virus exposure. The onset of diabetes in NOD mice is relatively slow and random. The onset of diabetes in NOD mice is known to be highly variable from one mouse to another. Therefore cyclophosphamide (CYP), an alkylating cytostatic drug is often employed to speed up diabetes onset in NOD mice (101). The mechanism for this accelerated diabetes by CYP is not completely defined but in some studies CYP has been shown to activate the immune response in NOD mice by suppressing T-helper cells (102). In this project we injected CYP into our transgenic NOD mice to accelerate and synchronize NOD diabetes. 


\section{Beta cell death in diabetes}

Pancreatic beta cells undergo cell death in both types of diabetes. Type 2 diabetes is characterized by both insulin resistance and pancreatic beta cell dysfunction, which leaves the beta cell unable to compensate for insulin resistance with increased insulin secretion (103). During the development of type 2 diabetes, the normal insulin secretion of beta cells is impaired and beta cells may eventually undergo degeneration. The studies in the animal models of type 2 diabetes have demonstrated that beta cell death is responsible for beta cell failure $(104 ; 105)$. Free fatty acids, NO, high glucose and amyloid polypeptide have been suggested to cause beta cell apoptosis in experimental type 2 diabetes like situations (106-109).

In type 1 diabetes, the destruction of beta cells is caused by direct interactions with cytotoxic CD8 (110-112) or CD4 T cells (113), or indirectly via soluble cytokines or free radicals released by inflammatory cells within the islet lesion (114-116). Beta cell death could be either through necrosis or apoptosis, which are biochemically and morphologically distinct. Necrosis is the result of direct toxic or physical injury to tissue. During necrosis cells swell, the plasma membrane bursts and contents of the cytoplasm are released. In contrast, during apoptosis programmed cell death is executed through an intrinsic cascade that triggers cysteine proteases to activate endonucleases, resulting in DNA fragmentation and associated nuclear and cytoplasmic condensation. There is no leakage of cellular contents as the plasma membrane remains intact. Apoptosis can occur in both normal physiological processes such as morphogenesis, homeostatic 
maintenance of tissues and removal of harmful cells $(117 ; 118)$ and pathological situations.

Apoptosis has been recognized as the main mode of beta cell death in NOD mice (119). There are indications that beta cells die by apoptosis in the early stages of human type 1 diabetes (120-122). In cultured human islets cytokines induce mainly apoptosis but not necrosis (123-125).

\section{Signaling during apoptosis}

Cell apoptosis occurs following a cascade of cell signaling and caspase-mediated events. A diverse group of cell signaling pathways, such as MAP kinase, Akt and NFkappa B , have been shown to be involved in regulating pro- and anti-apoptotic protein activity and expression. Cell fate is thought to be determined by the balance between negative and positive regulation by these signaling pathways.

It is generally recognized that there are two primary modes of apoptosis induction. One is extrinsic induction in which apoptosis induced by activation of cell surface receptors like the Fas or tumor necrosis factor (TNF) receptor, called " death receptors". These receptors contain cysteine-rich extracellular ligand binding domains, and a cytoplasmic death domain. After ligand binding, these receptors interact with a variety of death domain adaptor protein, such as FADD, TRADD and RIP, which can activate caspases, as well as cell signaling pathways such as the MAP kinase and NFkappa B pathways. The other route of apoptosis stimulation is through intrinsic induction that occurs via 
the disruption of intracellular homeostasis without involving cell surface receptor. It is widely reported that many organelles such as lysosomes, Golgi apparatus, endoplasmic reticulum, and mitochondria contribute to apoptotic cell death (126). Of the organelles involved in apoptosis, the mitochondria have received the most attention. Mitochondrial dysfunction causes the release of cytochrome $\mathrm{c}$ into the cytoplasm where it binds to apoptotic protease activating factor 1 (Apaf-1), and triggers the assembly of a complex called the apoptosome, a multimeric structure composed of cytochrome c, Apaf-1 and ATP or dATP. The apoptosome at the same time recruits and activates pro-caspase- 9 through the Apaf-1 caspase recruitment domain. Once activated, the caspase9/apoptosome complex is a stable and potent structure. The primary target of caspase- 9 complex is pro-caspase-3, one of the most potent effector caspases in apoptosis.

Regardless of the mode of induction (extrinsic vs. intrinsic), the caspases are consequently involved in a cascade of cleavage events that result in the initiation and execution of apoptosis. Caspases are cysteine-containing aspartic acid-specific proteases that exist as zymogens in the soluble cytoplasm, endoplasmic reticulum, mitochondrial intermembrane space, and nuclear matrix of virtually all cells (127). In response to apoptotic stimuli, the initiator caspases, such as caspase-2,-8,-9, and-10, act as upstream transducers and cleave downstream executioner caspases. The executioner caspases, such as caspase- $3,-6$, and -7 , ultimately degrade or cleave a variety of other cellular proteins. One of these proteins is a caspase-dependent endonuclease, which is freed from its inhibitor by caspase- 3 and subsequently cuts DNA into oligonucleosomal (180-bp) fragments (128). 


\section{Molecular effectors and signaling transduction of pancreatic beta cell apoptosis in}

\section{Type 1 diabetes}

\section{T cells}

It has been established that CD4+ and CD8+ as well as macrophages are needed to produce insulitis and diabetes in animal models (129). But the precise mechanism by which these T-cells exert their effector function is not clear. However, convincing evidence suggests that CD4+ T-cells play an important role in beta cell destruction during type 1 diabetes. It is unquestionable that CD4+ T cells are both necessary and sufficient to cause type 1 diabetes in animal models $(130 ; 131)$. Activated islet specific CD4+, but not CD8+ cells can transfer diabetes (132). Further, CD4+ T-cells destroy islet beta-cells in the absence of CD8+ T-cells (133). However, non-activated CD4+ T cells from prediabetic NOD mice are incapable of transferring diabetes without CD8+ T cells. Purified CD4+ T cells from young prediabetic NOD mice even inhibit diabetes transfer by spleen cells from diabetic NODs $(134 ; 135)$. The above data suggest that CD4+ T-cells probably act as regulatory $\mathrm{T}$ cells and their destructive effect on beta cells seems dependent on the stage of diabetes development.

CD8 $+\mathrm{T}$ cells are usually necessary but usually not sufficient to cause beta cell destruction. CD8 $+\mathrm{T}$ cells alone are not capable of transferring diabetes. However, the development of beta cell specific CD4 $+\mathrm{T}$ cells is dependent on prior activation of CD8 $+\mathrm{T}$ cells, because transfer of diabetes by non-activated CD4+ $\mathrm{T}$ cells from 
prediabetic NOD mice requires CD8 $+\mathrm{T}$ cells $(136)$. Furthermore, $\mathrm{CD} 8+\mathrm{T}$ cell have a unique role in the initiation of disease, which can not be performed by CD4 $+\mathrm{T}$ cells. Thus depleting CD8+ $\mathrm{T}$ cells using anti-CD8 antibodies retards the development of diabetes in NOD mice. The above data indicated that possibly CD8+ $\mathrm{T}$ cells act by amplifying CD4+ $\mathrm{T}$ cell responses and other inflammatory responses in the infiltrate. NOD mice homozygous for $\beta 2 \mathrm{~m}^{\text {null }}$ allele, which are deficient in both cell surface class I MHC expression and CD8 $+\mathrm{T}$ cell, showed no evidence of insulitis nor did they develop diabetes (137-140). Transfer of diabetes to NOD $\beta 2 \mathrm{~m}^{\text {null }}$ recipients with spleen cells from diabetic wild-type NOD mice was significantly delayed compared with control NOD mice, demonstrating the importance of CD8 $+\mathrm{T}$ cells in the effector phase of autoimmune diabetes.

The mechanism of $\mathrm{T}$ cell direct cytotoxicity has been thought to be through Fas/FasL binding pathway or the perforin and granzyme pathway, which involves the insertion of tubular perforin complexes into the cell membrane and osmotic cell death. Cell-bound molecules (such as members of the TNF family) and soluble cytokines are also an alternative mechanisms used to kill target cells.

\section{Perforin}

Perforin is a 534 amino acid glycoprotein, the expression of which is mainly confined to CD8 + T cells and NK cells. When cytotoxic T cells interacts with a target cell, they release perforin which permeabilizes cells, allowing granzyme into the cytosol, where it activates caspase- 3 and induces cell death. 
To assess the relative roles of perforin in beta cell destruction, several transgenic mice have been used. The available in vivo data on perforin are somewhat contradictory and often model-dependent. Both in transgenic mice expressing the lymphocytic Choriomeningitis virus glycoprotein under the control of the rat insulin promoter and in 8.3 $\mathrm{T}$ cell receptor $\mathrm{CD} 8+\mathrm{T}$ cell mediated diabetes, beta cell death is perforin independent (141-144). However, in transgenic mice expressing the Influenza virus hemagglutinin in beta cells, CD8+ destruction of beta cells is dependent on perforin (145).

However, in the NOD mouse perforin-mediated lysis of beta cells has been thought to be a major mechanism of beta cell destruction. Perforin deficient NOD mice develop insulitis, but diabetes incidence is reduced and delayed (146). The data suggest that initiation of disease seems not to require perforin-dependent beta cell lysis, however, perforin appear to be important as an effector mechanism of beta cell destruction in the NOD mouse. Low diabetes incidence in perforin deficient NOD mice suggests that other mechanisms are involved in beta cell destruction in the NOD model.

\section{Fas ligand}

Fas (CD95/APO-1) belongs to the RNFR family that is able to signal apoptosis through intracellular death domain. Fas is constitutively expressed on activated lymphocytes in some mouse organs. Its expression can be up-regulated by the cytokines IFN $\gamma$, IL- 1 and TNF $\alpha$ in various cells lines. FasL (CD95L) is a membrane protein expressed on activated $\mathrm{T}$ cells (147). The FasL binding to Fas leads to activation of intracellular 
signaling pathway results in cell death. It has been suggested that Fas probably play an important role in beta cell death in type 1 diabetes both in humans and in the NOD mouse. However, much of the evidence comes from in vitro studies with isolated human or mouse islets. Cytokines such as IL-1 upregulate Fas expression on both human and mouse beta cells, resulting in apoptosis $(148 ; 149)$. Fas expression in beta cell has been found to correlate with beta cell destruction in NOD mice (150). However evidence for these studies comes mainly from immunostaining of pancreas sections that are difficult to interpret due to the complex composition of infiltrated islets. In contrast, using flow cytometry to directly identify Fas expressing beta cells in NOD mice, Fas expression is detected on a limited number of beta cells (1-5\%) even in old ( $>125$ days) NOD mice, suggesting that at least in the NOD mouse Fas may not be an important mechanism of beta cell destruction. The more controversial data comes from an in vivo Fas-deficient NODlpr mice study. These mice lacking Fas did not develop insulitis and diabetes, and also were resistant to diabetogenic T-cell transferring diabetes (151-153). However, islets from these NODlpr mice lacking Fas, when grafted into diabetic mice, are unable to be protected from autoimmune destruction and restore normoglycemia of the recipient diabetic mice (154). Finally, the apparent controversy was found to be due to the fact that Fas-deficient NOD mice have abnormal FasL-expressing lymphoid cells that inhibit the development of diabetes (155). Therefore it still remains to be determined what the role of Fas is in development of type 1 diabetes.

\section{Cytokines}


The proinflammatory cytokine IL-1 is produced mainly by activated macrophages and affects nearly every cell type, often in conjunction with other cytokines. IFN $\gamma$ is produced by $\mathrm{T}$ cells and NK cells. IFN production is stimulated by macrophage-derived cytokines including TNF $\alpha$, IL-12, IL-18 and by IFN $\alpha$ itself. TNF is a pleiotropic cytokine, produced mainly by activated macrophages and $\mathrm{T}$ cells.

Expression of these cytokines in the islet lesion has been characterized. In early insulitis in the NOD mouse and the BB rat, expression of IL-1, TNF $\alpha$, and IFN $\gamma$ can be detected $(156 ; 157)$. IL-1 mRNA and protein expression are detected in the infiltrate of islets from NOD mice (158), as is TNF $\alpha(159 ; 160)$. There is also elevated expression of IFN $\gamma$ after 3 months of age in female NOD mice $(161 ; 162)$. The presence of these cytokines in islets of NOD mice suggests that they may be involved in beta cell destruction and diabetes.

In vitro study, in rodent islets, IL-1 alone or combined with IFN $\gamma / \mathrm{TNF} \alpha$ could cause both necrosis and apoptosis, however, in human islets, a combination of the three cytokines is required to induce similar cytotoxic effect (163). Furthermore, human beta cells exposed to cytokines die mainly in a process of apoptosis, whereas beta cell destruction in rodent islets constitutes a mixture of necrosis and apoptosis.

To address the effector role of cytokines in vivo, systemic administration either anticytokine antibody or cytokines has been used. The data from in vivo studies using systemic administration of cytokines is contentious.(164). In contrast, the data from anti-cytokine intervention using antibodies or soluble receptors against IL-1, TNF $\alpha$ and 
IFN $\gamma$ have almost unanimously shown inhibitory effects on diabetes on NOD mice and $\mathrm{BB}$ rats (165). However, despite these data it remains to be demonstrated whether these effects are exerted by blocking cytokine action directly on the beta cells or by immune modulatory effects of these cytokine antagonists (166).

To clarify the more direct role of locally produced cytokines in beta cell destruction, in the past 10 years, cytokine transgenes have been introduced into beta cells of both nondiabetic-prone animals and NOD mice. In non-diabetes-prone animals, only IFN $\alpha / \gamma$ or TNF $\alpha / B 7$ transgenic expression produced both insulitis and diabetes. In NOD mice, overexpression of IL-2 in beta cell could speed up diabetes onset. However, overexpression of TNF $\alpha$ has shown that the time of TNF $\alpha$ expression is critical in determining its ability to enhance or prevent the onset of diabetes. Overexpression of TNF $\alpha$ in beta cells of adult NOD mice leads to rapid infiltration in the islets without loss of beta cells or diabetes (167). But when TNF $\alpha$ is expressed in beta cells of neonatal NOD mice diabetes occurs rapidly in all mice (168). This suggested that TNF $\alpha$ could have very diverse effects depending on the location of action and time window. Several systemically cytokine-deficient NOD mice also have been used to address the function of cytokines in NOD diabetes development. Only IFN $\gamma$ receptor $\alpha$-chain disruption and IL-1 receptor deficiency produce a protective effect, indicating that these receptors may be playing an important role in the development of diabetes. But interestingly, IFN $\gamma$ receptor $\beta$-chain disruption did not show any protection from diabetes onset in NOD mice. 
Overall, although in vitro studies suggest that cytokines either alone or combination could exert direct destruction effect on pancreatic beta cell, however, the clear conclusion is still difficult to draw from the above in vivo studies. Since redundancy, compensatory mechanisms and secondary pathology must be involved in single cytokine transgenic or knock out model (169), these studies may only provide limited information on the in vivo relevance of the local role of cytokines as effectors of beta cell destruction.

\section{Cell signaling pathways}

Several signaling pathways and transcription factors have been found to mediate cytokine signaling in beta cells. IL-1 could bind IL-1 receptors including IL-1R1 and IL-1R2. The low affinity IL-1R1 is the signal-transducing receptor, whereas the high affinity IL-1R2 is a decoy receptor (170). Since IL-1R1 shares no significant homology with conserved protein kinase domains, it is unlikely to have any intrinsic protein kinase activity (171) and may need to recruit cytoplasmic proteins to transmit its signals. These cytoplasmic proteins include IL-1 receptor accessory protein (IL-AcP), adaptor protein MyD88, IL-1R1 activated kinase (IRAK) and TNF-receptor-associated factor-6 (TRAF6). IL-1-induced signal transduction involves several major pathways, such as the activation of PI3K; mitogen-activated protein kinases (MAPK); protein kinase $\mathrm{C}$ $(\mathrm{PKC})$ and transcription factor nuclear factor $\mathrm{\kappa B}(\mathrm{NF} \kappa \mathrm{B})$ and activator protein-1(AP-1). $\mathrm{NF} \mathrm{KB}$ is the main transcription factor for iNOS gene expression, which can cause NO dependent beta cell destruction. 
TNF receptors include 2 types of receptors, one is the p60 receptor and the other is the p80 receptor. These two receptors have similar extracellular but different intracellular domains. P60 receptor cytosolic protein has a death domain which the $\mathrm{p} 80$ receptor lacks. This death domain is considered crucial for transmitting the death signal through interacting with the TNF receptor associated death domain (TRADD), which in turn recruits the Fas-associated death domain (FADD). Finally, TNF receptor associated factor 2 (TRAF2) will bind to the p60/TRADD/FADD complex and mediate subsequent events, such as modulation of c-jun $\mathrm{N}$-terminal kinase (JNK), p38 kinase, PKC, and transcription factor NFKB.

IFN $\gamma$ signals are through the IFN $\gamma$ receptor 1, which subsequently recruits accessory factor proteins (IFN $\gamma$ receptor 2). Once they associate together, a cytosolic protein kinase called Janus tyrosine kinase 1 and 2 (JAK1/2) are activated by autophosphorylation and transphosphorylation. JAK1/2 will further activate transcription factor STAT1 through phosphorylation. Activated STAT1 will translocate to the nucleus inducing gene expression such as caspase expression, thereby inducing a proapoptotic response (172).

Among these signaling pathway induced by cytokines, it should be noted that cytokine not only induced death signal such as activation of $J \mathrm{NK}$, p38, AP-1, it also induced survival and cell defense signal such as PI3K/Akt, ERK pathway, which indicates that balance among those different pathway will finally determine the beta cell fate. 


\section{$\underline{\text { ROS and cell signaling }}$}

ROS are species of oxygen which are in a more reactive state than molecular oxygen, and in which, the oxygen is reduced to varying degrees. ROS from mitochondria and other cellular sources have been traditionally regarded as toxic by-products of metabolism with the potential to cause damage to lipids, proteins, and DNA (173). However, more and more, recent evidence suggests that ROS are not only injurious byproducts of cellular metabolism but also essential participants in cell signaling and regulation $(174 ; 175)$. This apparent paradox in the roles of ROS as essential intracellular signaling molecule and as toxic by-products of metabolism probably partially depends on the different concentration and cellular sources of ROS generation. The typical example is the effects of nitric oxide, which has both regulatory functions and cytotoxic effects depending on the enzymatic source and relative amount of NO generated (176). NO could function as a signaling messenger if produced in low concentrations by the constitutive isoform of nitric oxide synthase (NOS) in endothelial cells or neurons, and also as a toxic product with potential to cause damage to tissue if produced in high concentrations (two or three orders of magnitude higher) by the inducible NOS in macrophages and other immune-effector cells. This dichotomy between signal transduction and toxic function is likely to be preserved for other reactive oxygen species such as hydrogen peroxide and superoxide.

However, to be considered as a potential signaling molecule, ROS must: 1) be produced by a cell when stimulated to do so; 2) have an action in a cell, either the cell which 
produces it or a nearby cell; 3) be removed in order to turn off, or reverse, the signal. It is now clear that some ROS, particularly hydrogen peroxide $\left(\mathrm{H}_{2} \mathrm{O}_{2}\right)$ and superoxide, fulfill these criteria. Hydrogen peroxide is a small, diffusible, and ubiquitous molecule that can be synthesized, as well as destroyed, rapidly in response to external stimuli. It has been shown that $\mathrm{H}_{2} \mathrm{O}_{2}$ can mimic the stimulatory effects of insulin on glucose transport and lipid synthesis in adipocytes (177). It has been well demonstrated that ligand stimulation of non-phagocytic cells results in an increase in intracellular ROS. This phenomenon has been observed in a wide variety of cell types and is stimulated by a diverse collection of ligands, including cytokines (178-180) as well as peptide growth factors acting through tyrosine kinase (181-184) and G-protein-coupled receptors (185).

\section{Cellular sources of ROS}

Any electron-transferring protein or enzymatic system can result in the formation of ROS. Therefore both enzymatic and nonenzymatic sources contribute to total cellular ROS generation. It has been proven that ROS can be generated in cells by several pathways.

\section{Mitochondrial}

Cellular energy metabolism is based on the production of ATP through the electrontransport reaction in which $\mathrm{O}_{2}$ accepts electrons and $\mathrm{H}^{+}$and then is reduced to water. During this process, leakage of a single electron being transferred to $\mathrm{O}_{2}$ could result in the production of $\mathrm{O}_{2}^{-}$. Mitochondria normally consume the vast majority of $\mathrm{O}_{2}$ to 
generate ATP through the respiratory chain. However, $1-2 \%$ of electrons are leaked to generate $\mathrm{O}_{2}{ }^{-}$in reactions mediated by coenzyme $\mathrm{Q}$ and ubiquinone and its complexes $(186 ; 187)$. Thus mitochondria are believed to be a major site of ROS production in vivo (188). NADH-ubiquinone reductase and ubiquinol-cytochrome c reductase, which contain ubisemquinone as an important constituent, were shown to generate superoxide and hydrogen peroxide (189). The potential for mitochondrial ROS to mediate cell signaling has gained significant attention on the regulation of apoptosis (190-193). Some studies suggest that TNF $\alpha$ and IL-1 induced apoptosis may involve mitochondria derived ROS (194-196). It also has been found that mitochondrial ROS could trigger hypoxia induced transcription $(197 ; 198)$.

\section{Edoplasmic reticulum (ER)}

ER is another membrane bound intracellular organelle that is primarily involved in lipid and protein biosynthesis. In ER, superoxide could be generated by the leakage of electrons from NADPH cytochrome p450 reductase (199). Although there is no direct link between ER derived oxidants and cellular signaling, there is evidence for redox regulation of ER related protein folding and secretion (200-202).

\section{NADPH oxidase}

NADPH oxidase is a plasma membrane associated oxidase. In phagocytic cells, it has been well characterized that NADPH oxidase serves a specialized function in host defense against invading microorganism(203;204). Activated macrophages and neutrophils can produce large amounts of superoxide and its derivatives via the 
phagocytic isoform of NADPH oxidase. This multicomponent enzyme consists of the membrane-bound cytochrome $\mathrm{b}_{558}$ complex comprising $\mathrm{gp} 91^{\text {phox }}$ and $\mathrm{p} 22^{\text {phox }}$, the cytosolic proteins $\mathrm{p} 47$ and $\mathrm{p} 67$, and a low molecular-weight G protein of the rac family. Phagocytic NADPH oxidase becomes activated upon translocation of cytosolic p47, p67 and a $G$ protein of the rac family to the membrane-bound cytochrome $b_{558}$ complex. Activated enzyme catalyzes the the one-electron reduction of $\mathrm{O}_{2}$ to $\mathrm{O}_{2}{ }^{-}$, with $\mathrm{NADPH}$ as the electron donor through the transmembrane protein cytochrome $b_{558}$. The activation of phagocytic NADPH oxidase can be induced by microbial products such as bacterial lipopolysaccharide, by lipoproteins, or by cytokines such as interferon- $\gamma$, interleukin- $1 \beta$ or interleukin-8(205). The activation of NADPH oxidase is mainly controlled by the rac isoform rac2 in neutrophils and rac1 in macrophages and moncytes(206;207).

Nonphagocytic $\mathrm{NAD}(\mathrm{P}) \mathrm{H}$ oxidases have been implicated as the sources of growth factor and /or cytokine stimulated oxidant production(208-212), which plays a role in the regulation of intracellular signaling cascades in various types of nonphagocytic cells including fibroblasts, endothelial cells, vascular smooth muscle cells, cardiac myocytes and thyroid tissue(213-221). Rac1 also has been found to be involved in the induction of NADPH oxidase activity. Angiotensin II increases $\mathrm{NAD}(\mathrm{P}) \mathrm{H}$ driven superoxide production in cultured vascular smooth muscle cells and fibroblasts. Thrombin PDGF, and TNF $\alpha$ stimulate $\mathrm{NAD}(\mathrm{P}) \mathrm{H}$ oxidase dependent superoxide production in vascular smooth muscle cells. IL-1 and TNF $\alpha$ increase $\mathrm{NAD}(\mathrm{P}) \mathrm{H}$ dependent superoxide production in fibroblasts. 
However, compared with phagocytic cells, the rate of superoxide production in nonphagocytic cells is much lower, only about one-third of that of neutrophils. Unlike neutrophils, some nonphagocytic cells such as vascular smooth muscle cells generate superoxide and hydrogen peroxide mainly intracellularly.

\section{Xanthine oxidase}

In addition to intracellular membrane-associated oxidases, soluble enzymes such as xanthine oxidase, aldehyde oxidase, dihydroorotate dehydrogenase, flavoprotein dehydrogenase and tryptophan dioxygenase can generate ROS during catalytic cycling (222). The most extensively studied of these is xanthine oxidase, which generates superoxide by converting hypoxanthine into xanthine and xanthine into uric acid. Xanthine oxidase is derived from xanthine dehydrogenase by proteolytic cleavage(223). Under normal conditions, xanthine oxidase accounts for only a minor proportion of total ROS production(224). However, there is evidence that TNF treatment induced ROS production in endothelial cells could be through xanthine oxidase(225). Some other data suggest that ROS produced by xanthine oxidase has been implicated as a major souce of oxidative stress under pathological conditions such as ischemia and reperfusion(226).

\section{Other source of ROS}

In addition to several sources of ROS described here, there are various other enzymic and nonenzymic mechanisms of ROS production such as Lipoxygenase, 
cyclooxygenase and dopamine, it has been shown that cytokines such as IL-1 or TNF $\alpha$ could induce ROS production through lipoxygenase or cyclooxygenase $(227 ; 228)$.

\section{Signaling molecules targeted by ROS}

\section{Protein Tyrosine Kinases and Phosphatases}

Although ROS are involved in regulating many signaling pathways, the signaling molecules targeted by ROS have remained largely unexplored. However, lots of evidence suggests that ROS regulation could occur at multiple levels in the signaling pathways from receptor to nucleus.

\section{Protein Tyrosine Kinases and Phosphatases}

There are various examples of growth factors, cytokines, or other ligands that trigger ROS production in nonphagocytic cells through their corresponding membrane receptors. Such ROS production can mediate a positive feedback effect on signal transduction from these receptors through upregulating protein phosphotyrosine.

Reversible protein phosphorylation is the key biochemical event in most cell signaling pathways. In general, the upregulation of phosphotyrosine signaling by oxidants may be rationalized in terms of two different effects: the inhibition of protein tyrosine phosphatases(PTPs) and /or the activation of phosphotyrosine kinases. Actually, some studies have shown that both phosphotyrosine phosphatases and kinases may be targets of oxidative stress. But it is still unclear which one is predominant. 
ROS could reversibly inactivate PTPs and / or protein phosphatase A by the direct oxidation of cysteine in the active site of these enzymes. (229) All PTPs share a common and also essential catalytic cysteine residue in their active sites, which is extremely reactive, with a lower $\mathrm{pKa}$ (about 5.5) than the $\mathrm{pKa}$ (about 8) of other cysteine residues in most proteins $(230)$. The low pKa makes the thiolate anion especially susceptible to the inhibitory action of ROS by forming a sulfenic acid (CyssOH) intermediate. This transient intermediate could be reversed by a thiol-reducing agent such as glutathione. It has been reported $\mathrm{H} 2 \mathrm{O} 2$ treatment could inhibit PTPs in vitro (231) as well as in several cell lines such as MO7e (232), HER14 cells(233), Jurkat $\mathrm{T}$ lymphocytes(234) and HELA cells(235). Antioxidants such as $\mathrm{N}$ acetylcysteine (NAC) inhibits $\mathrm{H} 2 \mathrm{O} 2$-induced phosphatase inactivation in glia cell lysate(236). Since the fully active PTPs can efficiently remove phosphotyrosine residues and destroy binding sites for other signaling molecules shch as PI3-kinase, ROS inactivation of PTP could enhance tyrosine receptor induced downstream cellular signaling. Because the level of tyrosine phosphorylation of cellular proteins is determined by the balance of PTK and PTP activity, oxidant induced inactivation of PTPs results in an apparent enhancement of tyrosine phosphorylation.

Although activation of PTK by ROS could be the consequence of ROS inhibition of PTPs, however, recent data also suggested that ROS might directly affect some cytoplasmic PTK activation such as src family tyrosine kianses(237;238). The src family of tyrosine kinases is a closely related groupd of nonreceptor kinases involved in 
signaling pathways that, in response to the activation of cell-surface receptors by growth factors, cytokines, or cell-surface ligands, control the growth and differentiation of cells(239).

Both in vivo and in vitro studies have been shown that NO and a relatively low concentrations $(<100 \mu \mathrm{M})$ of peroxinitrite could directly increase c-src activation while high concentration of peroxinitrite inactivate c-src. $(240 ; 241)$. ROS such as NO and $\mathrm{H} 2 \mathrm{O} 2$ might react with thiol group of Src molecules to form disulfides (s-s) bond, which destabilize the Src structure for Tyr-416 autophosphorylation-associated activation. Such NO activated Src kinase will be abolished when treated with reducing agents such as 2-ME and dithiothreitol, which should interrupt the the NO mediated SH group modification forming S-S bond(242).

Therefore, upregulation of tyrosine phosphorylation by ROS through PTP inhibition is a plausible cellular event, but PTP inhibition can not be the sole mechanism and activation of PTK by ROS might be an alternative mechanism.

\section{Serine/Threonine Kinases and Phosphatases}

The MAP kinases belong to a large family of praline-directed serin/threonine kinases including extracellular signal regulated kinase (ERKs), c-Jun N-terminal kinase (JNK) and p38 MAPK (p38). Many studies have shown that addition of exogenous $\mathrm{H} 2 \mathrm{O} 2$, and exposure to radiation or to drugs known to induce production of $\mathrm{H} 2 \mathrm{O} 2$, such as menadion, lead to activation of the MAP kinase including a new family member, Big MAP kinase 1(BMK1)(243-248). The mechanisms by which exogenous or 
endogenously produced ROS activate the MAP kinases are not well defined. Several studies suggested that ROS activate MAP kinase cascade through a Ras-dependent mechanism(249-251). Ras, a small G protein, could be directly altered by oxidation of a cysteine close to the guanine nucleotide binding site, resulting in activation(252-254). Also activation of the MAP kinases could be the result of activation of the Src kinase family. Since c-Src was found to be required for the $\mathrm{H}_{2} \mathrm{O}_{2}$ and UV induced activation of $\operatorname{JNK}(255 ; 256)$ and $\mathrm{H} 2 \mathrm{O} 2$ induced activation of $\operatorname{ERK} 5(257 ; 258)$. Another mechanism has been proposed for JNK and p38 activation that involved ROS-dependent dissociation of a signalosome that maintains the pathway in an inactive state. ASK1, a MAPKKK for JNK and p38 associates with reduced thioredoxin (Trx) in non-stressed cells. Oxidation of $\operatorname{Trx}$ by ROS releases ASK-1, and leads to JNK and p38 activation(259). ASK 1 knockout mice exhibited lower levels of JNK and p38 activation in comparison to wild type after $\mathrm{H} 2 \mathrm{O} 2$ or $\mathrm{TNF} \alpha$ stimulation(260).

Other serine/threonine kinases such as Akt and PKC also have been found to be activated by ROS. Treatment of cells with $\mathrm{H} 2 \mathrm{O} 2$ leads to the activation of Akt $(261 ; 262)$.Akt is a pleckstrin-homology domain containing serine/threonine kinase. Since Akt activity is stimulated by growth factors through the activation of PI3kinase(263-265), it is possible that $\mathrm{H} 2 \mathrm{O} 2$ enhanced PTK induced downstream cellular signaling results in Akt phosphorylation and activation.

PKC is involved in signal transduction to various effector pathways that regulate transcription and cell cycle control. This enzyme is typically activated by the lipid 
second messenger diacylglycerol $(266 ; 267)$. However, treatment of cells with $\mathrm{H} 2 \mathrm{O} 2$ could lead to activation of PKC in a phospholipids independent process that involves tyrosine phosphorylation in the catalytic domain $(268 ; 269)$. To search for the possible mechanism, a study using purified PKC reavealed that selective oxidative modification at the amino-terminal regulatory domain, which contains a zinc-thiolate structure, generated activated $\mathrm{PKC}(270)$. In contrast, oxidative modification at the carboxylterminal catalytic domain resulted in complete inactivation of the kinase(271). Thus oxidants appear to directly regulate PKC activity in the dual manner. Other studies suggested that ROS also could modify some phospholipids metabolites such as diacylglycerol to affect PKC activation(272;273). Takekoshi et al showed that the oxidized forms of diacylglycerol were more effective in activating PKC than its nonoxidized forms(274).

It should be noted that ROS could regulate serine/threonine phosphatases activity. Studies in vitro revealed that thiol oxidation of protein phosphatase 1 and $2 \mathrm{~A}$ inhibited the enzymic activity(275).

\section{Ca2+ signaling}

Changes in the cytosolic $\mathrm{Ca} 2+$ level play a role in the modulation of several intracellular signal pathways, including $\mathrm{PKC}$ and calmodulin-dependent signal pathways(276). Oxidative radical stress could increase cytosolic $\mathrm{Ca} 2+$ level through the mobilization of intracellular $\mathrm{Ca} 2+$ stores and /or through the influx of extracellular $\mathrm{Ca} 2+(277-281)$. Oxidant-induced $\mathrm{Ca} 2+$ mobilization is blocked by herbimycin $\mathrm{A}$, a 
PTK inhibitor(282;283) and is partly suppressed in mutant cells that do no express Syk or Lyn $(284 ; 285)$. This suggests that the intracellular Ca2+ level is regulated by ROS probably through the activation of upstream PTKs. Furthermore, this ROS-mediated increase in the cytosolic $\mathrm{Ca} 2+$ level could contribute to the oxidative stress-mediated activation of $\mathrm{PKC}(286)$ and to the transcriptional induction of the $\mathrm{AP}-1(287 ; 288)$.

\section{Redox regulation of Transcription factors such as NF-kB, AP-1, HIF, p53, et al}

$\mathrm{NF}-\mathrm{\kappa B}$, a transcription factor that regulates the expression of a number of genes involved in immune and inflammatory responses, stress response, cell growth and cell survival, has long been considered oxidant responsive $(289 ; 290)$. It is the first eukaryotic transcription factor shown to respond directly to oxidative stress in certain types of cells(291). However, the mechanisms by which ROS regulate this activity have remained elusive. Recently, some evidence suggested one possible mechanism contributes this effect. This mechanism involves the oxidative enhance of upstream signal cascades, which could result in increasing phosphorylation of ІкB, a critical step in NF- $\mathrm{KB}$ activation. I $\mathrm{B}$ B has been well known an endogenous inhibitor for NF- $\mathrm{KB}$ activity. Once IKB is phosphorylated, it is rapidly degraded in proteasome dependence. Exposure to $300 \mu \mathrm{M} \mathrm{H} 2 \mathrm{O} 2$, increased phosphorylation of $\mathrm{I \kappa B} \alpha$ was found in EL4 T cells(292), and similar induction of IkB phosphorylation was seen in Jurkat T cells after a mild oxidative shift in the intracellular thiol pool(293).

Activator protein-1(AP-1), a transcriptional complex typically composed of c-Fos and c-Jun preteins, has also been demonstrated to be regulated by redox mechanisms. Many 
different oxidative stress-inducing stimuli, either exogenous oxidants such as relatively low concentrations of hydrogen peroxide, UV light, $\gamma$-irradiation or ligand induced ROS such as interleukin-1 treatment, lead to AP-1 activation(294-298). The activity of AP-1 has been revealed to be regulated by redox through the conserved cystein residues that are located in the DNA binding domain of each Fos and Jun protein(299;300). The modification of these residues by a sulfhydryl modifying agent, such as $\mathrm{N}$ ethylamaleimide(NEM) or diamide, reduce its activity, whereas treatment with reductants, such as dithiothreitol (DTT), enhance DNA binding. Further evidence suggests that the redox regulation of AP-1 DNA binding is facilitated by the reducing activity of redox factor-1 (Ref-1) protein that may act directly on this critical cysteine residue(301). Other transcription factors such as c-Myb, p53, Sp-1 have similar redox mechanism to regulate their DNA binding(302-304).

\section{Mechanisms of ROS signaling action}

\section{Oxidative modification of proteins}

The chemistry of ROS suggests that ROS could primarily react with some amino acid residues such as cystein residues and protein bound metals, including heme iron. Oxidative modifications of some critical amino acids within the functional domain or regulation domain of protein may alter protein structure and function. By far, the best described of such modifications involves cysteine residues. Signaling proteins containing cysteines have been suggested as targets for ROS. The sulfhydryl group ($\mathrm{SH})$ of a single cysteine residue may be oxidized to form sulfenic (-SOH), sulfinic (- 
$\mathrm{SO} 2 \mathrm{H})$ or sulfonic $(-\mathrm{SO} 3 \mathrm{H})$. Formation of the latter two compounds is essentially irreversible and therefore unlikely involved in signaling. Although these reducible forms are often considered as the mediators of redox signaling(305;306), not all cysteine residues are equally susceptible to reaction with ROS. As the pKa of most protein cysteine residues is around 8.3 , they remain protonated at physiological $\mathrm{pH}$. Thus the reaction rate of most protein cysteines with ROS is too slow to be of physiological relevance. However, this situation is dramatically altered when cysteine is bound to a metal(307) or is in the thiolate anion (-S-) form. The resulting thiolate can then react rapidly with $\mathrm{H} 2 \mathrm{O} 2$ to form sulfenic acid. The typical example is PTP, which has already been mentioned before. With $\mathrm{pKa}<6$, the catalytic site cysteine residue of PTP is extremely reactive and rapidly forms a thiolate anion at physiological $\mathrm{pH}$, and could be easily oxidized by ROS.

Two or more cysteine residues within the same protein may be oxidized to form an intermolecular disulfide bridges, thereby altering its conformation and regulating its activity. The studies of bacteria transcritption factor OxyR have provided the wellestablished example of oxidative stress response activation by disulfide bond formation. The transcription factor OxyR could be activated by ROS and trigger the expression of defense activities including superoxide dismutase and peroxidase. $\mathrm{H} 2 \mathrm{O} 2$ can act directly on OxyR, generating a reactive oxidized derivative of a cysteine within the protein, which then can form a disulfide bond. Alternatively, OxyR can be activated by disulfide bond formation resulting from the altered redox state of the cytosol(308;309). Thioredoxin (Trx) also has a propensity for forming an intramolecular disulfide which 
has been shown to be involved in redox signaling. The Trx family has a conserved catalytic site, called a thoredoxin fold, with two close cysteine residues, one of which is a thiolate. An intramolecular disulfide can be easily formed if one of them is oxidized to a sulfenic acid. One example of signaling role for Trx is that Trx could regulate the activity of signaling kinase ASK1, one of the MAP kinase kinase kinases upstream of JNK, through its reversible oxidation(310). This study has shown that Trx is an inhibitor of ASK1 by binding to its amino-terminal domain that both TNF $\alpha$ and ROS activate ASK1 by inducing dissociation of Trx. Some evidence suggest that with respond to oxidant stress, Trx could translocate from the cytosol to the nucleus to bind and activate transcription factor NFKB or Ref-1, whose activation facilitates other transcription factors DNA binding to mediate transcription(311;312).

Finally, two identical or different proteins containing cystein residues also can be oxidized by ROS to form intermolecular disulfide bonds and result in homodimerization or heterodimerization reactions, therefore regulating their function.

\section{Alteration in intracellular redox state}

Redox state is a term that has historically been used to describe the ratio of the interconvertible oxidized and reduced form of a specific redox couple. Recently in biological research, it generally describes an indicator of the redox environment of cell. And it also can be used to correlate with several aspects of cell signaling (313). In several cases, changes in the intracellular thiol/disulfide redox state have been shown to 
trigger the same redox-responsive signaling proteins and pathways as those triggered by $\mathrm{H} 2 \mathrm{O} 2(314-317)$.

The cellular cytosol is normally maintained under strong "reducing" conditions. There are many redox couples such as GSSG/2GSH couple and $\operatorname{TrxSS} / \operatorname{Trx}(\mathrm{SH})_{2}$ couple in a cell that work together to maintain the redox environment. Glutathione(GSH) is considered to be the major thiol-disulfide redox buffer of the cell. Therefore, the GSSG/2GSH couple is the most abundant redox couple in a cell. Many researchers estimate the redox state of the system by taking the ratio of [GSH]/[GSSG]. Changes of the half-cell reduction potential $\left(\mathrm{E}_{\mathrm{hc}}\right)$ of the GSSG/2GSH couple appear to correlate with the biological status of the cell: proliferation $\mathrm{E}_{\mathrm{hc}} \approx-240 \mathrm{mV}$; differentiation $\mathrm{E}_{\mathrm{hc}} \approx-$ $200 \mathrm{mV}$; or apoptosis $\mathrm{E}_{\mathrm{hc}} \approx-170 \mathrm{mV}(318)$.

Trx is another important thiol-system in the cell. Its level is 100 to 1000 fold less than GSH. As mentioned before, it reduces cystine residues in the DNA-binding sites of several transcription factors and is therefore important in gene expression(319;320). In contrast to the small-molecule GSH that forms intermolecular disulfides, Trx is a protein that usually forms intermolecular disulfides. The reduction of the disulfide back to the dithiol form is catalyzed by Trx reductase, the source of electrons being NADPH(321;322).

\section{$\underline{\text { ROS and type } 1 \text { diabetes }}$}


It is general believed that ROS contribute to autoimmune mediated beta cell destruction. Since ROS are so essential in autoimmune diabetes, on the other hand, pancreatic beta cell contain extremely low ROS scavenge system, many trials using antioxidants to treat diabetes and prevent beta cell damage have been performed in both in vitro and in vivo studies. In vitro most of beta cell tumor lines studies provide pretty consistent results that antioxidants provide protection from ROS and cytokine induced toxicity(323-327). However, the relevance of these antioxidant protective results from beta cell tumor lines is still uncertain due to the difference between primary beta cells and tumor cell lines. It has been shown that treatment of isolated islets with antioxidants do not always reduce cytokine toxicity(328). Systemic treatment with antioxidants is most often performed in vivo. However, the major ambiguity in those in vivo studies is the site of protection. The protection of delaying diabetes onset with systemic antioxidant treatment could be produced at the immune system rather than directly at pancreatic beta cells(329). The studies for the proposal where antioxidant treatment has been directly targeted to beta cells are not only limited but the results are also controversial. Adenoviral expression of MnSOD was partially effective against cytokines in isolated primary islets(330). However, beta cell specific overexpression of the secreted form of SOD had no effect on NOD diabetes(331). Thioredoxin overexpression in beta cell delays NOD diabetes onset(332), but thioredoxin has an additional very potent anti-apoptotic effect, which may contribute to this significant benefit.

Therefore, it is still not clear what roles ROS play in type 1 diabetes. To provide more detail and specific analysis, we employed NOD mice with specifically overexpressing three antioxidants including MnSOD, catalase and MT in pancreatic beta cells. These 
three antioxidant proteins have been shown to be able to scavenge many types of ROS and protect from STZ or hypoxia induced beta cell damage(333-335). However, unexpectedly two cytoplasm antioxidants, catalase and MT, but not mitochondrial MnSOD, dramatically hastened both spontaneous and cyclophosphamide induced diabetes onset in NOD mice. This result suggests that the role of ROS is more complicated than previously proposed and normal cytoplasmic ROS may be necessary to trigger beta cell self protective response during autoimmune type 1 diabetes.

\section{Potential mechanism by which antioxidants could sensitize to diabetes in NOD} mice

Most studies dealing with the pathogenesis of IDDM have emphasized the immune assault against beta cells. However, there are many evidences that suggested that the beta cell destruction of IDDM depends on a balance between beta cell damage and repair/regeneration. The progressive beta cell damage leading to IDDM seems to follow markedly different temporal courses in individual patients. Some individuals at high risk for developing IDDM, and presenting with impaired beta cell function, appear to recover beta cell function when followed prospectively. Moreover, after the clinical onset of IDDM, most patients experience a transitory period of improved insulin secretion. In vitro and in vivo experimental data suggest that beta cells are indeed able to repair themselves after damage(336). Diabetes in the NOD mouse can be reversed for extended periods of time by the administration of anti-CD3(337). Dispersed beta cells or whole islets can survive and regain their function after a toxic assault. Furthermore, 
the abnormal insulin release and glucose oxidation of islets isolated from NOD mice during the prediabetic period is completely restored after 1 week in tissue culture (338). In NOD mice, beta cell proliferation indeed has been found to be increased before diabetes onset although beta cell mass is continuously reduced (339), which suggests that hyperglycemia in type 1 diabetes probably results from a long-term negative balance between immune-mediated beta cell damage and beta cell repair/regeneration.

More and more evidence suggests that apoptosis is the main mode of beta cell death in early type 1 diabetes. However, apoptosis is a highly regulated form of cell death, affected by both extracellular signals and intracellular ATP levels, and expression of apoptotic and antiapoptotic genes and proteins(340). Beta cell programmed death also emphasizes that it is the beta cell itself that make the final decision for beta cell survival or death in the early type 1 diabetes(341).

During the early type 1 diabetes, it is certain that immune attack triggers death signaling pathways in pancreatic beta cells, on the other hand, immune stress also induces some survival signaling pathways(342).

Some signaling pathway by which extracellular stimuli suppress apoptosis has been characterized. Survival factors, such as insulin-like growth factor (IGF), bind to their cell surface receptors trigger receptor autophosphorylation and the activation of receptor kinase. Cellular scaffold proteins such as insulin receptor substrate (IRS) bind to the autophosphorylation sites and are phosphorylated on multiple tyrosine residues by the 
activated receptor kinase. Phosphoylated IRS proteins couple IGF receptors to the PI3K and extracellular ERK cascades. In mice, there are at least three IRS proteins including IRS-1 and IRS-2, which are expressed in pancreatic beta cells. All IRS proteins contain an NH2-terminal PH domain adjacent to a PTB domain, followed by a variable length $\mathrm{COOH}$-terminal tail with numerous tyrosine phosphorylation sites.

In pancreatic islet, recent data has reported that Irs-2 branch of insulin/IGF signaling play a key role in beta cell survival and function $(343 ; 344)$. In mice, both Irs-1 knock out and Irs-2 knock out are markedly induced insulin resistant, however, only Irs-2 knock out mice fail to sustain compensatory insulin secretion due to decreased beta cell mass compared with wild-type and Irs-1 knock out mice and eventually developed diabetes. In contrast, overexpression of Irs-2 prevents diabetes in Irs2 knock out mice, obese mice and streptozotocin treated mice (345). This data suggested that the convergence of peripheral insulin resistant and islet defects around the Irs-2 branch of the insulin/IGF signaling pathway may reveal the common pathway to diabetes.

Irs-2 branch of insulin/IGF signaling promote cell survival at least in part by activating the PI3K and its downstream target Akt. PI3K is recruited and activated via phosphorylated IRS protein interaction. Products of PI3K attract several serine kinases including Akt and phosphoinositide-dependent kinase(PDK1/2) to co-localize at the plasma membrane. Akt will be activated through phosphorylation by PDK. One function of Akt is to phosphorylate and inhibit proapoptotic components of the intrinsic cell death machinery present within the cytoplasm including Bad, Caspase 9, and 
Forkhead transcription factors such as FKHRL1, Foxol and AFX. It has been shown that Akt activity is both necessary and critical for beta cell survival. Mice lacking Akt2 produce insulin resistant and pancreatic beta cell failure and loss, which finally result in severe diabetes(346). Increased expression of Aktl in pancreatic islets protects from STZ induced diabetes and against free fatty acid induced beta cell apotosis( $347 ; 348)$. Activation of Akt by IGF protects islets from cytokine toxicity $(349 ; 350)$ and delays NOD type 1 diabetes onset(351).

This insulin/ IGF signaling pathway could be turned off by protein tyrosine phosphatase (PTP). The fully active PTPs can efficiently remove phosphotyrosine residues and destroy binding sites for other signaling molecules such as PI3-kinase. Inhibition of PTP will increase activity of insulin/IGF signaling and improve survival. PTP inhibitors such as vanadate have been tried to treat insulin resistant in type 2 diabetes. Recently it was also found that diabetes in mice lacking IRS2 could be reversed by crossing with PTP1B knock out mice(352), indicating that specific phosphatase inhibitors might be useful treatments for diabetes. Therefore finding an endogenous inhibitor for PTP might provide an insight for this therapy.

PTPs contain an essential catalytic cysteine residue in their active sites, which is extremely reactive, with a lower pKa (about 5.5) than the pKa (about 8) of other cysteine residues in most proteins (353). The low pKa makes the thiolate anion especially susceptible to the inhibitory action of ROS by forming a sulfenic acid (CyssOH) intermediate. This transient intermediate could be reversed by a thiol-reducing 
agent such as glutathione. It has been reported $\mathrm{H} 2 \mathrm{O} 2$ treatment could inhibit PTPs in vitro(354) as well as in several cell lines such as MO7e(355), HER14 cells(356), Jurkat T lymphocytes (357) and HELA cells(358). Antioxidants such as N-acetylcysteine (NAC) inhibits $\mathrm{H} 2 \mathrm{O} 2$-induced phosphatase inactivation in glia cell lysate(359). More importantly, once insulin receptor(360) or EGF receptor (361) was triggered, endogenous ROS would be produced and inactivate PTP1B, indicating that inhibition of PTPs by ROS may be a physiologically important event during cell signaling. Catalase had been proven to abolish insulin-stimulated production of $\mathrm{H} 2 \mathrm{O} 2$ as well as inhibition of intracellular PTPs (362).

Overall, the insulin/IGF signaling pathway is activated by tyrosine phosphorylation of the insulin/IGF receptor and key post-receptor substrate proteins and balanced by the action of specific PTP. PTP activity, in turn, is highly regulated in vivo by oxidation/reduction reactions involving the cysteine thiol moiety required for catalysis. Our antioxidants overexpression may disrupt this balance through protecting PTP from inhibition of ROS.

\section{Hypotheses}

It is undoubted that cytokine could produce intracellular ROS. IL-1 beta also has been shown to activate and phosphorylate Akt in several cell types(363-365) as well as in mouse islet (366). Therefore, we hypothesize that during immune attack the beta cell in NOD mice is exposed to many stressors including lymphocytes and cytokines, in 
response pancreatic beta cell will first trigger defense system through activating Irs-2 related Akt pathway. ROS may play an important role during this cell survival signaling. Our antioxidant transgenes scavenger this minimal ROS and disrupt this defense system.

Both MT and Catalase transgenes had no deleterious effect on the beta cell structure or function either in FVB background or in NOD mice at the young age ( $<42$ days). Therefore we suspect such ROS regulation in survival pathway of pancreatic beta cells is more important in pathological situation such as autoimmune attack in type 1 diabetes than in physiological situation. 


\section{New Hypothesis}

limited ROS are essential for pancreatic $\beta$-cell survival during diabetic stress.

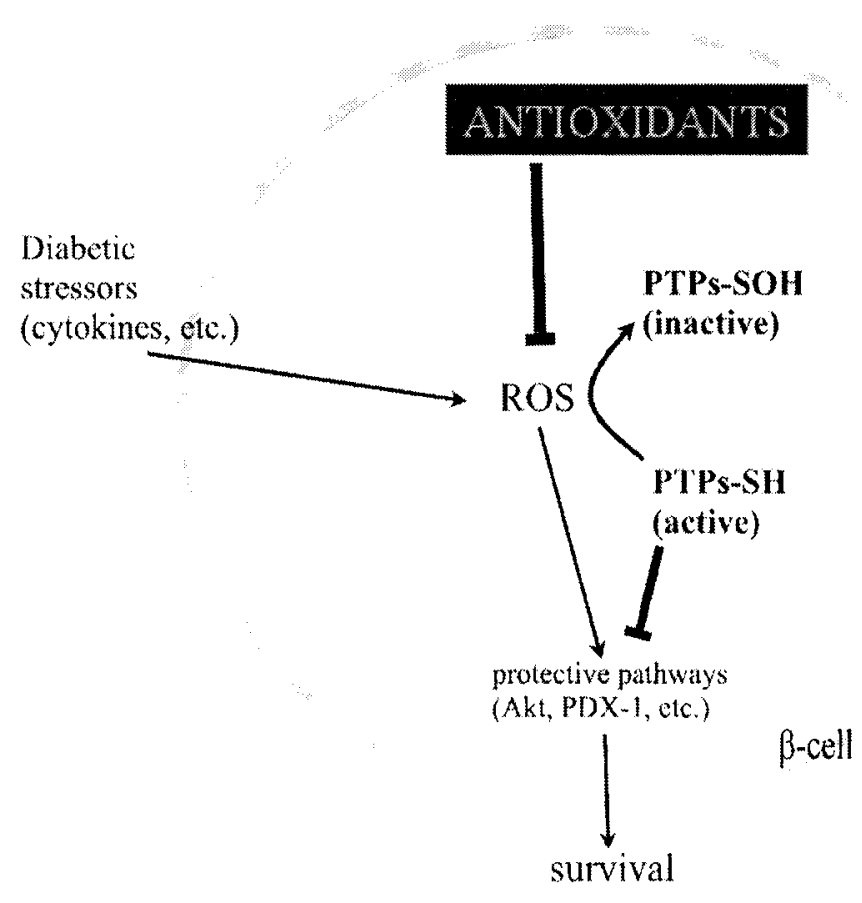




\section{MATERIALS and METHODS}

Chemicals: Collagenase (type V), Glutathione peroxidase from bovine erythrocytes, $\mathrm{H}_{2} \mathrm{O}_{2}$, hypoxanthine, xanthine oxidase, 3-morpholinosydnonimine (SIN1), S-nitro-N-acetyl-penicillamine (SNAP), and streptozotocin were bought from Sigma (St. Louis, MO). Hank's balanced salt solution (HBSS), RPMI 1640 medium, fetal bovine serum (FBS) and PCR reaction reagents (including Platinum Taq DNA polymerase, dNTP, Tris PCR buffer and $\mathrm{MgCl}_{2}$ ) were supplied by Invitrogen (Carlsbad, CA). Proteinase $\mathrm{K}$ was purchased from Qiagen (Valencia, CA) and ${ }^{109}$ cadmium was from Amersham (Piscataway, NJ). Rat insulin standard was bought from Linco (St. Charles, MO). 5- (6)-chloromethyl-2', 7'-dichlorodihydrofluorescein diacetate $\left(\mathrm{CM}-\mathrm{H}_{2}\right.$ DCFDA), picogreen was purchased from Molecular Probes (Eugene, OR). Alarma Blue was bought from Biosource International (Camarillo, CA). Rabbit antiserum to guinea pig insulin, was purchased from BioGenex (San Ramon, CA). Mouse anti-horse MT antibody was supplied by Dako (Carpinteria, CA). Sheep anticatalase and anti-human SOD antibody was bought from Biodesign International (Saco, Maine). For construction of the transgene enzymes were obtained from New England Biolabs (Beverly, MA). Other non-indicated reagents were standard chemicals from Sigma (St. Louis, MO), Fisher Scientific (Pittsburgh, PA) or Amersham Biosciences (Piscataway, NJ).

Solutions: The following solutions, very commonly used in this project, will not be further described wherever they were used. They are islet culture medium (with or without phenol red) (RPMI 1640 medium supplemented with $10 \%$ fetal bovine serum 
plus $100 \mathrm{U} / \mathrm{ml}$ penicillin and $100 \mu \mathrm{g} / \mathrm{ml}$ streptomycin), modified KRB buffer (KrebsRinger bicarbonate buffer, containing the designated concentration of glucose and supplemented with $0.1 \% \mathrm{BSA}$ and $10 \mathrm{mM}$ Hepes, $\mathrm{pH} 7.4$ ), islet sonication buffer (10mM Tris/HCl, pH 7.0, 1mM EDTA, 1mg/ml RIA grade BSA,), acid ethanol for islet insulin extraction (75 ethanol / 2 concentrated $(12 \mathrm{M}) \mathrm{HCl} / 23 \mathrm{H}_{2} \mathrm{O}, \mathrm{v} / \mathrm{v} / \mathrm{v}$ ), islet DNA digestion buffer $(0.1 \mathrm{M}$ Tris $/ \mathrm{HCl}, \mathrm{pH} 8.5,5 \mathrm{mM}$ EDTA, $0.2 \%$ SDS, $200 \mu \mathrm{g} / \mathrm{ml}$ proteinase $\mathrm{K}$ ), Tris-acetate-EDTA (TAE) buffer for electrophoresis $(0.04 \mathrm{M}$ Tris/HCl, 0.001 M EDTA, pH 8.5).

Animals: All mice were housed in ventilating cages at the University of Louisville, Research Resource Center with free access to tap water and standard mouse chow. All animal procedures were approved by the Institutional Animal Care and Use Committee. The laboratory was certified by the American Association of Accreditation for Laboratory Animal Care. The presence of transgenes in transgenic mice was determined by PCR of mouse tail DNA and/or by observation of coat color which was a product from a co-injected second transgene tyrosinase.

Maintenance of NOD mice and generation of transgenic NOD strain congenic for transgenes: $\quad \mathrm{MT}$, catalase, MnSOD transgenic mice were established in our laboratory on the FVB strain with pancreatic beta cell overexpression of the human MT II gene, rat catalase and human MnSOD. In more detail, the construct of MT transgenic mice was described in the above method and material of Chapter I. The catalase transgene, designated Cat, was constructed in a plamsid pKS/RIP provided by Dr. 
Fatima Bosch (Barcelona, Spain) as described previously(367). This gene contained the rat insulin I promoter linked to $1.8 \mathrm{~kb} \mathrm{BamHI} / \mathrm{Xho}$ I fragment of the rabbit beta globin gene that included the last beta globin intron and the globin polyadenylation sequence. An SV-40 enhancer sequence was contained in the downstream portion of the gene. The catalase cDNA was inserted into a unique Eco RI site of pKS/RIP located $45 \mathrm{bp}$ downstream from the rabbit beta globin intron. The rat catalase cDNA contained the entire $1581 \mathrm{bp}$ catalse coding sequence and was cleaved from the transgene MyCat(368) with Sal I and Hind III. The termini of the catalase fragment were converted to Eco RI sites by blunt ending and ligation to Eco RI linkers. The 4250 bp transgene was removed from the plasmid sequences by cutting with Xho I and Sac I. The MnSOD transgene, designated as MnSOD, was constructed in the same plasmid $\mathrm{pKS} / \mathrm{RIP}$ by replacing the catalase cDNA with a full length human MnSOD cDNA.

NOD mice purchased from Jackson Laboratory (Bar Harbor, Maine), were housed in individually ventilated microisolator cages at the Research Resource Center in University of Louisville. Strict cage changing and animal handling procedures were carried out to minimize viral infection. The standard mouse chow was Laboratory Rodent Diet 5001 (PMI Feeds, St. Louis, MO) containing 23\% protein and 4.5\% fat. This diet was suitable for maintaining a high incidence of diabetes in NOD mice. Transgenic NOD mice with beta cell specific expression of MT, catalase and MnSOD were generated from our transgenic FVB mice using a speed congenic procedure described by Serreze, et al.(369). In details, the MT, catalase and MnSOD transgenic FVB mice were backcrossed to NOD mice for up to 10 generations. Since the $5^{\text {th }}$ or $7^{\text {th }}$ generation, PCR based genotyping with the aid of microsatellite markers was performed 
to find a founder animal congenic for both transgene and all 19 NOD diabetic susceptible alleles. This animal was used as the progenitor for additional one or two backcrosses to NOD mouse for more homozygosity of NOD mouse genome. The produced transgenic and nontransgenic NOD offspring were intercrossed to generate animals which were used in this study.

PCR typing of NOD diabetes loci: The appropriate PCR primer pairs for polymorphic microsatellite markers of diabetic susceptible alleles of NOD mice were based on the report of Serreze et al (370) and the Mouse Genome Database in Jackson Laboratory. Those primers were purchased from Research Genetics and listed in Table 5-1. Mouse tail DNA was extracted from transgenic NOD offspring and control FVB and NOD mice with Qiagen DNAeasy Kit (Qiagen, Valencia, CA) according to the manufacturer instructional manual. PCR reaction was performed in a $20 \mu \mathrm{l}$ volume containing $1.5 \mu \mathrm{l}$ sample DNA (about 20ng DNA), $200 \mu \mathrm{M} \mathrm{dNTP}, 0.2 \mu \mathrm{M}$ of each primer, 0.45 unit of Platinum Taq DNA polymerase, $16 \mathrm{mM}\left(\mathrm{NH}_{4}\right)_{2} \mathrm{SO}_{4}, 67 \mathrm{mM}$ Tris$\mathrm{HCl}, \mathrm{pH} 8.8,0.01 \%$ TWEEN-20, and appropriate concentrations of $\mathrm{MgCl}_{2} \cdot \mathrm{MgCl}_{2}$ concentrations were varied between 1 and $5 \mathrm{mM}$ based on different primer sets (Table 5-2). PCR reaction was carried out in an Eppendorf thermocycler equipped with a heated hood. The reaction contained a first polymerase activation step at $95^{\circ} \mathrm{C}$ for $2 \mathrm{~min}$, followed with 32 cycles of amplification, and ended with an extenstion step at $72^{\circ} \mathrm{C}$ for 7 min. Each amplification cycle consisted of 45 seconds of denaturing at $94^{\circ} \mathrm{C}, 45$ seconds of annealing at $57^{\circ} \mathrm{C}$ and $1 \mathrm{~min}$ of extension at $72^{\circ} \mathrm{C}$. PCR products were fractionated on $6 \%$ NuSieve (FMC) agarose/TAE and stained with $0.5 \mu \mathrm{g} / \mathrm{ml}$ ethidium 
bromide. Control PCR reactions of inbred FVB and NOD mouse DNA were exerted every time and were fractioned in parallel to PCR products from other samples in order for a clear-cut discrimination of NOD diabetic allele from FVB normal allele. The PCR $\mathrm{Mg}^{2+}$ concentration and approximate size of PCR products from FVB and NOD strains for each set of microsatellite markers were summarized in Table 5-2.

PCR typing of transgenes: To determine the presence of transgenes, mouse tail DNA was extracted with Qiagen DNAeasy kit (Qiagen, Valencia, CA) according to the manufacturer instructional manual. PCR reaction was performed in a $20 \mu \mathrm{l}$ volume containing $1.5 \mu \mathrm{l}$ sample DNA (about $20 \mathrm{ng}$ DNA), $200 \mu \mathrm{M} \mathrm{dNTP}, 1 \mu \mathrm{M}$ of each primer, 0.8 unit of Platinum Taq DNA polymerase, $2 \mathrm{mM} \mathrm{MgCl}_{2}$ and $10 \mathrm{mM}$ Tris $1 \times$ PCR buffer (Invitrogen, Carlsbad, CA). PCR reaction was carried out in an Eppendorf thermocycler equipped with a heated hood. The reaction contained a first polymerase activation step at $95^{\circ} \mathrm{C}$ for $2 \mathrm{~min}$, followed with 35 cycles of amplification, and ended with an extension step at $72^{\circ} \mathrm{C}$ for $7 \mathrm{~min}$. Each amplification cycle consisted of $1 \mathrm{~min}$ of denaturing at $94^{\circ} \mathrm{C}, 1 \mathrm{~min}$ of annealing at $57^{\circ} \mathrm{C}$ and $1 \mathrm{~min}$ of extension at $72^{\circ} \mathrm{C} . \mathrm{PCR}$ products were fractionated on $0.9 \%$ agarose gel in TAE electrophoresis buffer and stained with $0.5 \mu \mathrm{g} / \mathrm{ml}$ ethidium bromide. The sequences for each set of primers for each transgene were as follows: MnSOD (forward 5'-GGATCCTGAGAACTTCAG-3', reverse 5'-TTCTGCCTGGAGCCCAGATAC-3'); Catalase (forward 5'AATATCGTGGGTGACCTCAA-3'， reverse 5'-GGATCCTGAGAACTTCAG-3'); MT (forward 5'-AATCGGTTGTGGACTGAGGA-3', reverse 5'CCTGATAAGATCACTGAGGA-3'). In addition to the primers for transgene, another 
set of primers (forward 5'-CTGGTGATGGCTTCCTTG-3', reverse 5'CTCAATGTTGAGCAGGAA-3') was included in every PCR reaction in order to monitor the quality of DNA sample and PCR reaction. This pair of primers was used to identify heme oxygenase which is ubiquitously expressed in all strains of our mice. At each time control PCR reactions for transgene positive and negative DNA were also performed.

\section{Immunohistochemistry for insulin, MT, Catalase, MnSOD and cleaved-caspase}

3: Transgenic or control mouse pancreas was fixed in $10 \%$ formaldehyde in $0.1 \mathrm{M}$ phosphate buffer ( $\mathrm{pH}$ 7.2), dehydrated in an ascending graded series of ethanol and subsequently infiltrated with paraffin. Serial sections were cut at $5 \mu \mathrm{m}$, mounted on polylysine coated slides and then rehydrated in a descending graded series of ethanol. Slides were treated with $3 \%$ hydrogen peroxide followed by an additional $10 \mathrm{~min}$ incubation with Power Block (Biogenex). Sections were treated with primary antibody (rabbit anti-guinea pig insulin antibody diluted 1 to 100 or rabbit anti-catalase, mouse anti-horse MT and sheep anti-human SOD antibodies at a 1:50 dilution or rabbit anti-cleaved-caspase-3 at 1:500). Primary antibody incubations were 90 min at $37^{\circ} \mathrm{C}$. After 4 washes in phosphate buffered saline slides were incubated with the appropriate either fluorescence-labeled second antibody or biotin-labeled second antibody followed by peroxidase labeled streptavidin and developed with 3-amino-ethylcarbazone (AEC) as chromagen. Slides without primary antibody treatment were used as negative control. To examine the cellular localization of MnSOD and catalase expression, the immunostained MnSOD and catalase transgenic islets were visualized with a Zeiss 510 
LCSM laser scanning confocal microscope using FITC/rhodamine barrier filters with excitation settings of 543 and $488 \mathrm{~nm}$, respectively. Lasar scanning confocal sections was obtained with $0.3-\mu \mathrm{m}$ steps for at least one cell layer within the islet. Maximum intensity $z$-axis projections for three sections $(1 \mu \mathrm{m}$ thick $)$ was constructed.

Islet isolation: The isolation procedure was based on a modification of the method of Gotoh et al (371). Mice were anesthetized with avertin at the dose of $6 \mathrm{mg} / \mathrm{g}$ body weight via intraperitoneal injection. The pancreas was inflated with $3 \mathrm{ml}$ of $1.55 \mathrm{mg} / \mathrm{ml}$ collagenase Type $\mathrm{V}$, and carefully removed from the mouse body and incubated at $37^{\circ} \mathrm{C}$ for 20 min. Digestion was stopped by adding cold HBSS followed by vigorous shaking and 3 washes in $50 \mathrm{ml}$ cold HBSS and passage through a $200 \mu \mathrm{m}$ mesh. The final pancreas pellet was resuspended in $10 \mathrm{ml}$ Histopaque 1077 , overlaid with $10 \mathrm{ml}$ of HBSS and centrifuged at $700 \times \mathrm{g}$ for $20 \mathrm{~min}$ at $10^{\circ} \mathrm{C}$. Most of the gradient, excluding the pellet was collected and washed twice with cold HBSS. Islets were then handpicked and maintained in islet culture medium at $37^{\circ} \mathrm{C}$ and $5 \% \mathrm{CO}_{2}$ plus humid air. Islets were normally used the day after isolation. For experiments requiring extended culture, medium was changed every two days.

Assays for insulin secretion, insulin content and DNA content. Glucose stimulated islet insulin secretion was measured by static assay on 96-well tissue-culture microplates. For each well 6-10 islets were hand picked into modified KRB buffer containing $3 \mathrm{mM}$ glucose at $37^{\circ} \mathrm{C}$. After two washes in $3 \mathrm{mM}$ glucose modified $\mathrm{KRB}$ 
solution, the islets were incubated for consecutive 30 min incubations in $200 \mu \mathrm{l}$ of 3 and $20 \mathrm{mM}$ glucose modified KRB solution. The supernatant was removed carefully for the measurement of released insulin. To determine islet insulin content, islets were sonicated in $150 \mu \mathrm{l} 10 \mathrm{mM}$ Tris $\mathrm{HCl}, 1 \mathrm{mM}$ EDTA, $1 \mathrm{mg} / \mathrm{ml}$ RIA grade BSA, $\mathrm{pH} 7.0$ for 30 seconds. Fifty $\mu \mathrm{l}$ of the solution was used to extract islet insulin with $100 \mu \mathrm{l}$ acid ethanol at $4{ }^{\circ} \mathrm{C}$ overnight. The remainder of the sonicate was digested with an equal volume of $200 \mu \mathrm{g} / \mathrm{ml}$ proteinase $\mathrm{K}$ in $100 \mathrm{mM}$ Tris $\mathrm{HCl}, \mathrm{pH} 8.5,5 \mathrm{mM}$ EDTA, $0.2 \%$ SDS at $55^{\circ} \mathrm{C}$ for 2 hours and used for islet DNA quantification with picogreen kit from Molecular Probes (Eugene, OR). Insulin was measured with the coated tube RIA kit from Diagnostic Products (Los Angeles, CA) and rat insulin standards.

Measurement of glothothine peroxidase activity in isolated islets: Islet Gpx activity was measured by Glutathone peroxidase assay kit (Cayman Chemical Company, Ann Arbor, MI). The kit measures Gpx activity indirectly by a coupled reaction with glutathione reductase. Oxidized glutathione, produced upon reduction of hydroperoxide by Gpx, is recycled to its reduced state by glutathione reductase and NADPH. The oxidation of NADPH to NADP+ is accompanied by a decrease in absorbance at $340 \mathrm{~nm}$. Under conditions in which the Gpx activity is rate limiting, the rate of decrease in the $\mathrm{A} 340$ is directly proportional to the Gpx activity in the sample(372). 100 islets were sonicated in $250 \mu$ l of prechilled assay buffer $(50 \mathrm{mM}$ Tris-cacodylic acid, $\mathrm{pH} 8.2,1 \mathrm{mM}$ diethylenetriamineeprentaacetic acid) for $1 \mathrm{~min}$ on ice. After solubilization for $30 \mathrm{~min}$ on ice, the sonicate was centrifuged at $20,000 \times \mathrm{g}$ for $30 \mathrm{~min}$. The supernatant was used to determine islet Gpx activity performed in a 96- 
well plate. In each well $20 \mu \mathrm{l}$ of the supernatant was mixed with $100 \mu \mathrm{l}$ of assay buffer and $50 \mu \mathrm{l}$ of co-substrate mixture, followed by a quick addition of $20 \mu \mathrm{l}$ cumene hydroperoxide. After carefully shaking the plate for a few seconds, the absorbance was read in a microplate reader at the wavelength of $340 \mathrm{~nm}$ for 10 min at a 1 min interval. The absorbance increasing rate of each well was calculated. Gpx activity was determined from a standard curve obtained with bovine erythrocyte Gpx (Sigma). Values were expressed per $\mathrm{mg}$ of islet protein in the sonicate, determined with the Pierce BCA protein assay.

In vivo glucose tolerance test: Prior to the test, sex- and age-matched mice were fasted overnight (about 16 hours). On the second day, mice were injected i.p. with a sterile $10 \%$ glucose solution at a dose of $1 \mathrm{~g} / \mathrm{kg}$ body weight. Tail blood glucose of each mouse was measured by a glucometer (OneTouch Ultra, Life Scan) at the times $0,5,15$, $30,60,120$ min after glucose administration.

In vivo STZ treatment. For MT transgene study, a total of 10 MTNOD mice and 10 control NOD mice received a single intraperitoneal injection of freshly dissolved $\mathrm{STZ}$ in $0.1 \mathrm{~mol} / 1$ sodium citrate $(\mathrm{pH} 4.5)$ at a dose of $180 \mathrm{mg} / \mathrm{kg}$ body weight. Mice were sex-matched at the age between 10 and 17 weeks. The tail blood glucose levels were monitored daily up for six days after STZ treatment by a glucometer (OneTouch Ultra, Life Scan, Milpitas, CA). 
Cyclophosphamide administration and diabetes monitoring: Age and sex matched transgenic and nontransgenic NOD mice received two doses of intraperitoneal injection of $200 \mathrm{mg} / \mathrm{kg}$ body weight of cyclophosphamide. The first and second injections were two weeks apart. The mouse tail blood glucose level was monitored using a glucose meter (OneTouch Ultra, Life Scan) every other day after first injection of CYP. Mouse was considered diabetic after two consecutive readings of blood glucose over $200 \mathrm{mg} / \mathrm{dl}$. The onset of diabetes was dated from the first of these two sequential measurements. Some mice were sacrificed after 8 days of CYP injection. Pancreas was removed for pancreatic insulin measurement, histology and immunohistochemistry study.

$H \& E$ staining and insulitis score: Transgenic or control mouse pancreas was fixed in $10 \%$ formaldehyde in $0.1 \mathrm{M}$ phosphate buffer $(\mathrm{pH} 7.2$ ), dehydrated in an ascending graded series of ethanol and subsequently infiltrated with paraffin. Serial sections were cut at $5 \mu \mathrm{m}$, mounted on polylysine coated slides. Slides were stained with hematoxylin and eosin with a standard protocol. The severity of insulitis was scored blindly in $\mathrm{H} \& \mathrm{E}$ sections. Insulitis category includes no-insulitis, peri-insulitis, intra-insulitis and atrophy islets. Results were expressed as mean islet percentages for each insulitis category in an individual mouse. In each group data were collected from at least three mice and each mouse was examined with 3 or 4 slides.

Islet IB-1 expression after cytokine treatment: The messenger RNA level of iNOS in cultured islets was measured by real-time quantitative RT-PCR. Eighty to one 
hundred overnight-cultured islets were treated without or with cytokines (mouse recombinant interleukin- $1 \beta 5 \mathrm{U} / \mathrm{ml}$ plus interferon- $\gamma 100 \mathrm{U} / \mathrm{ml}$ ) in $300 \mu \mathrm{l}$ culture medium for six hours in $1.5 \mathrm{ml}$ microtubes. After treatment islets were rinsed with fresh HBSS solution twice and islet total RNA was extracted with an RNA preparation kit from Stratagene (Absolutely RNA Microprep Kit, Stratagene, La Jalla, CA) according to the manufacturer instructional manual. The RNA sample was treated with DNase to remove all traces of genomic DNA contamination and its concentration was determined by Ribogreen RNA quantification kit (Molecular Probes, Eugene, OR). Fifty ng total islet RNA was reverse-transcribed to cDNA with a StrataScript reverse transcriptase (Stratagene) in the presence of oligo dT based on the manufacturer provided procedure. Real time quantitative PCR was prepared using Brilliant ${ }^{\mathrm{TM}}$ plus Two-Step Quantitative RT-PCR Core Reagent kit (Stratagene) and executed using $\mathrm{Mx} 4000^{\mathrm{rM}}$ real-time multiplex quantitative PCR system (Stratagene). The cDNA sequences for murine $\beta$ actin and iNOS were obtained from GenBank, and the primer and probe sequences were designed using Primer3 software (Steve Rozen and Helen J. Skaletsky (2000) Primer3 on the WWW for general users and for biologist programmers. In: Krawetz S, Misener S (eds) Bioinformatics Methods and Protocols: Methods in Molecular Biology. Humana Press, Totowa, NJ, pp 365-386). To avoid amplification of genomic DNA, the primer-probe sets were designed to span exon-exon boundaries. The probes were labeled with a fluorescent reporter 6-carboxyfluorescin (FAM) at the 5' end and a quencher, 6-carboxytetramethylrhodamine (TAMRA) at the 3' end. The sequences for the primer-probe sets for each gene were as follows: IB-1 (forward 5'CTGCCACTGTCTATGACAAC-3'， reverse 5'-TCCTCATACTCCTCACCAAT-3', 
probe 5'-6FAM-CCTCCTCGCCCTACGAGTCA-TAMRA-3'); $\beta$-actin (forward 5'ATGGCTGGGGTGTTGAAGGT-3', reverse 5'6FAMTACAATGAGCTGCGTGTGGC-TAMRA-3', probe 5'CACCCTGTGCTGCTCACCGAGGC-3'). PCR amplifications were performed in a total volume of $25 \mu \mathrm{l}$, containing $1 \mu \mathrm{l}$ of cDNA sample (transcribed from $\sim 50 \mathrm{ng}$ total islet RNA), $900 \mu \mathrm{M}$ of each primer, $250 \mu \mathrm{M}$ of the corresponding probe, $2.0 \mu \mathrm{l}$ of GAUC mix (200 $\mu \mathrm{M}$ each of dATP, dCTP and dGTP, but $400 \mu \mathrm{M}$ of dUTP), $0.01 \mathrm{U} / \mu \mathrm{l}$ Uracil-DNA-N-glycosylase (UNG), $0.05 \mathrm{U} / \mu$ l of SureStart Taq DNA polymerase, $1 \times$ core PCR buffer, $5.5 \mathrm{mM} \mathrm{MgCl}_{2}$. For each reaction, UNG reaction was processed at $50^{\circ} \mathrm{C}$ for $2 \mathrm{~min}$ followed a polymerase activation step at $95^{\circ} \mathrm{C}$ for $10 \mathrm{~min}$, then amplification was executed by alternating between $95^{\circ} \mathrm{C}$ for $15 \mathrm{~s}$ and $60^{\circ} \mathrm{C}$ for $60 \mathrm{~s}$ for 40 cycles. The sample IB-1 and $\beta$-action mRNA levels were calculated respectively from standard curves of IB-1(0.01-800 ng total RNA) and $\beta$-actin(0.01-800 ng total RNA) using FVB control islets. Data were expressed as folds of IB-1 expression over $\beta$-actin expression.

Western blot: Fifty to one hundred freshly isolated islets from transgenic and control mice were lysed in 30 to $40 \mu \mathrm{l}$ ice-cold lysis buffer (containing $20 \mathrm{mM}$ Tris, $\mathrm{pH} 7.5$, $150 \mathrm{mM} \mathrm{NaCl}, 1 \mathrm{mM}$ EDTA, $1 \mathrm{mM}$ EGTA, $1 \%$ Triton X-100, $2.5 \mathrm{mM}$ sodium pyrophosphate, $1 \mathrm{mM} \beta$-glycerophosphate, $1 \mathrm{mM} \mathrm{Na}_{3} \mathrm{VO} 4,1 \mathrm{mM} \mathrm{DTT}, 1 \mu \mathrm{g} / \mathrm{ml}$ leupeptin, and $1 \mathrm{mM}$ PMSF). After determination of protein concentration by Pierce BCA kit, 5 to $10 \mu \mathrm{g}$ lysate proteins are separated by SDS-PAGE (discontinuous 20\% mini-gel, BioRad) for 2 hours at 120 volts. The separated proteins were transferred onto PVDF 
membrane (Amersham) for 1.5 to 2 hours at 30 volts. After transfer, the membrane was blocked in 5\% dry milk in TBS containing $0.1 \%$ Tween 20 for 1 hour. The membrane was then incubated with various mouse or rabbit antisera directed against phosphor-Akt (1:1000 dilution), Akt (1:1000 dilution), phosphor-Foxo1 (1:1000 dilution), Foxo1 (1:1000 dilution), PDX-1 (1:7000 dilution), cleaved-caspase 3(1:1000), total caspase 3 (1:1000) and $\beta$-actin (1:4000 dilution) overnight at $4^{\circ} \mathrm{C}$. Following extensive washing, membrane was further incubated with HRP labeled secondary anti-mouse or anti-rabbit antibody (1:2000 dilution) for 1 hour at room temperature. Immune complexes were identified using ECL plus kit (Amersham) and visualized by Molecular dynamics Storm system or film exposure.

Cell viability assay by Alamar Blue: The Alamar Blue assay, which incorporates a redox indicator that changes color and fluorescence in response to cell metabolic activity, is a commonly used method to assess cell viability and/or proliferation of mammalian cells (373) and micro-organisms (374). In our studies, 15 overnightcultured FVB control islets or transgenic islets were hand picked into $200 \mu$ fresh culture medium (no phenol red) containing 1:20 diluted Alamar Blue in a 96-well plate. Islets were cultured for $4 \mathrm{hr}$ and the Alamar Blue fluorescence was measured on a fluorescent microplate reader (Tecan, Durham, NC) at the excitation wavelength of 535 $\mathrm{nm}$ and the emission wavelength of $595 \mathrm{~nm}$. This measurement provided an absorbance value indicating the pretreatment metabolic activity and was used to normalize the posttreatment metabolic activity. After three washes with fresh culture medium, islets were cultured in $200 \mu \mathrm{l}$ culture medium containing various agents, including $\mathrm{H}_{2} \mathrm{O}_{2}$ and STZ, 
at various concentrations for varying time. In the end of treatment, fifty $\mu 1$ culture medium was replaced with $50 \mu \mathrm{l}$ fresh culture medium containing 1:5 diluted Alamar Blue, for a final dilution of 1:20. The color was developed for another $4 \mathrm{hr}$ and the fluorescence was measured again. A fluorescent value from the "blank well", which contained no islets but exactly followed the above procedure with highest level of ROS treatment, was deducted from all other fluorescent values. Islet cell viability was calculated as the ratio of fluorescence after treatment to the fluorescence before treatment. The untreated islet cell viability was arbitrarily set as $100 \%$.

\section{Islet cell viability after cytokine treatment or cytokine combined with different}

drugs. Islet cell viability was indicated by islet cell metabolic activity that was measured with Alamar Blue, as described above. In detail, fifteen overnight-cultured islets were hand picked into $200 \mu \mathrm{l}$ fresh culture medium (no phenol red) containing 1:20 diluted Alamar Blue in a 96-well microplate. A pre-treatment 4-hr metabolic activity of the islets was measured for normalizing the post-treatment islet metabolic activity. After three washes of fresh culture medium (no phenol red), islets were cultured for six days in $200 \mu \mathrm{l}$ culture medium (no phenol red) supplemented with or without varying concentrations of cytokines (mouse recombinant interleukin-1 $\beta$ plus interferon- $\gamma$ ). Every other day $100 \mu \mathrm{l}$ culture medium was replaced with $100 \mu \mathrm{l}$ fresh culture medium (no phenol red) containing cytokines, thereby no change of final cytokine levels. In the end of treatment, $50 \mu \mathrm{l}$ culture medium was replaced with $50 \mu \mathrm{l}$ fresh culture medium containing 1:5 diluted Alamar Blue, for a final dilution of 1:20. The color was developed for another $4 \mathrm{hr}$ and the fluorescence was measured again. A 
fluorescent value from the "blank well", which contained no islets but exactly followed the above procedure with highest level of cytokine treatment, was deducted from all other fluorescent values. Islet cell viability was calculated as the ratio of fluorescence after treatment to the fluorescence before treatment. The untreated islet cell viability was arbitrarily set as $100 \%$.

Measurement of ROS production after cytokines treatment: Control or transgenic islets were loaded with $5 \mu \mathrm{M} \mathrm{CM}-\mathrm{H}_{2} \mathrm{DCFDA}$ for $30 \mathrm{~min}$ followed by three washes of fresh culture medium. These loaded DCF islets were exposured to cytokines (mouse recombinant interleukin- $1 \beta$ plus interferon- $\gamma$ ) for $16 \mathrm{hrs}$. The fluorescence of each islet was activated at an excitation wavelength of $485 \mathrm{~nm}$ and recorded at an emission wavelength of $530 \mathrm{~nm}$. ROS was monitored from randomly sampled individual islets using a fluorescence microscope equipped with a digital camera. Images were analyzed with ImagePro software (Media Cybernetics, Silver Spring, MD). More than 100 islets from at least three separate islet isolations were studied for each group. The results were expressed as the mean fluorescence intensity.

Data analysis: Data are presented as the mean \pm standard error. Statistical analysis was performed by one-way or two-way ANOVA and Dunnet's post hoc (2-tailed) test.

Computations were carried using statistical programs from SPSS (version 10.0) and Sigmastat (version 2.03). The cumulative incidence of diabetes was calculated for each group and the significant difference was tested by Kaplan-Meier survival test using 
SPSS program (version 10.0). Two-way ANOVA and Dunnet's post hoc (2-tailed) test were used to test the difference between transgenic and control NOD mice before and after CYP treatment. 


\section{RESULTS}

Production of transgenic NOD mice congenic for MT, catalase, or MnSOD transgene:

In our lab, we already generated MT, catalase and MnSOD transgenic FVB mice. Therefore using speed congenic method (Fig. 2-1), MT, catalase or MnSOD transgenic FVB mice were backcrossed to NOD mice at least five times. Starting from the third generation, transgene positive offspring were selected for PCR genotyping of 19 diabetic susceptible alleles. These new congenic mice which were found homozygous for all 19 diabetic susceptible alleles (Fig. 2-2) were used as founders to breed with NOD mice one more time. The offspring were inter-crossed to maintain the line and produce transgenic and nontransgenic littermates used in this study.

In order to rule out the possibility of ectopically expressing these transgenes in tissues other than islets, western blotting for islets, brain, heart, lung, muscle, liver, intestine, kidney, bone marrow, thymus and spleen from control and transgenic NOD mice was performed. The results (Fig. 2-3) demonstrate that high levels of transgenic catalase transgenes are specifically expressed in transgenic islets. Although catalase was also expressed in other tissues such as lung, liver, intestine, kidney, thymus and spleen, the levels of expression in transgenic mice were indistinguishable from control mice. Moreover, the size of transgenic catalase was different from the endogenous catalase. 
Immunohistochemical staining of catalase, MT and MnSOD shown in Fig. 2-4 further demonstrates that these transgenes were specifically overexpressed in pancreatic beta cells. In addition, immunoreaction for MnSOD by confocal laser scanning (E, inset) is granular, indicating typical mitochondrion-like staining pattern. In contrast, immunoreactions for catalase (E2, inset) and MT (E1, inset) were evenly distributed in the cytoplasm, indicating unlike MnSOD, they were mainly overexpressed in cytoplasm. In addition, both transgenic and control NOD mice had similar insulin staining.

To determine whether the antioxidant transgenes enhanced pancreatic beta cell ROS scavenging ability in the NOD background, transgenic MTNOD and control NOD mice were injected with STZ (180 mg/kg body weight), which is well known to destroy pancreatic beta cells through ROS production, which induces experimental diabetes. After STZ treatment, the blood level of both transgenic and control NOD mice were monitored every day. Data in Fig. 2-5 demonstrated that MT could significantly delay STZ induced diabetes onset, suggesting MT would have the same antioxidant protective effect against toxins on the NOD background as it did on the FVB background (375).

The evaluation of islet function and structure in transgenic NOD mice: Since several transgenes have produced unintended beta cell dysfunction, we also characterized these transgenic islets with respect to pancreatic islet morphology and insulin content, isolated islet insulin content, DNA content, protein content and glucose stimulated insulin secretion. The data showed that both transgenic and nontransgenic NOD mice at less than 42 days of age contained similar pancreatic insulin content and 
also had similar insulin content, DNA levels and protein levels in isolated islets (Table 2-1). In addition, these transgenic islets have similar glutathione peroxidase activity as control NOD islets (Fig. 2-6).

Insulitis is a special morphological characteristic of NOD mice. Figure 7 showed that our transgenic NOD mice also generated the same extent of insulitis as control NOD mice. In addition both transgenic and control NOD mice had similar insulin staining (Fig. 2-7). These results demonstrated the MT, or catalase overexpression was not harmful to the beta cell.

The acceleration of NOD diabetes onset by cytoplasmic antioxidants MT or catalase but not mitochondrial MnSOD:

Using these MTNOD, CatNOD and SODNOD mice we tested the potential effect of beta cell antioxidant transgenes on NOD diabetes. Transgenic NOD and control NOD mice were injected with CYP twice at a dose of $200 \mathrm{mg} / \mathrm{kg}$. After the first injection diabetes onset and incidence were determined by the occurrence of hyperglycemia. To our great surprise, the MT and catalase transgenes remarkably speeded up NOD diabetes (Fig. 2-8), instead of delaying the onset of diabetes as we had hypothesized. However in SODNOD mice, diabetes developed at a similar time as in control NOD mice after injection of CYP. This accelerated diabetes onset was confirmed by measurement of pancreatic insulin levels in transgenic MT and control NOD mice before and after CYP injection. 
As shown in Fig. 2-9, the pancreatic insulin content in MTNOD and control NOD mice was similar before CYP injection. However, 8 days after CYP injection the pancreatic insulin level in MTNOD and CatNOD mice was only $50 \%$ of their original value before CYP injection; whereas the control NOD mice preserved almost $80 \%$ of their original insulin. This suggested that more beta cells were destroyed in MTNOD mice than in NOD mice after CYP injection.

This result was unexpected, and completely opposite to our original hypothesis that ROS scavengers would be helpful to prevent type 1 diabetes. Therefore, we measured spontaneous diabetes onset in both transgenic and nontransgenic NOD mice. The data (Fig. 2-10) showed that all male MTNOD and CatNOD mice developed diabetes more quickly than control male NOD mice $(p<0.05$, by Kaplan-Meier survival analysis and Mantel-Cox Log-rank test), which indicated that overexpression of cytoplasmic antioxidants MT and catalase accelerated NOD spontaneous diabetes onset.

\section{MT and catalase overexpression accelerates beta cell apoptosis after CYP injection:}

To determine what kind of cell death MTNOD and CatNOD islets undergo, immunohistochemistry was performed to measure cleaved caspase-3 staining in pancreatic islets from both transgenic and control NOD mice before and after CYP injection. As shown in Fig. 2-11, six days after CYP injection, both MTNOD islets contain higher cleaved caspase- 3 staining than control islets, which demonstrated that MTNOD and CatNOD islets undergo apoptosis more quickly than control NOD islets after CYP injection. 
Analysis of IB-1 expression as shown in Fig. 2-13, another important anti-apoptic protein in islets (376-378), revealed that IB-1 mRNA expression by RT-PCR was significantly reduced to $50 \%$ of original level in MTNOD and CatNOD islets after CYP injection. In addition, insulitis score (Fig2-13 ) either before or after CYP injection was similar in both transgenic and control NOD mice except that the percentage of atrophic islets was higher in transgenic mice (about $30 \%$ ) than in control NOD mice ( $10 \%)$.

\section{In vitro susceptibility of MT and catalase islets to cytokine toxicity:}

It is well established that inflammatory cytokines suppress pancreatic beta cell insulin secretion and lead to cell death through apoptosis and necrosis $(379 ; 380)$. In this study, both cell viability by Alamar Blue and cleaved caspase- 3 expression by western blot were assessed in cultured control NOD and transgenic islets after exposure to cytokines. After 24 hrs cytokine treatment, MT decreased islet cell viability dose dependendently (Fig. 2-14) and catalase also was found to inhibit islet survival at $0.5 \mathrm{X}$ concentration of cytokines (Fig. 2-15 ) . Cleaved caspase-3 expression in MT islets (Fig. 2-16) was higher than control islets at both 12 and 24 hrs after cytokine treatment, in spite of the fact that both catalase and MT could dramatically decrease cytokine induced ROS production (Fig 2-24). Furthermore, IB-1 expression was also decreased in both MT and CatNOD islets treated with cytokines for $48 \mathrm{hrs}$ ( Fig. 2-17).These data suggest that MT and catalase sensitize islet to cytokine toxicity.

Reduction in activity of the PI3K/Akt pathway in MTNOD and CatNOD islets after CYP injection: The above results demonstrated that overexpression of 
cytoplasmic antioxidants accelerated NOD type 1 diabetes onset, instead of protecting from diabetes onset. Since these results were obtained with two independent antioxidants: catalase and MT, we hypothesized that a low level of ROS was essential for maintaining or stimulating some beta cell survival pathway during diabetes stress and overexpression of antioxidant could suppress these protective pathways by scavenging ROS. To test this hypothesis, we measured the activity of PI3K/Akt pathway, one of the important protective pathways in beta cell. After 4 or 7 days beyond CYP injection, p-Akt and PDX-1 expression were significantly decreased in MTNOD and CatNOD islets compared with control NOD islets (Fig. 2-18, 2-20 and 221). Since PDX-1 expression is inhibited by transcription factor Foxol, corepressor of PDX-1, Foxol could be phosphorylated by p-Akt and retained in the cytoplasm (by nuclear exclusion) which would finally increase PDX-1 expression. Therefore we also measured p-Foxol expression. Results (Fig. 2-19) show decreased p-Foxol expression in MTNOD islets but not in control NOD islets after CYP injection. These results suggest that catalase and MT overexpression reduced PI3K/Akt pathway activity after CYP injection.

In vitro susceptibility effect of MT and catalase on islets to cytokine toxicity is due to lower PI3K/Akt activity: Data from Fig. 2-22 suggested that overexpression of catalase and MT sensitized islet to cytokine toxicity and the PI3K inhibitor wortmannin could normalize NOD islet cell death to similar level as seen in MTNOD islets. Consistent with in vivo results p-Akt, p-Foxol and PDX-1 expression ( Fig. 2-23) were significantly decreased in MTNOD islets after $6 \mathrm{hrs}$ cytokines treatment. So, the in vitro 
susceptibility effect of MT and catalase to cytokine toxicity also might be due to lower $\mathrm{PI} 3 \mathrm{~K} /$ Akt activity.

\section{Lower ROS may produce higher PTP activity in MTNOD islets after cytokine treatment:}

The activation of protein tyrosine phosphatase has been found to be reversibly inhibited by ROS in several protein tyrosine kinase pathways (381-383). Firstly, we measured the ROS production induced by cytokines in transgenic and control islet using the DCF method. As shown in Fig. 2-24 both MT and catalase significantly reduced ROS production after 16 hrs cytokine treatment. Fig. 2-25 had shown that the PTP inhibitor, vanadate, could reverse the sensitization effect of MT to cytokine toxicity, which suggested that elevated cytosolic antioxidants may result in higher PTP activity in beta cells by protecting PTPs from ROS, thereby causing decreased beta-cell activity of the PI3K/Akt survival pathway. 


\section{DISCUSSION}

In present study, overexpression of cytoplasmic antioxidants sensitize to both CYP induced and spontaneous type 1 diabetes. Caspase- 3 expression showed that the rapid induction of diabetes was due to greatly increased level of apoptosis in transgenic NOD islets. This increased susceptibility is unlikely to be due to the direct damaging effect of the transgenes since the transgenic NOD mice at young age had similar pancreatic insulin level, beta cell function and structure as control NOD mice. Moreover, these antioxidant transgenes make the beta cell more resistant to STZ toxicity. Other potential artifacts that could explain this result also have been ruled out: In vitro studies showed that MT did not sensitize islets to CYP toxicity, in fact, it provided significant protection (data not shown), which indicates that our results were not due to direct sensitization of beta cells to CYP toxicity by antioxidant transgenes. Western blot data from Fig 3 also rules out the possibility that ectopic overexpression of antioxidant transgenes in other tissues, might alter the immune response in transgenic NOD mice. Likewise, increasing susceptibility in transgenic NOD mice cannot be attributed to other antioxidants compensatory changes caused by MT or catalase overexpression, because we found no difference in activity of glutathione peroxidase between transgenic and control NOD mice (Fig 6 ). Finally, this sensitization effect occurs on two different transgenic antioxidant mice, which rules out the possible damaging effect due to transgene insertion to genomic DNA. Therefore, our current data suggest overexpression of cytoplasmic antioxidant proteins in pancreatic beta cells increases susceptibility to NOD mice. 
This finding runs complete contrary to what has been proposed for oxidative stress and type 1 diabetes. It is generally believed that oxidative stress contributes to autoimmune mediated demise of beta cells $(384 ; 385)$, however, there is very limited data for this proposal which specifically targets the beta cell. For in vivo studies, systemic treatment with antioxidants is most often performed. However, the major ambiguity in those in vivo studies is the site of protection, since the protection of delaying diabetes onset with systemic antioxidant treatment could be produced at the immune system rather than directly at pancreatic beta cells(386). The studies where antioxidant treatment has been directly targeted to beta cells are not only limited but the results are also controversial. Adenoviral expression of MnSOD was partially effective against cytokines in isolated primary islets(387). However, beta cell specific overexpression of the secreted form of SOD had no effect on NOD diabetes(388). Thioredoxin overexpression in beta cell delays NOD diabetes onset(389), but thioredoxin has an additional very potent antiapoptotic effect, which may contribute to this significant benefit. Therefore, it is still not clear what roles ROS play in type 1 diabetes. In vitro most of beta cell tumor lines studies provide pretty consistent results that antioxidants provide protection from ROS and cytokine induced toxicity(390-394). But the relevance of these antioxidant protective results from beta cell tumor lines is still uncertain due to the difference in cell survival between primary beta cells and tumor cell lines. It has been noted that tumor cell lines have either abnormal amplification and overexpression of survival signal such as constitutive Akt activation or survival pathways which often can not be controlled by normal regulation(395-397). 
Furthermore, it has been shown that treatment of isolated islets with antioxidants does not always reduce cytokine toxicity $(398 ; 399)$. The explanation for the difference between our data and data from in vitro beta cell tumor lines could be that ROS have dual functions in the pancreatic beta cell during immune attack, one is ROS acting as signal involving survival pathway regulation, and the other is a damage effect. In primary beta cells, it might be very important for delaying beta cell destruction that ROS act as protective signal activating beta cell protective response. However, in beta cell tumor lines, the ability of their survival is already highly amplified, which make the role of ROS as survival signal much less important. In beta cell tumor lines, overexpression of antioxidants mainly provides protection from ROS damage effect. Our result that cytoplasmic antioxidants overexpression in the beta cell accelerated NOD type 1 diabetes implies that cytoplasmic ROS have an important role in maintaining beta cell survival in the presence of immune attack.

It is not new that ROS act as signal molecular, and our results also are not without precedents in other cell types. For example, the proapoptotic effects of antioxidants such as catalase have been reported (400). Low dosage of ROS such as NO, has antiapoptotic effects on several cell systems(401-403). Recently low dosage NO has been found to provide protection from apoptosis in pancreatic beta cells through activating the PI3K/Akt survival pathway(404;405).

Although ROS are involved in regulating many signaling pathways, the signaling molecules targeted by ROS have remained largely unexplored. Lots of evidence 
suggests that ROS regulation could occur at multiple levels in the signaling pathways from receptor to nucleus. However, recently protein tyrosine phosphatase has received more attention as an ROS targeted signaling molecule. ROS can reversibly inactivate PTPs by the direct oxidation of cysteine in the active site of these enzymes (406). It has been reported $\mathrm{H} 2 \mathrm{O} 2$ treatment could inhibit PTPs in vitro (407) as well as in several cell lines (408-410). Antioxidants such as N-acetylcysteine (NAC) inhibits H2O2induced phosphatase inactivation in glia cell lysate(201). Our cell viability result that the PTP inhibitor, vanadate, could rescue MTNOD islet from cytokine toxicity indicates that the antioxidant transgenic islets might have higher PTP activity due to low ROS compared with control NOD islets.

It is well known that fully active PTPs can efficiently remove phosphate from tyrosine residues and destroy binding sites for other signaling molecules such as PI3K. Therefore, inhibition of PTP by ROS could enhance tyrosine receptor induced downstream cellular signaling. Among these tyrosine receptor induced cellular signaling pathways, the Irs-2 branch of insulin/IGF signaling has recently been found to play a key role in beta cell survival and function $(287 ; 288)$. In mice, both Irs-1 knock out and Irs- 2 knock out are markedly insulin resistant, however, only Irs-2 knock out mice fail to sustain compensatory insulin secretion due to decreased beta cell mass compared with wild-type and Irs-1 knock out mice, and they eventually developed diabetes. However, the diabetes due to Irs- 2 knock out could be reversed by crossing with PTP1B knock out mice(296), indicating PTP might be a critical regulator in IRS-2 branch of insulin/IGF signaling. 
The IRS-2 branch of insulin/IGF signaling promotes cell survival at least in part by activating the PI3K and its downstream target Akt. It has been shown that Akt activity is both necessary and critical for beta cell survival. Loss of Akt2 produces insulin resistance and pancreatic beta cell failure and loss, which finally results in severe diabetes(290). Increased expression of Akt1 in pancreatic islets protects from STZ induced diabetes and against free fatty acid induced beta cell apoptosis(291;292). Activation of Akt by IGF protects islets from cytokine toxicity $(293 ; 294 ; 322)$ and improves human islet graft survival in diabetic NOD-SCID mice. Our in vivo CYP injection and in vitro cytokine treatment studies have shown that activation of the PI3K/Akt pathway in antioxidant transgenic NOD islets was reduced, consequently phosphorylation of its downstream transcription factor FOXO-1 also decreased and expression of PDX-1 was largely inhibited. Consistent with our results, recently Lei's group found that overexpression of glutathione peroxidase induced development of insulin resistance and obesity via reducing insulin-stimulated phosphorylation of the insulin receptor and Akt(323). These data imply that normal intracellular ROS is necessary for maintaining insulin/IGF mediated PI3K/Akt pathway activation and our elevated cytosolic antioxidants may result in higher PTP activity in beta cells by protecting PTPs from ROS, thereby causing decreased beta cell survival.

In our results, MnSOD overexpression, unlike catalase and MT, did not accelerate NOD diabetes onset. It is known that MnSOD is different from MT and catalase with respect to localization and which ROS species they inactivate. MT is present primarily in the 
cytoplasm. Catalase normally is found in peroxisomes, however when overexpressed in transgenic animals a large amount of catalase is also present in cytoplasm (324). Catalase specifically inactivates $\mathrm{H} 2 \mathrm{O} 2$. MT scavenges $\mathrm{H} 2 \mathrm{O} 2$ and many other $\mathrm{ROS}(279)$. In contrast, MnSOD is expressed in the mitochondria ( Fig 4) and inactivates superoxide and produces $\mathrm{H} 2 \mathrm{O} 2$. It has been shown that cytokines could produce ROS through mitochondria or cytoplasm (325). It is interesting and important to determine whether the different ability to accelerate diabetes is due to localization of the antioxidant or the species of ROS that is inactivated. To answer this question, our lab plan to overexpress another antioxidant, SOD1, which is cytoplasmic and only inactivates superoxide like MnSOD.

Overall, our results provide in vivo evidence that ROS play an important role in beta cell survival in type 1 diabetes, arguing against the current notion of the beneficial effects of antioxidant enzymes on type 1 diabetes. This concept should be reconsidered or modified to avoiding diminishing cytoplasm ROS in beta cell to the point where survival is impaired. 


\section{LIMITATION FOR THIS STUDY}

Some limitations in this study need to be pointed out. The major limitation to our results is that many the mice maintained in the animal facilities of the University of Louisville by our lab currently are infected with mouse Parvovirus (MPV), which is one of the most prevalent infectious pathogens in research institutions (326). MPV often replicates in mitotically active tissues, such as gastrointestinal tract, lymphocytes, and tumors. MPV has high resistance to temperature and harsh environmental conditions. In vivo, MPV can remain infectious for a very long time after initial exposure, even in adult mice (327). In general, MPV infection causes no clinical symptoms or diseases in infected infant or adult mice, whether they are immunocompetent or severely immunocomprised (SCID mice) (328). But MPV infections can alter immune function. $\mathrm{CD}^{+}$and $\mathrm{CD} 4^{+}$cell function may be inhibited $(329 ; 330)$. Lymphocytes from the spleen and popliteal lymph nodes showed inhibited function in one study (331). Therefore in NOD mice MPV contamination theoretically could delay diabetes onset instead of accelerating it. Although the rate of spontaneous diabetes onset in our NOD mice is similar to what has been reported, we cannot be certain what impact MPV infection has on transgenic NOD mice. Our results need to be replicated in mice free of MPV infection that are housed in pathogen-free facilities.

Also our conclusion that insulin/IGF/Akt pathway played an important role in antioxidant transgene sensitizing beta cell damage may not be complete. Other mechanisms discussed in the introduction such as the MAPK pathway and the transcription factor NFkappa B may be involved in our results. 


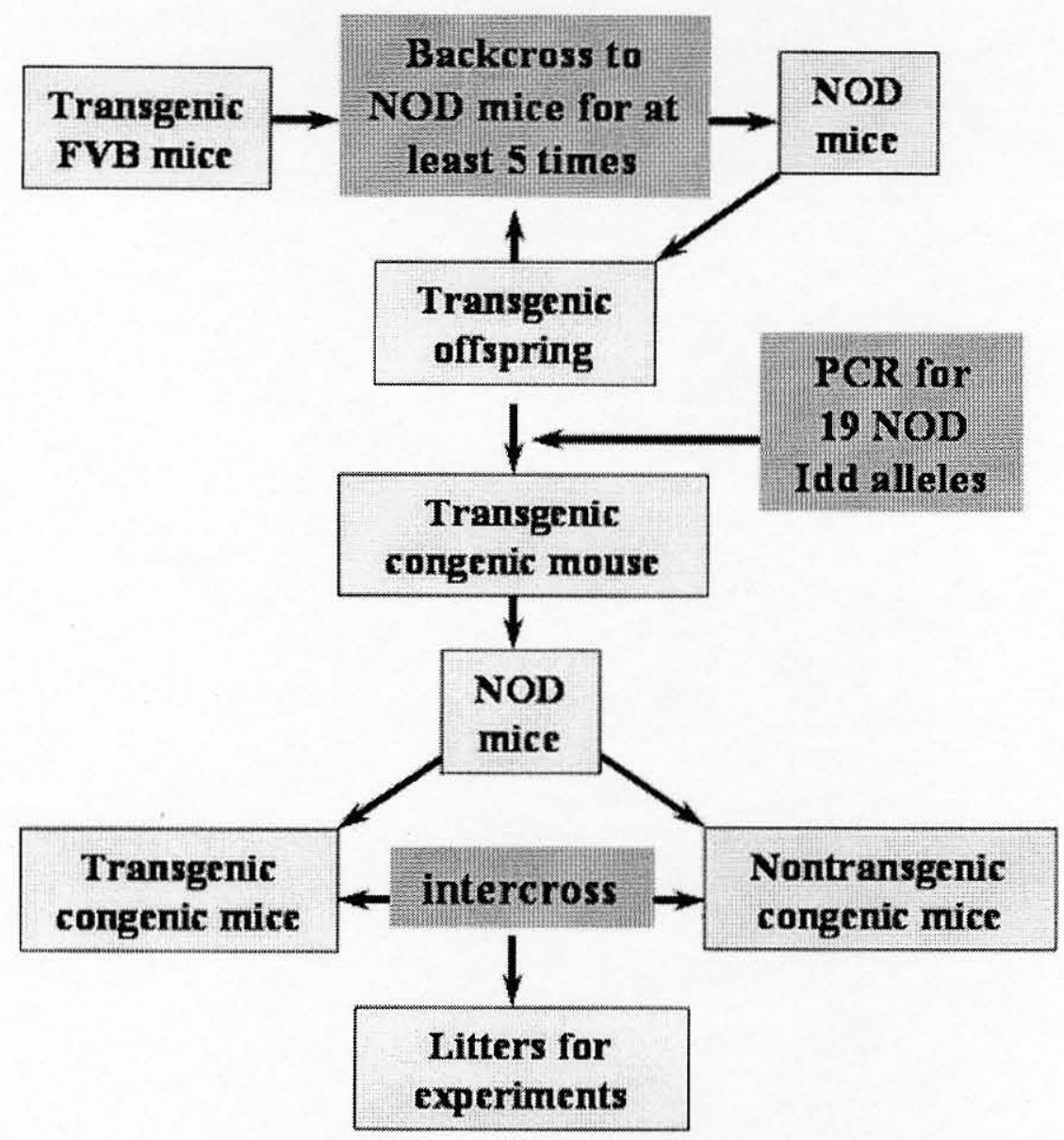

Fig 2-1. The breeding program for generation of consgenic NOD mice with beta cell antioxidant overexpression. 3 lines congenic NOD mice, designated as MTNOD, CatNOD and MnSODNOD, were produced with elevated beta cell specific expression of metallothionein, catalase and MnSOD protein. 


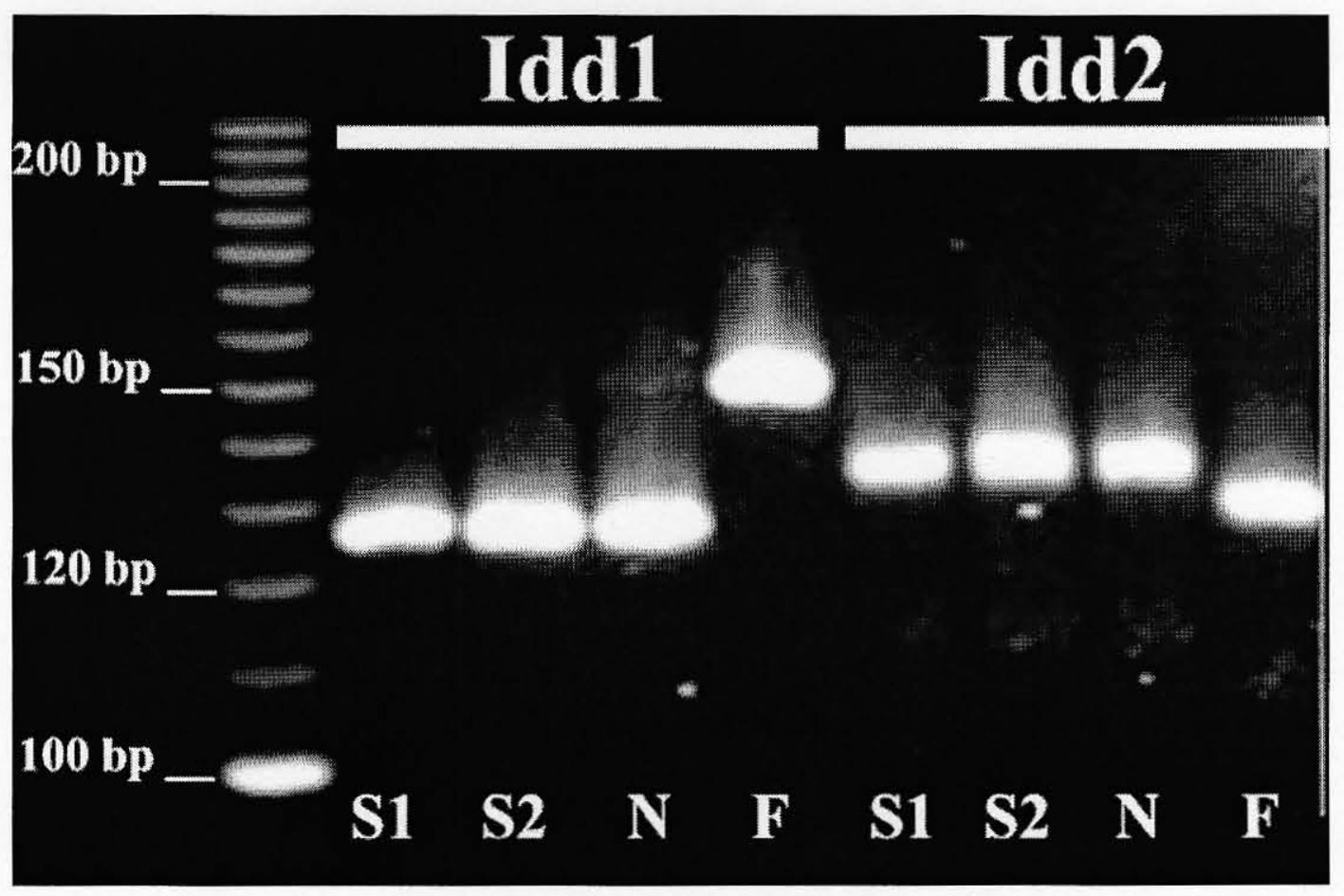

Fig 2-2. PCR-based genotyping of diabetic suseptible alleles in congenic NOD mice with beta cell specific expression of MnSOD transgene. Homozygosity of 19 NOD diabetes loci (IDD) in the congenic NOD mice was determined by PCR using polymorphic microsatellite markers linked with these Idds. This figure is a representative gel graph showing 19 Idd in two MnSOD congenic progenitors (S1, S2), inbred NOD $(\mathrm{N})$, and FVB $(\mathrm{F})$ mice. 
(atNol)

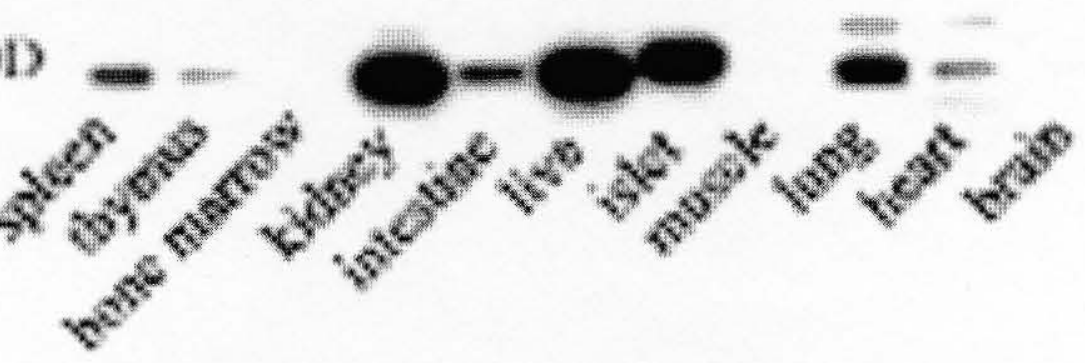

Fig 2-3. Catalase transgenes overexpressed in pancreatic islet. Isolated islets, spleen, thymus, bone marrow, kidney, intestine, liver, islet, muscle, lung, heart and brain from both transgenic and control NOD mice were lysed for western blot analysis. Representative blots showing catalase expression. 

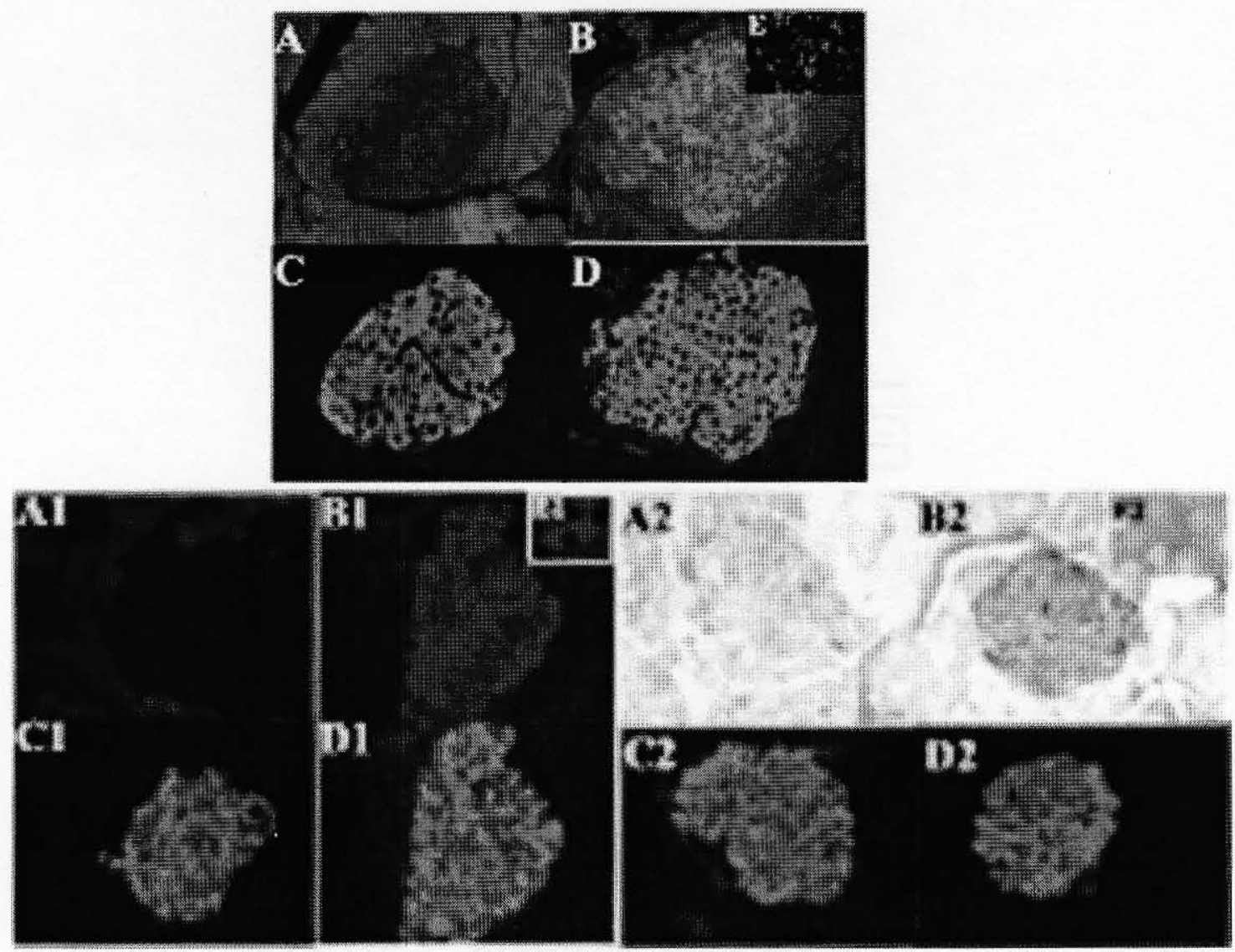

Fig 2-4. Immunostaining for MT, Catalase and MnSOD in transgenic and control NOD mice. Pancreaatic sections from both transgenic and control NOD were stained with anti-MnSOD (A, B, green), anti-MT (A1,B1, red) and anti-catalase (A2, B2, brown) primary antibody. Immunostaining for MnSOD (green staining) in control (A) and MnSOD transgenic islets (B, inset E) shows MnSOD overexpression that is granular consistent with mitochondrial localization (Inset E). Similar results were obtained for MT (A1, B1) and Catalase (A2, B2), except that MT and catalase showed cytoplasmic staining. MnSOD, MT and Catalase specifically expressed in transgenic islets(B,B1,B2), whereas almost no or very weak expression in control NOD islets(A, $\mathrm{A} 1, \mathrm{~A} 2)$. Insulin staining was similar in control $\mathrm{NOD}(\mathrm{C}, \mathrm{C} 1, \mathrm{C} 2)$ and transgenic islets(D,D1,D2). 


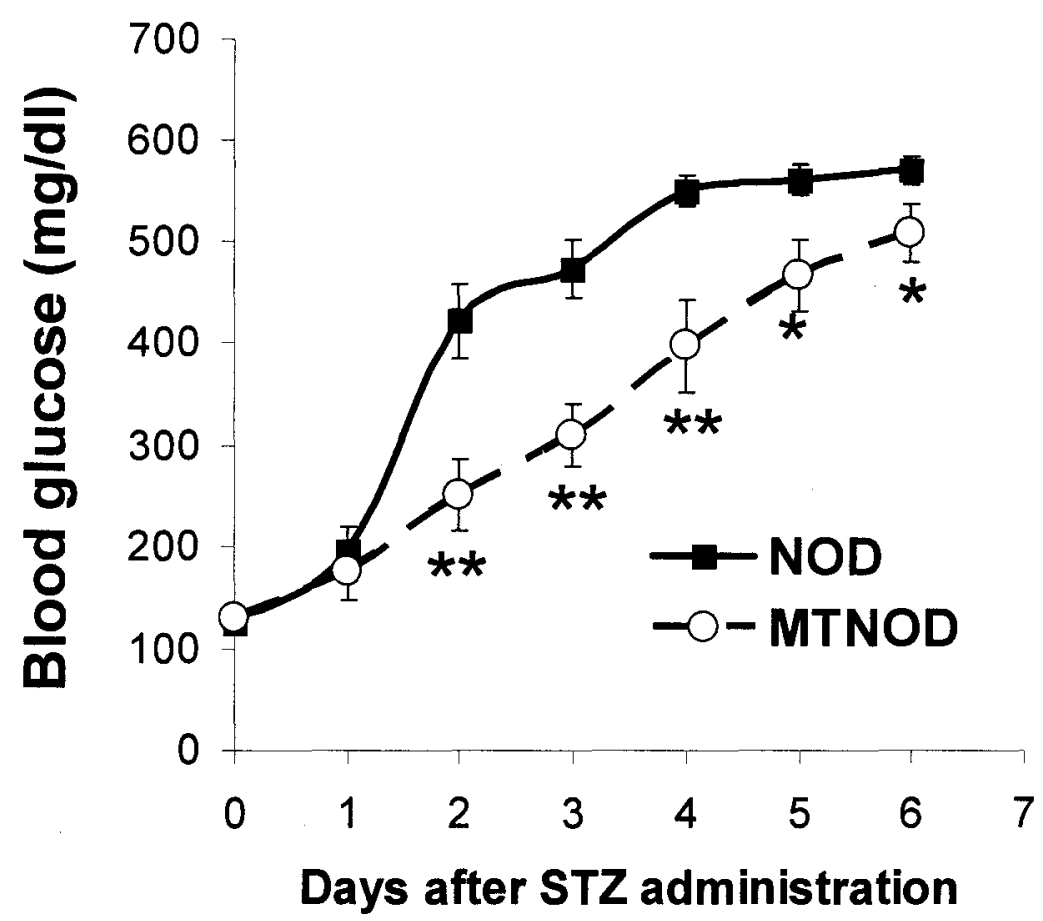

Fig 2-5. MT overexpression reduced STZ induced diabetes on NOD background. Sex and age matched MTNOD and NOD mice $(n=10)$ received a single dose $(180 \mathrm{mg} / \mathrm{kg}$ body weight) of STZ via ip injection. Blood glucose levels were monitored daily for 6 days following the injection. Data shown are the mean value $\pm \mathrm{SE}$ from 10 animals in each group. ${ }^{*}$ indicates $\mathrm{p}<0.05$, by two-way ANOVA. Vertical bars show the standard error of the mean. 


\begin{tabular}{|llll|}
\hline & $\begin{array}{l}\text { Islet DNA } \\
\text { (ng per islet) }\end{array}$ & $\begin{array}{l}\text { Islet insulin } \\
\text { (ng per islet) }\end{array}$ & $\begin{array}{l}\text { Pancreas insulin } \\
\text { (mU per gram wet tissue) }\end{array}$ \\
\hline NOD & $\mathbf{1 7 . 9 9} \pm 1.65$ & $112.08 \pm 18.30$ & $1609 \pm 176$ \\
MTNOD & $17.17 \pm 1.96$ & $108.08 \pm 35.93$ & $1458 \pm 178$ \\
CatNOD & $15.54 \pm 1.28$ & $139.48 \pm 9.07$ & $1632 \pm 332$ \\
\hline
\end{tabular}

Table 2-1. No alteration of isolated islet insulin content, DNA content and protein content in transgenic mice at age of 30 days. Data are the means \pm SE. No significant differences were found among groups. 


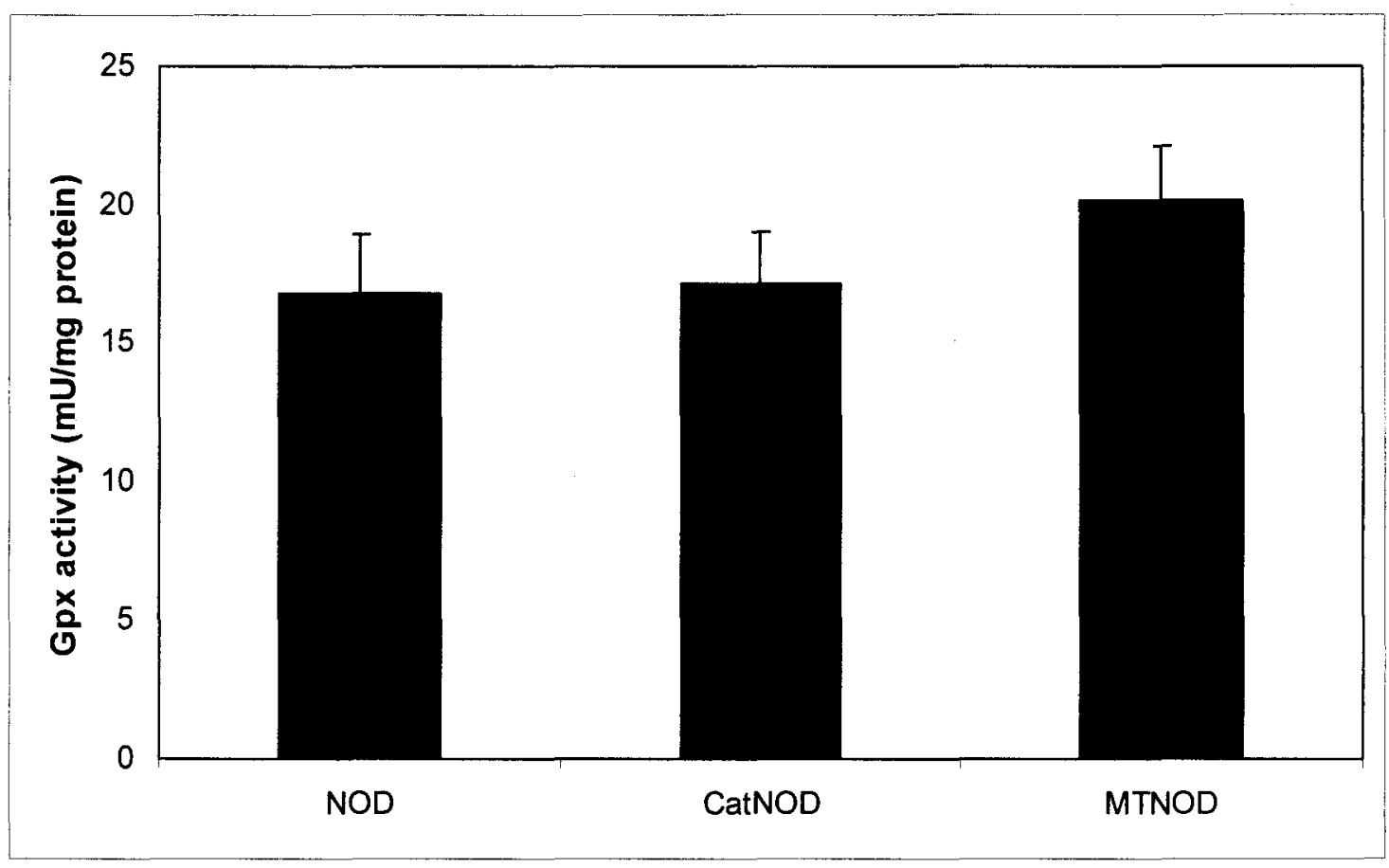

Fig 2-6. No alteration of Glutathione peroxidase activity in transgenic islets. Glutathione peroxidase activity assay was performed on isolated islets from total 9 transgenic and control NOD mice at age of 40 days. Activity expressed as equivalent milliunits of purified bovine erythrocyte glutathione peroxidase per milligram protein. Vertical bars indicate the standard error. 


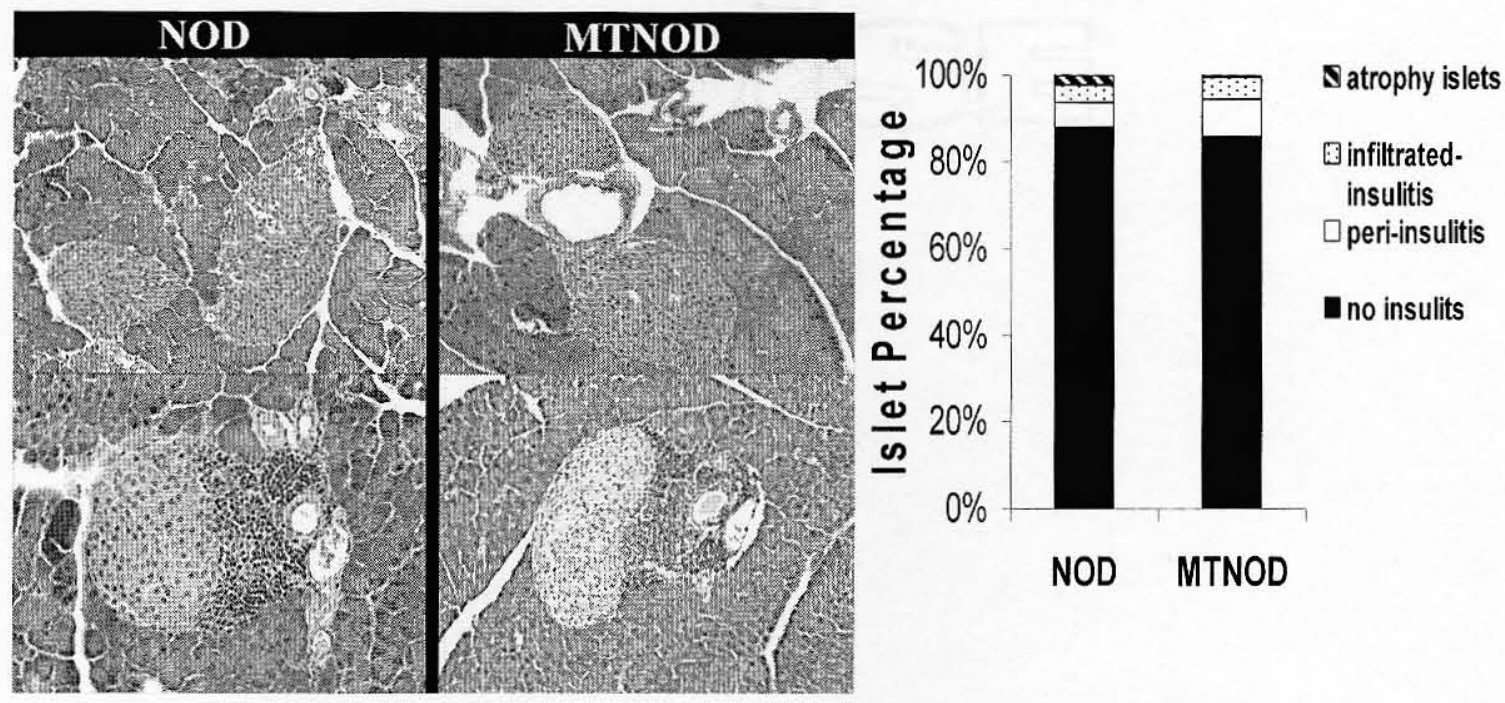

Fig 2-7. Insulitis and pancreatic insulin level in transgenic and control NOD mice.

(A) Insulitis in NOD and MTNOD congenic mice at the age of 7-9 weeks. Sections were stained with hematoxylin and eosin. Islet insulitis, the infiltration of lymphocytes, was only seen in a small portion of pancreatic islets in both NOD and MTNOD mice. Magnification X 200. (B) insulitis scores. The MTNOD mice developed similar severity of insulitis as control NOD mice did at the age of 7-9 weeks. 

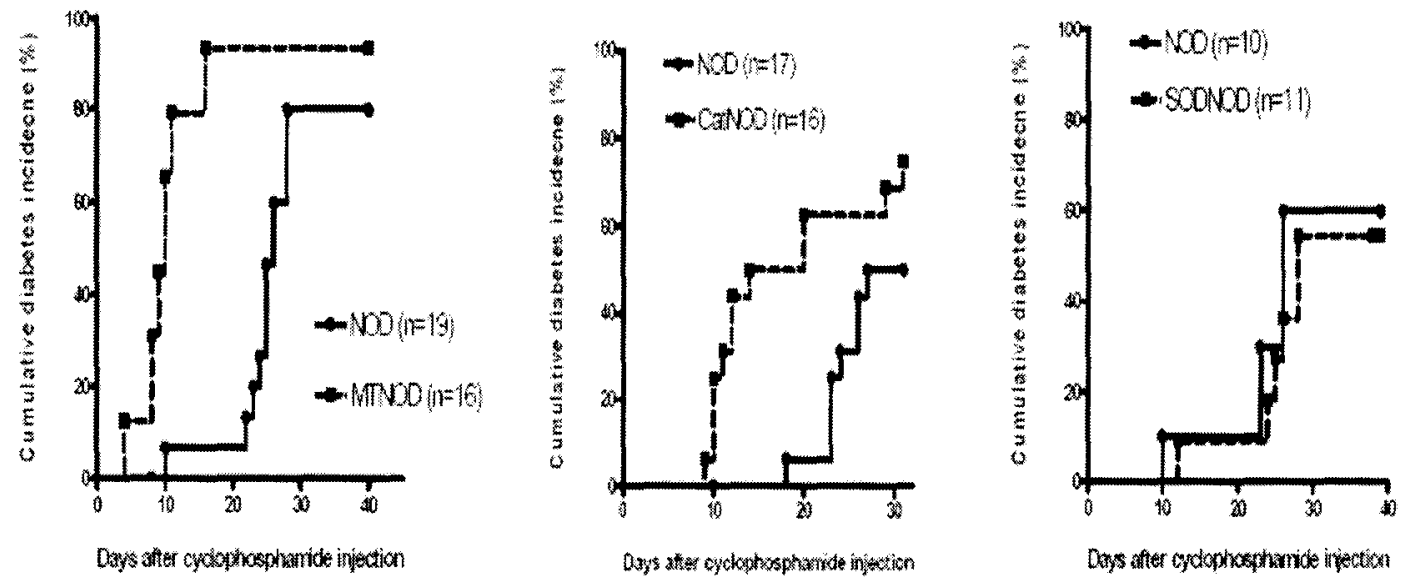

Fig 2-8. Cumulative diabetes incidence in control NOD, transgenic MTNOD, CatNOD and MnSODNOD mice after CYP administration. Age and sex-matched transgenic or nontransgenic NOD mice (age $=6-9$ weeks) were injected with CYP ( $200 \mathrm{mg} / \mathrm{kg}$ body weight via ip.) at days 0 and 14 . Tail blood glucose was monitored every other day. Onset of diabetes was defined as two consecutive measurements of nonfasting blood glucose levels $>200 \mathrm{mg} / \mathrm{dl}$. Kaplan-Meier survival analysis and Mantel-Cox Log-rank test revealed that MT and catalase significantly hastened NOD diabetes onset $(\mathrm{P}<0.01)$, but MnSOD had no effect on NOD diabetes $(\mathrm{P}>0.05)$. Each transgenic line was compared to simultaneously injected group of matched NOD mice. It is notable that isolated MT transgenic islets were more resistant to CYP treatment than nontransgenic islets (not show). 


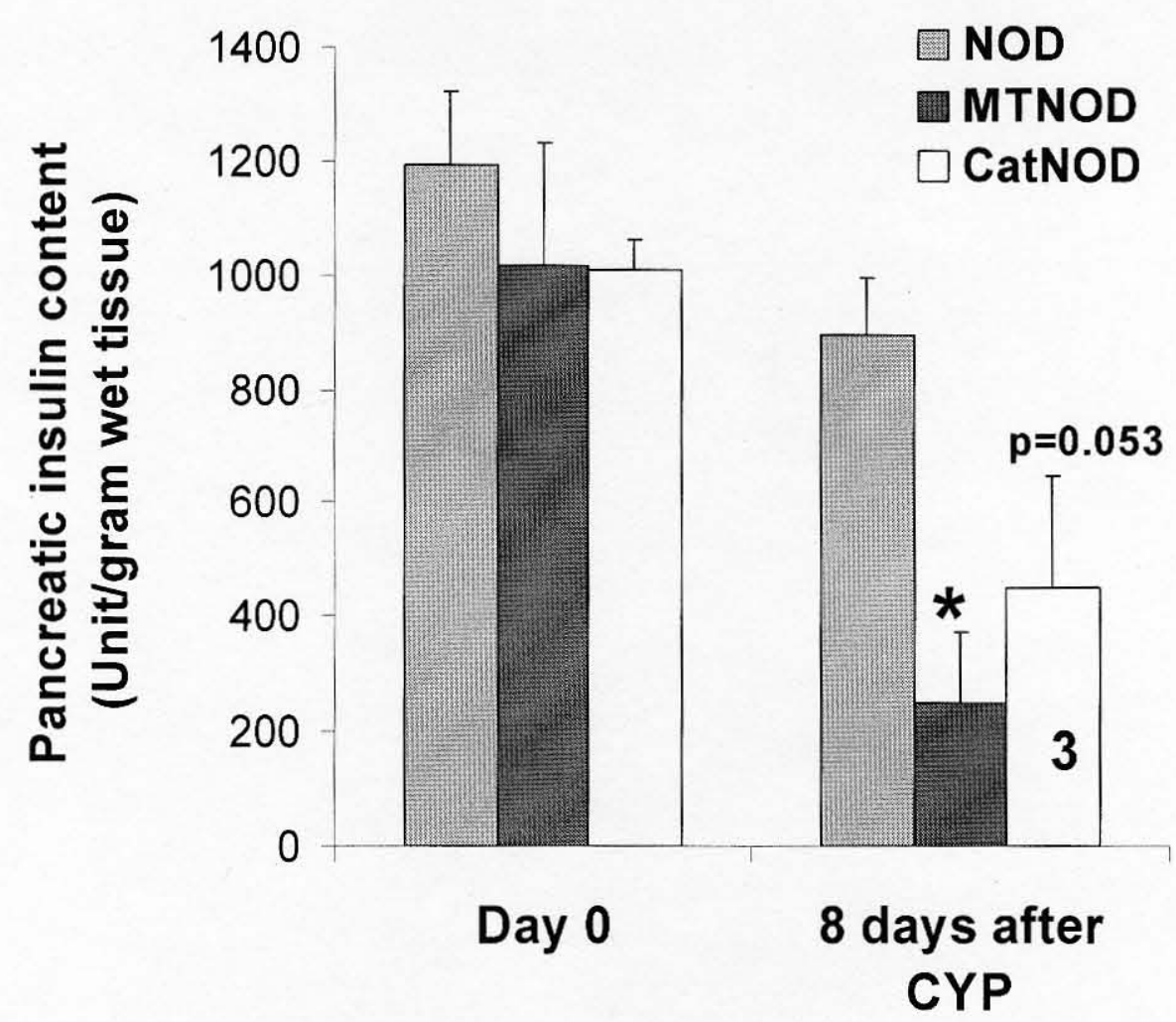

Fig 2-9. Preserved pancreatic insulin levels after CYP injection. Pancreatic insulin levels were measured in both MT transgenic and nontransgenic NOD mice before and different indicated days after CYP injection. Results are expressed as mean $\pm \mathrm{SE}$, taken from at least 4 mice in each group. ${ }^{*} \mathrm{P}<0.05$ in NOD $v$ MTNOD 8 days after CYP injection by one-way ANOVA. 

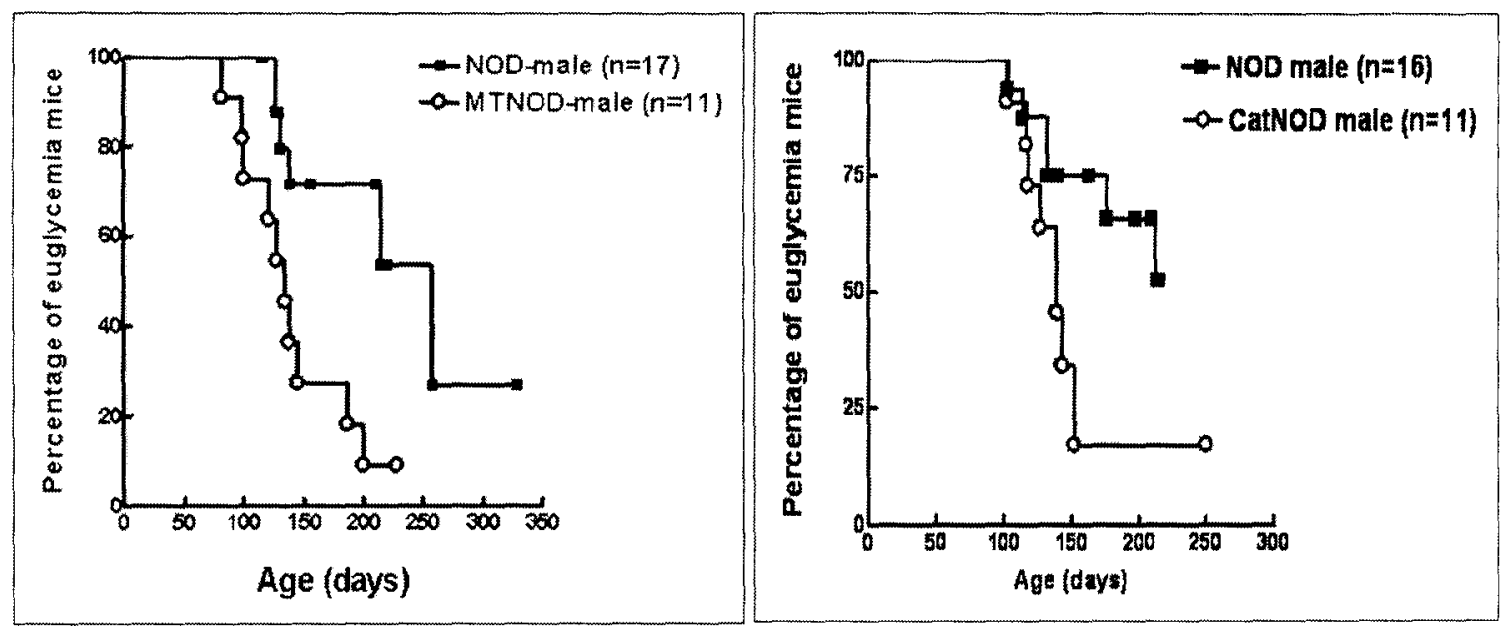

Fig 2-10. Accelerated spontaneous diabetes onset in MTNOD and CatNOD male

mice. Non-fasting blood glucose was monitored every other week in transgenic and control NOD mice. Onset of diabetes was defined when the first of two consecutive measurement of non-fasting blood glucose level $>200 \mathrm{mg} / \mathrm{dl}$ was reached. KaplanMeier survival analysis and Mantel-Cox Log-rank test revealed that either MT or catalase significantly hastened NOD diabetes onset $(\mathrm{P}<0.01)$. 


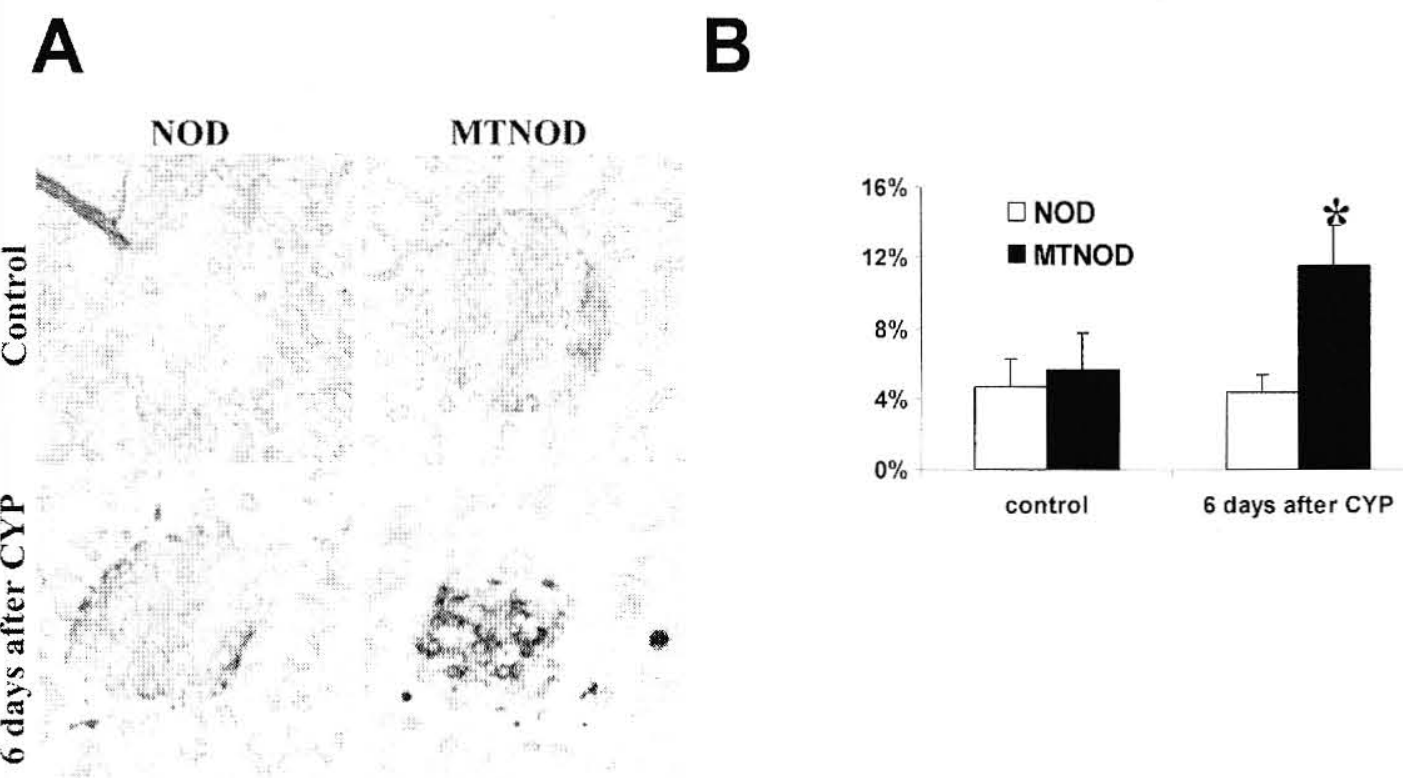

Fig 2-11. Increased pancreatic islet apoptosis in MT transgenic NOD mice after injection of CYP. NOD mice and MTNOD mice were untreated (control) or injected with CYP. (A) Representative photographs 6 days after CYP injection showing islet caspase-3 staining by polyclonal anti-rabbit cleaved caspase-3 antibody. (B) Average percentage of caspase-3 staining area in islets measured by ImagePro software.Data were collected from at least 4 mice in each group. A mean of 15 islets for each mouse was examined blindly. Vertical bars indicate SE. ${ }^{*} \mathrm{P}<0.01$ between NOD and MTNOD 6 days after CYP injection by two-way ANOVA. 


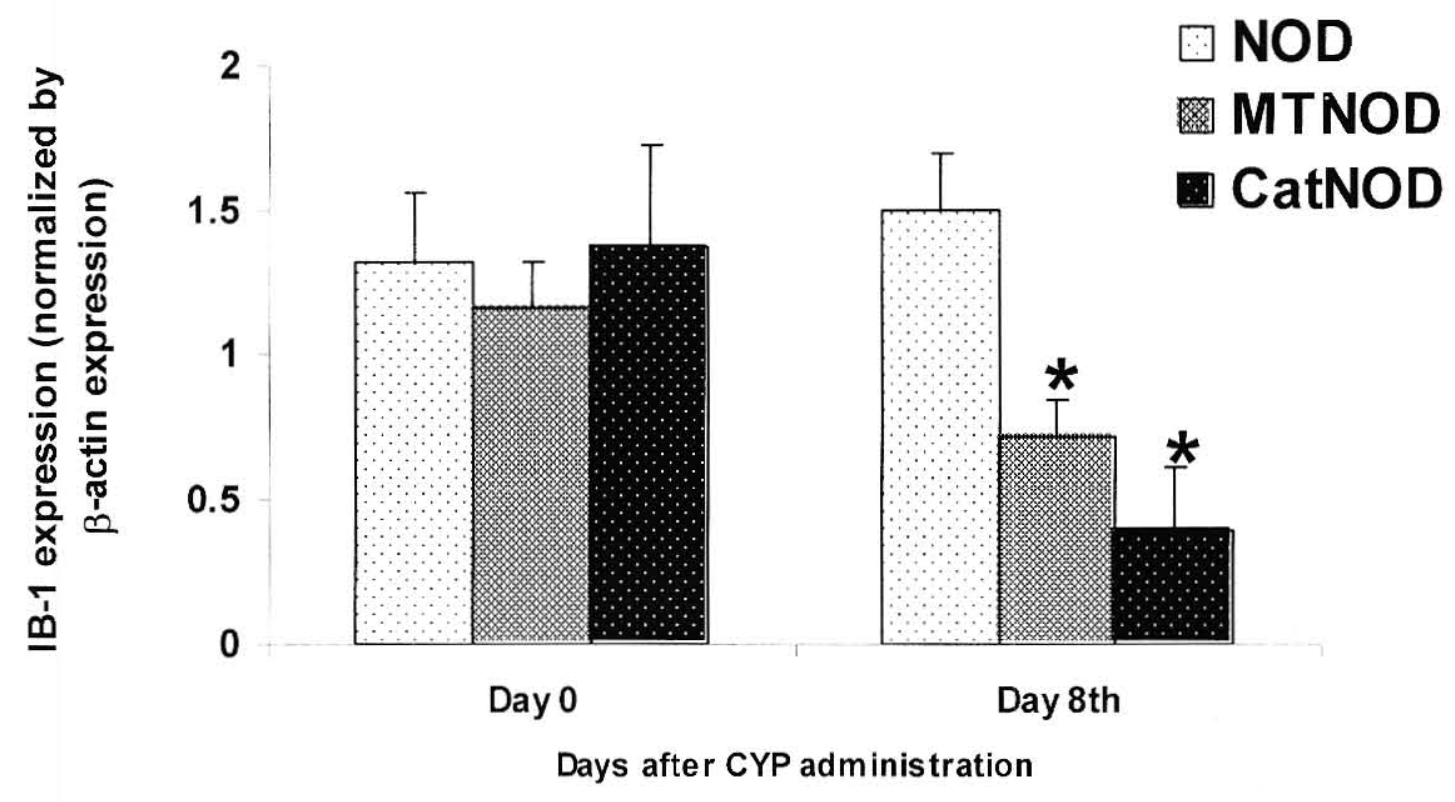

Fig 2-12. The effect of MT and catalase transgenes on islet-brain protein-1 (IB-1) expression in NOD mice before and after CYP administration. Both transgenic (MT and catalase) and control NOD mice received a CYP injection at a dose of $200 \mathrm{mg} / \mathrm{kg}$ via ip. Eight days later, mice were sacrificed and pancreatic islets were isolated. Islet total RNA was extracted and real-time quantitative RT-PCR was performed to determine the expression of IB-1. Results were normalized by islet beta-actin expression. Antioxidant transgenes, either MT or catalase, caused a significant reduction of islet IB-1 expression in NOD mice after CYP treatment. The numbers of each group was at least 4 . Vertical bars stand for SE. ${ }^{*} \mathrm{P}<0.05$ between control NOD and transgenic mice (MTNOD or CatNOD) by two-tail Student T-test. 


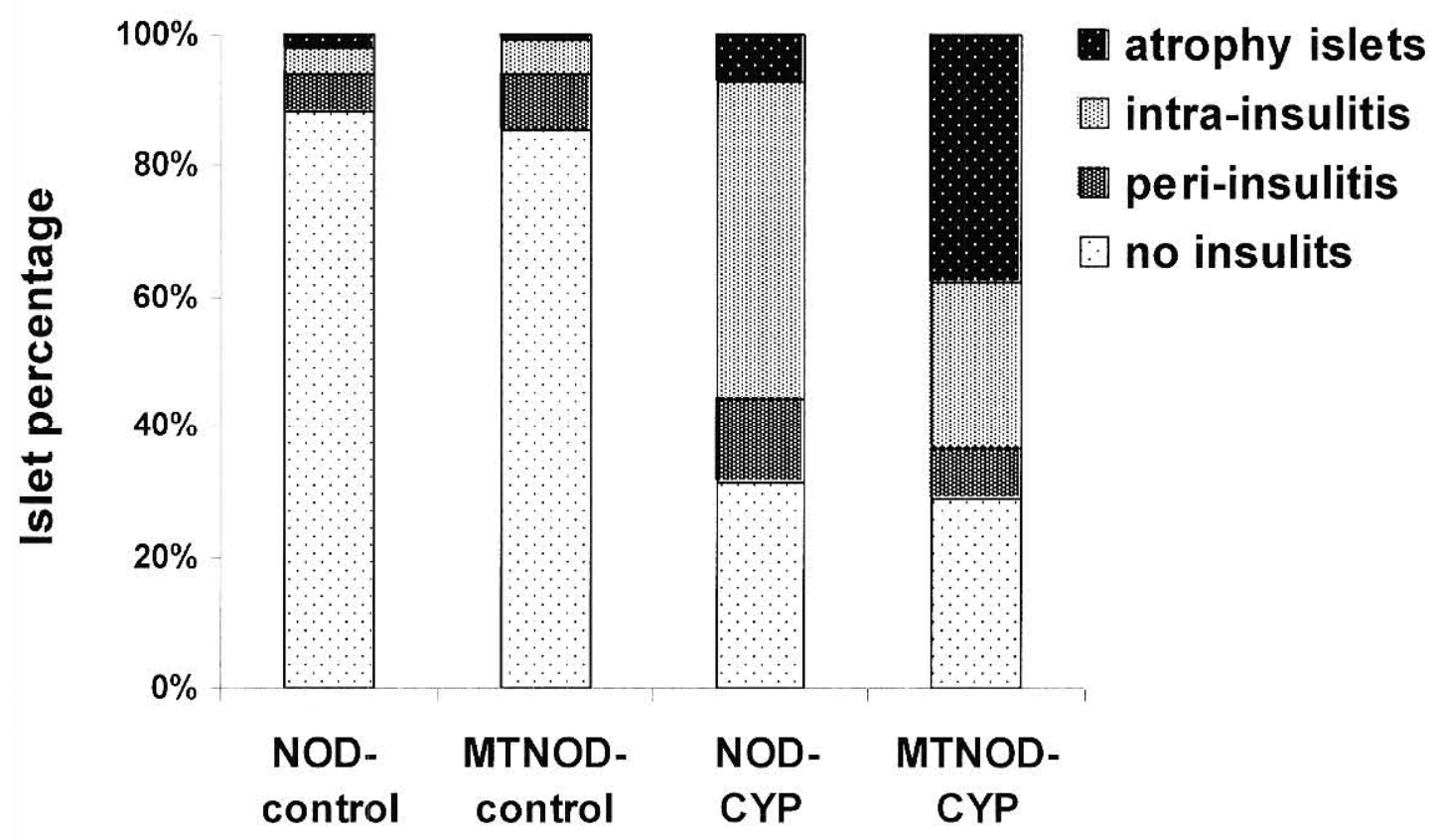

Fig 2-13. Insulitis in MT transgenic and nontransgenic NOD mice before and after CYP administration. Transgenic MTNOD and control NOD mice were either not injected (control) or injected with CYP for 6 days. The pancreata were removed and processed with standard histological procedure. The severity of insulitis was scored blindly in H\&E sections. Results were expressed as mean islet percentages for each insulitis category in an individual mouse. In each group data were collected from at least three mice and each mouse was examined with 3 or 4 slides. MT transgene significantly enhanced pancreatic islet death (atrophy after CYP administration. * $\mathrm{P}<0.01$ by rank sum test. 


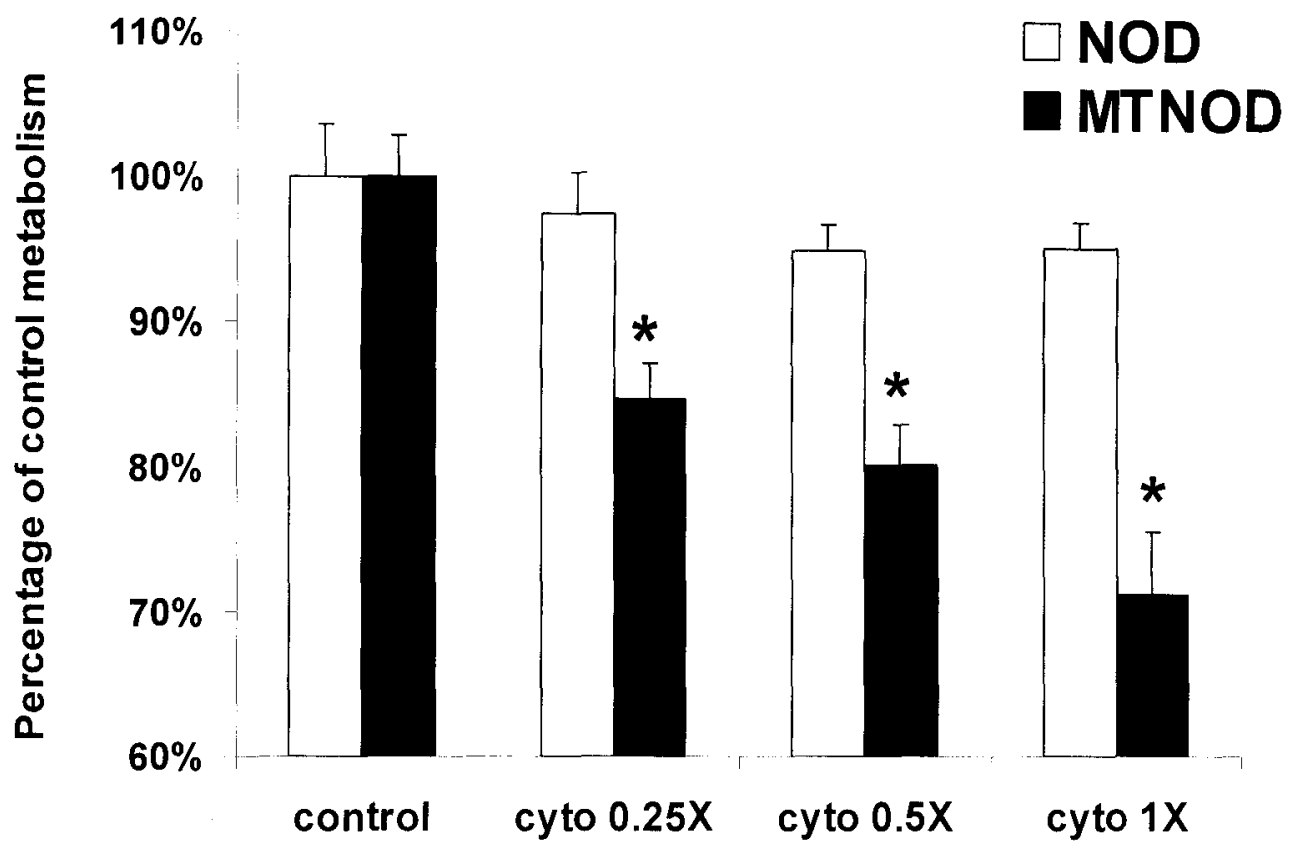

Fig 2-14. Cell viability in MTNOD transgenic and NOD control islets after cytokines' treatment. Isolated islets were exposed to the indicated concentrations of

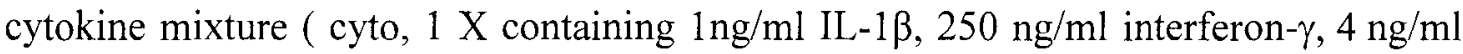
TNF- $\alpha$ ) for 24 hrs. Islet cell viability was measured by the Alamar Blue assay. Data were calculated from 3 to 5 independent experiments with duplicates or triplicates in each experiment. ${ }^{*}$ and ${ }^{* *}$ indicate that the values are different from the corresponding NOD control values $\left(^{*}, \mathrm{P}<0.01\right.$ by two-way ANOVA). Vertical bars indicate standard error of the mean. 


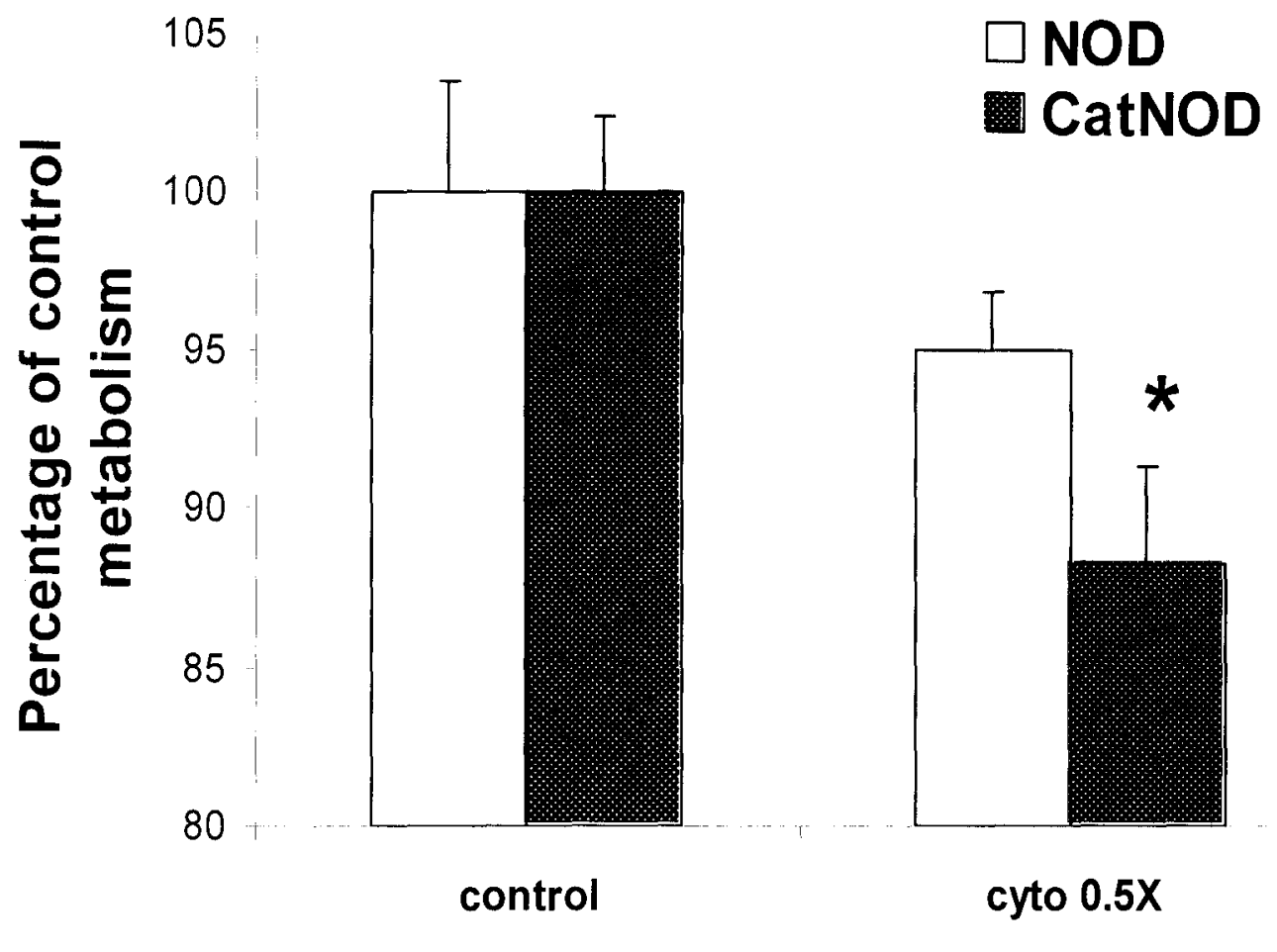

Fig 2-15. Cell viability in CatNOD transgenic and NOD control islets after cytokines' treatment. Isolated islets were exposed to the indicated concentrations of cytokine mixture ( cyto, 1 X containing $1 \mathrm{ng} / \mathrm{ml} \mathrm{IL-1} \beta, 250 \mathrm{ng} / \mathrm{ml}$ interferon- $\gamma, 4 \mathrm{ng} / \mathrm{ml}$ TNF- $\alpha$ ) for 24 hrs. Islet cell viability was measured by the Alamar Blue assay. Data were calculated from 3 to 5 independent experiments with duplicates or triplicates in each experiment. ${ }^{*}$ and ${ }^{* *}$ indicate that the values are different from the corresponding NOD control values (*, $\mathrm{P}<0.01$ by two-way ANOVA). Vertical bars indicate standard error of the mean. 
A

cytokines $2 \mathrm{X}$

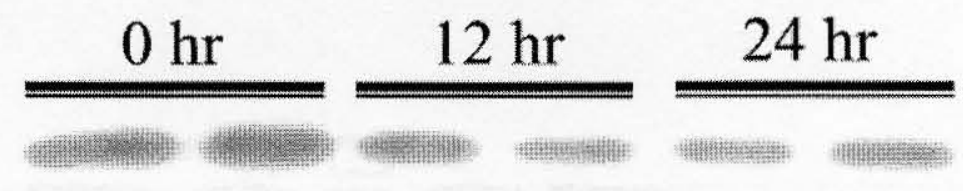

total caspase- 3

(35 KDa)

cleaved caspase-3

(17 KDa)
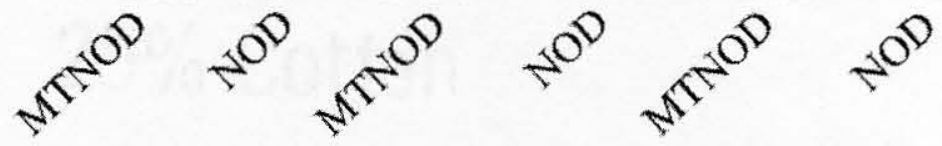

B

Cylokines 2X
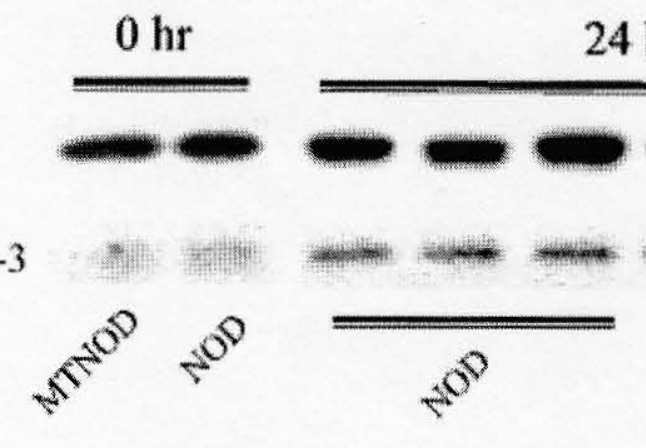

$24 \mathrm{hr}$

Total Caspase-3

( $35 \mathrm{KDa}$ )

Cleaved Caspase-3

(17 KDa)

Fig 2-16. Increased caspase-3 expression in MTNOD islets after cytokine treatment. Isolated islets from CatNOD or NOD mice were exposed to the indicated concentrations of cytokine mixture (cyto, 1X: $1 \mathrm{ng} / \mathrm{ml} \mathrm{IL-1b,} 250 \mathrm{ng} / \mathrm{ml}$ interferon-g, 4 $\mathrm{ng} / \mathrm{ml} \mathrm{TNF-a)}$ for 12 or 24 hours. Islet protein extract was fractionated by SDS-PAGE and analyzed by western blot using anti-cleaved caspase- 3 antibody. B. Representative image showing caspase-3 expression typical of three independent experiments. 


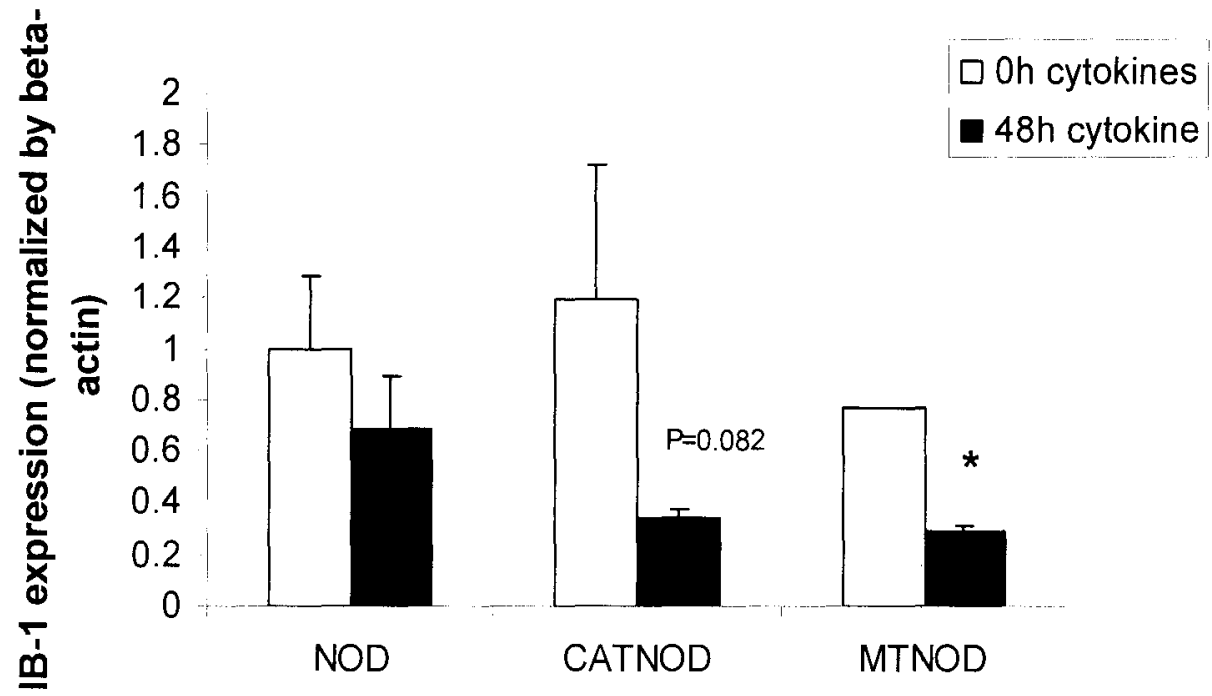

Fig 2-17. The effect of MT and catalase transgenes on islet-brain protein-1 (IB-1) expression in NOD islets treated with cytokines. Isolated islets from both transgenic (MT and catalase) and control NOD mice were exposed to cytokines for $48 \mathrm{hrs}$. Islet total RNA was extracted and real-time quantitative RT-PCR was performed to determine the expression of IB-1. Results were normalized by islet beta-actin expression. Antioxidant transgenes, either MT or catalase, caused a reduction of islet IB-1 expression in NOD mice after cytokines treatment. Vertical bars stand for SE. * $\mathrm{P}<0.05$ between control NOD and transgenic mice (MTNOD or CatNOD) by two-tail Student T-test. 


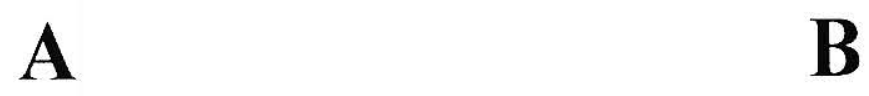

Phos-Akt $\frac{\text { control (Day 0) }}{\text { NOD }} \frac{4 \text { days after CYP }}{\text { MTNOD }}$

Akt

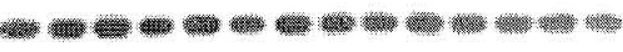
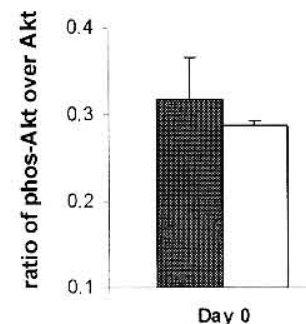

Day 0

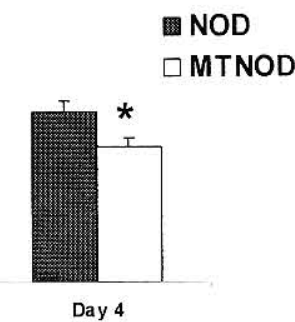

B

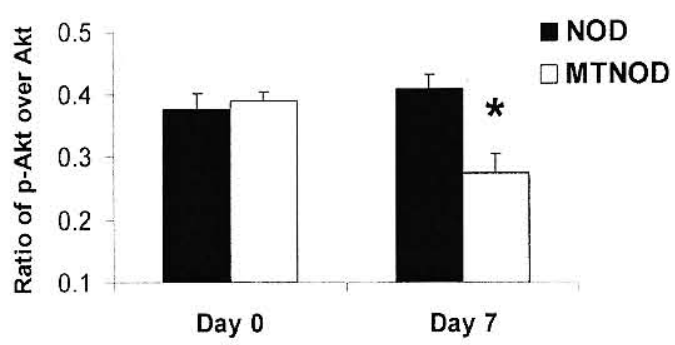

Days after CYP administration

Fig 2-18. Reduced Akt phosphorylation in MTNOD mice after CYP injection. Transgenic MTNOD and control NOD mice were not (Day 0) or injected with CYP for 4 or 7 days. Pancreatic islets were isolated and lysed for western blot analysis. (A) Representative blots showing Akt phosphorylation (activation). Each lane indicates an independent islet preparation from one mouse. (B) Densitometric analysis. The activity of Akt (Akt phosphorylation) was normalized by Akt expression. Data were collected from 3 mice in the group of Day 0 and 5 mice in the group of CYP treatment for each type of mice. Vertical bars indicate the standard error. ${ }^{*} \mathrm{P}<0.05$, and $\mathrm{b}^{*} * \mathrm{P}<0.01$ between NOD and MTNOD 7 days after CYP injection, and $\mathrm{a}^{* *} \mathrm{P}<0.01$ in NOD mice before and after CYP treatment by two-way ANOVA. 


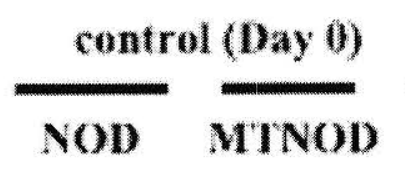

p-Foxo1

Actin
4 days after CYP
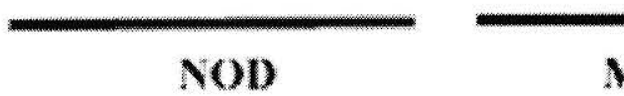

MTNOD

Fig 2-19. Reduced Foxo phosphorylation in MTNOD mice after CYP injection. Transgenic MTNOD and control NOD mice were not (Day 0) or injected with CYP for 4 days. Pancreatic islets were isolated and lysed for western blot analysis. Representative blots showing phosphorylated Foxol expression. Each lane indicates an independent islet preparation from one mouse. 

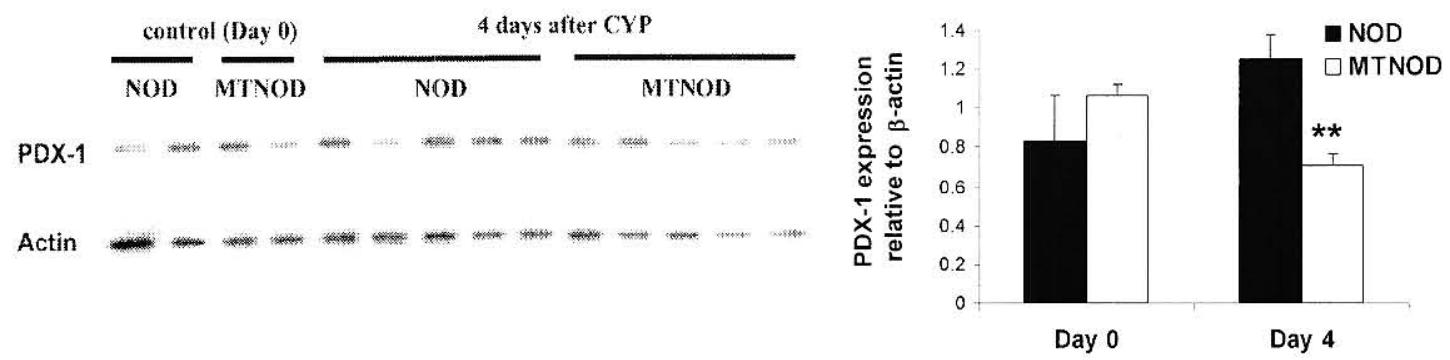

A

B
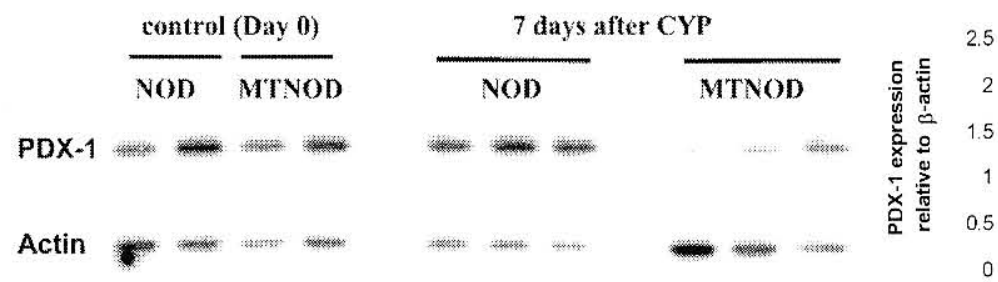

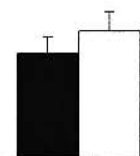

Day 0

Days after CYP administration

Fig 2-20. Reduced PDX-1 expression in MTNOD mice after CYP injection. Transgenic MTNOD and control NOD mice were not (Day 0) or injected with CYP for 4 or 7 days. Pancreatic islets were isolated and lysed for western blot analysis. (A) Representative blots showing PDX-1 expression. Each lane indicates an independent islet preparation from one mouse. (B) Densitometric analysis. The PDX-1 expression was normalized by b-actin level. Data were collected from 3 mice in the group of Day 0 and 5 mice in the group of CYP treatment for each type of mice. Vertical bars indicate the standard error. $* \mathrm{P}<0.05$, and $\mathrm{b}^{* *} \mathrm{P}<0.01$ between NOD and MTNOD 7 days after CYP injection, and $\mathrm{a}^{* *} \mathrm{P}<0.01$ in NOD mice before and after CYP treatment by twoway ANOVA. 


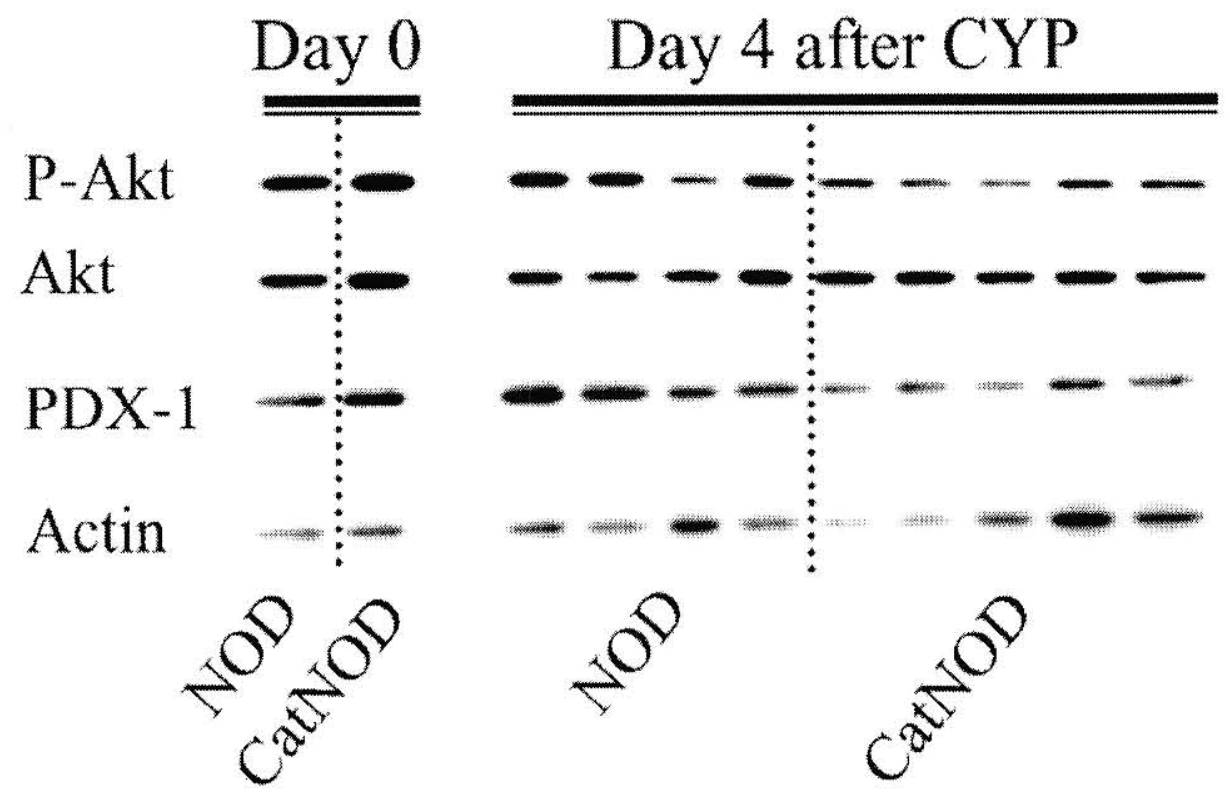

Fig 2-21. Reduced activity of the pathway from P-Akt through PDX-1 CatNOD islets obtained from the mice treated with CYP. Islets were isolated from the mice treated with CYP for 4 days, and $10 \mu \mathrm{g}$ islet protein extract was fractionated by SDSPAGE and analyzed by western blot using specific antibodies. Each lane indicates an independent islet preparation from an individual mouse. Densitometric analysis revealed that PDX-1 and phospho-AKT (P-AKT) normalized to AKT were not different between control NOD and transgenic mice before CYP treatment $(\mathrm{P}>0.05)$, but they were significantly lower in CATNOD samples than in NOD control samples after CYP treatment $(\mathrm{p}<0.05$ by one-way ANOVA). 


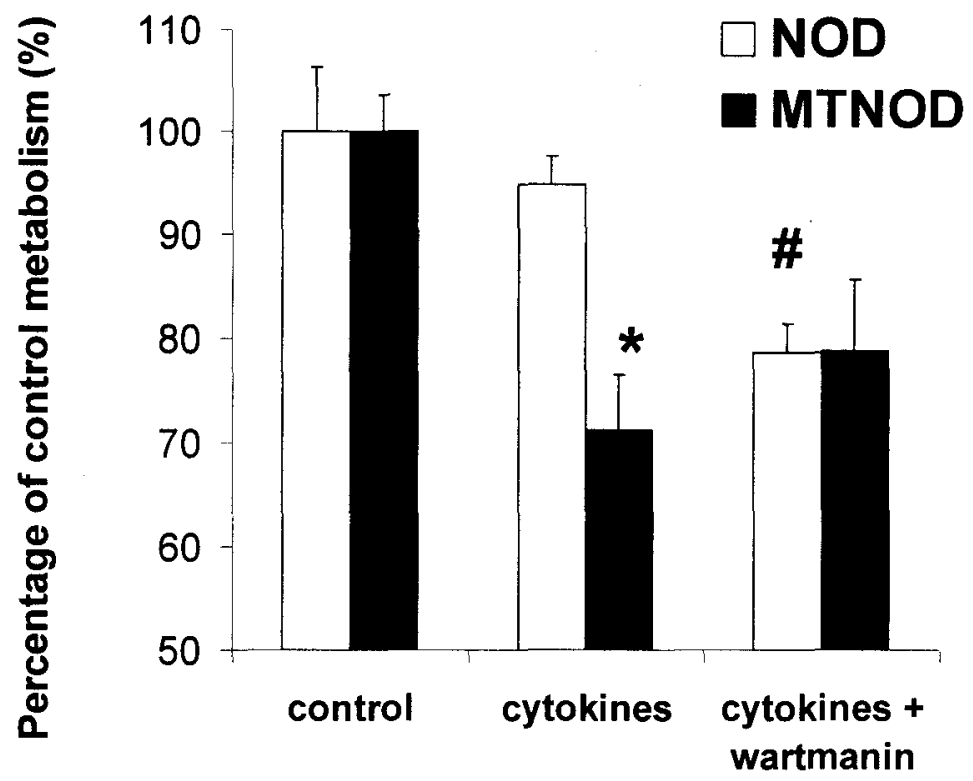

Fig 2-22. The PI3K inhibitor wartmanin sensitizes to cytokine toxicity in NOD but not MTNOD islets. MTNOD and NOD islets were cultured in medium containing the indicated concentrations of cytokines $(1 \mathrm{ng} / \mathrm{ml} \mathrm{IL-1b}, 250 \mathrm{ng} / \mathrm{ml}$ interferon-g, $4 \mathrm{ng} / \mathrm{ml}$ TNF-a) in the absence or presence of $1 \mathrm{mM}$ wartmanin for 24 hours. Islet cell viability was measured by Alamar blue assay. Results come from 3 independent experiments with duplicates or triplicates in each experiment. ${ }^{*} \mathrm{P}<0.01$ for the indicated group $v s$. control, and \# $\mathrm{P}<0.05$ for the indicated group vs. corresponding group treated with cytokines (two-way ANOVA). Vertical bars indicate the SE. 


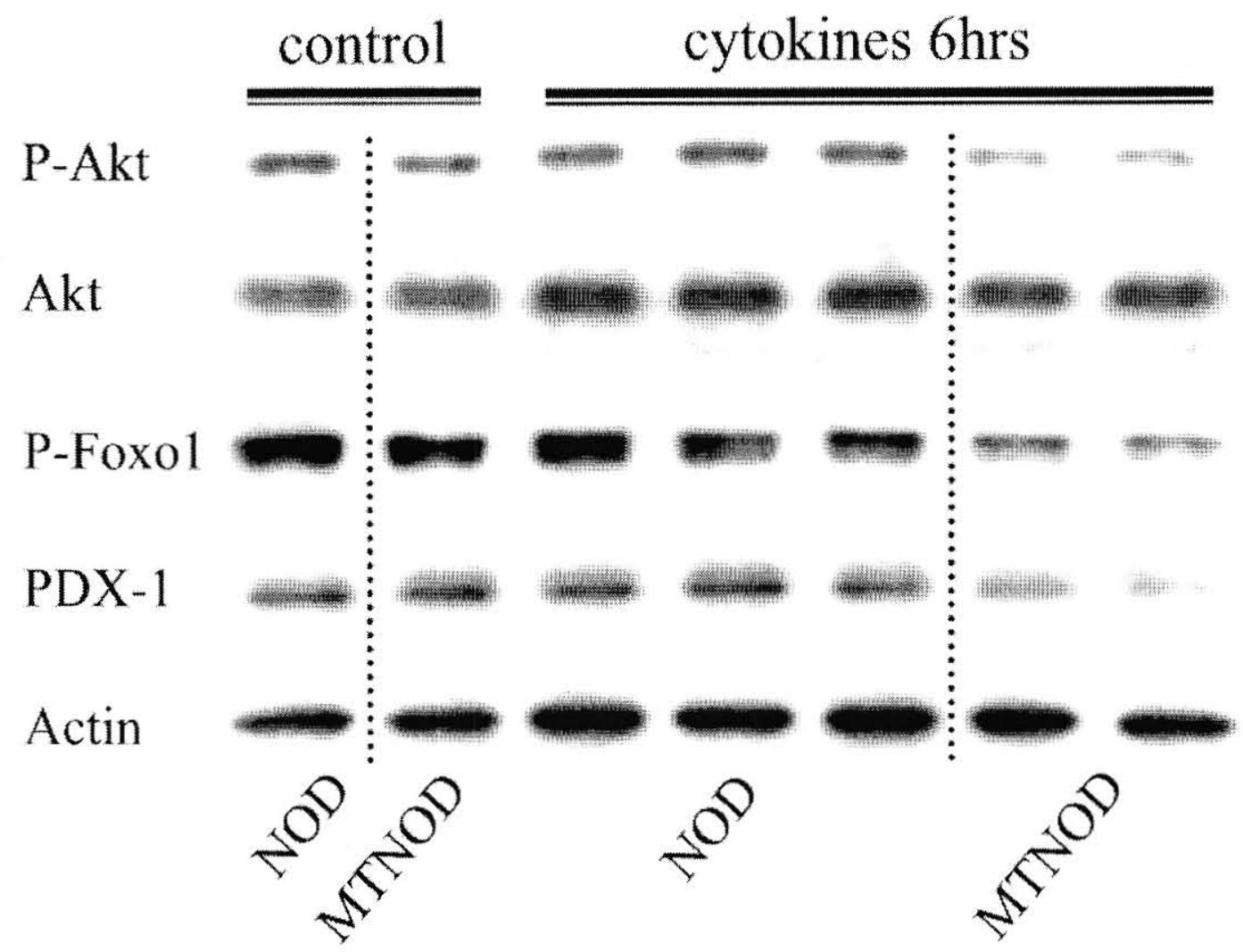

Fig 2-23. Western blot indicating reduced activity of the pathway from P-Akt through PDX-1 in MTNOD islets treated with cytokines. Isolated islets were cultured without (control) or with cytokines (IL-1b 2ng/ml and IFN-g $500 \mathrm{ng} / \mathrm{ml}$ ) for 6 hours. Ten $\mu \mathrm{g}$ islet protein extract was fractionated by SDS-PAGE and analyzed by western blot using specific antibodies. Each lane indicates an independent islet sample. Results are typical of two independent experiments. 


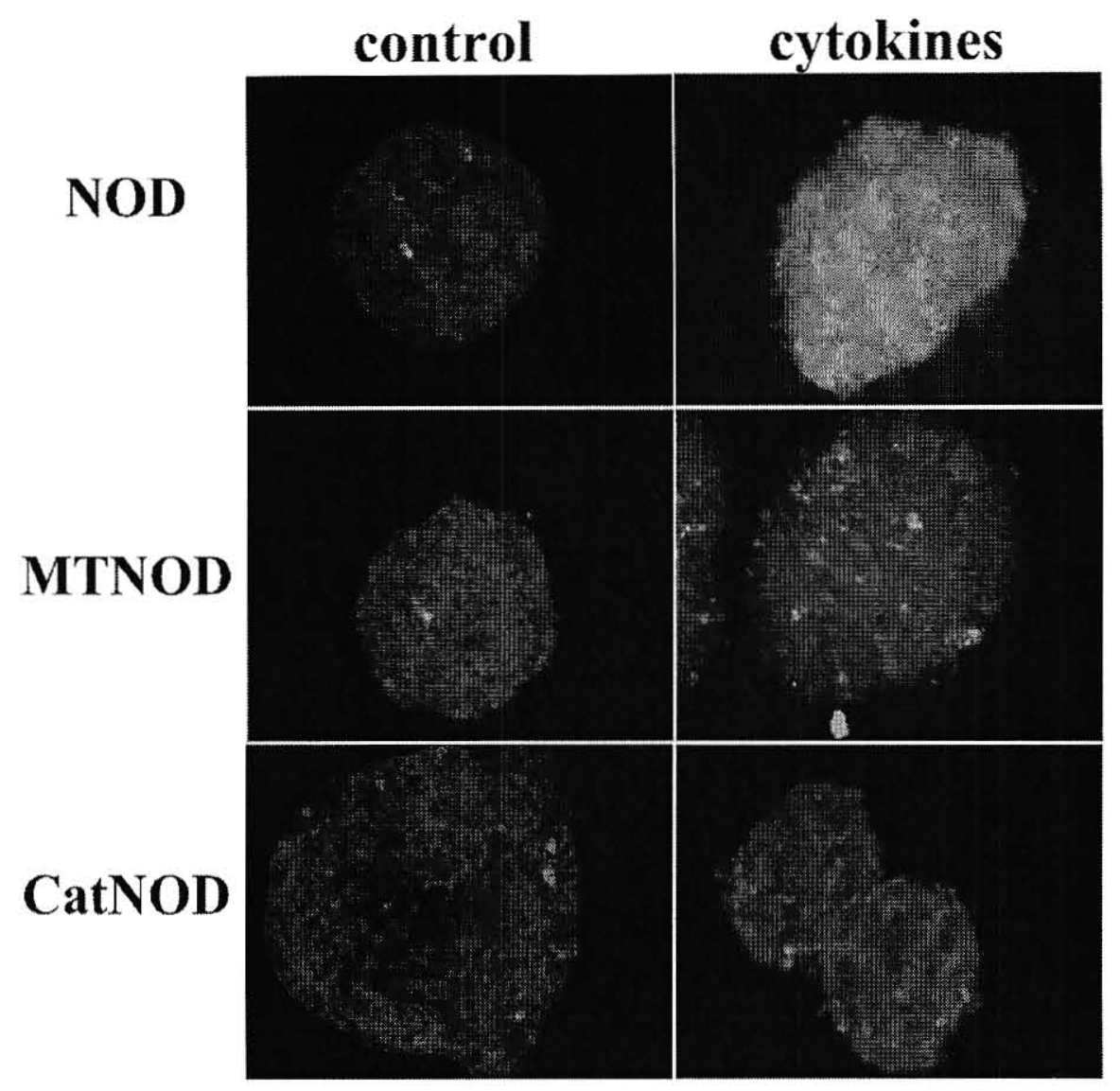

Fig 2-24. Reduced ROS production in MTNOD and CatNOD islets following treatment with cytokines. Isolated islets were preloaded with ROS sensitive dye CMH2DCFDA followed by cytokine treatment (IL-1b 1ng/ml, IFN-g 250ng/ml, TNF-a 4 $\mathrm{ng} / \mathrm{ml}$ ) for 16 hours. ROS production was indicated by increase of CM-H2DCFDA flourescence. Results are typical of 10 to 20 islets per group in two independent experiments. 


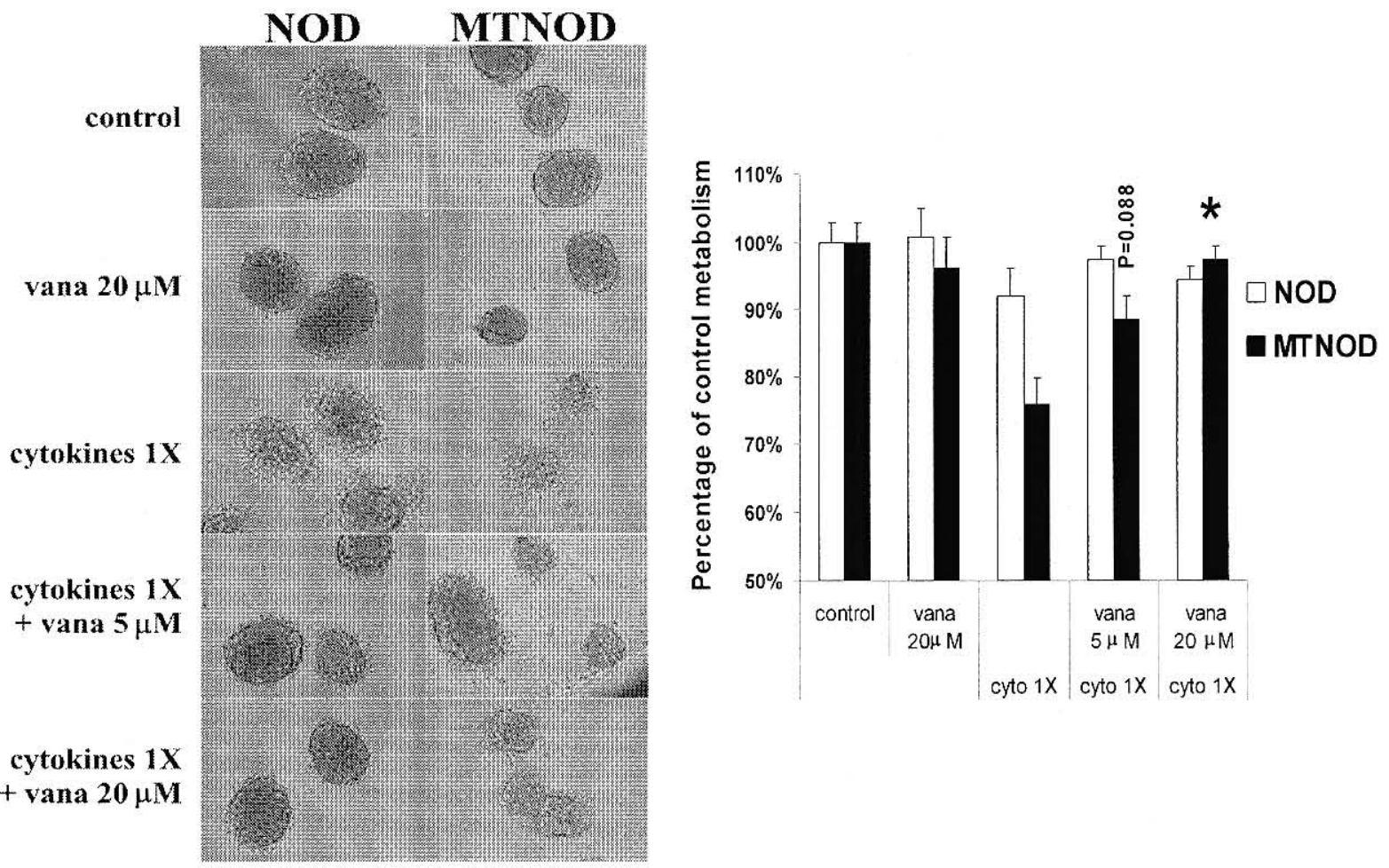

Fig 2-25. The rescue effect of orthovanadate against cytokine induced islet cell death in MTNOD islets. Both transgenic (MTNOD) and control (NOD) islets were cultured in a medium containing the indicated concentrations of sodium orthovanadate

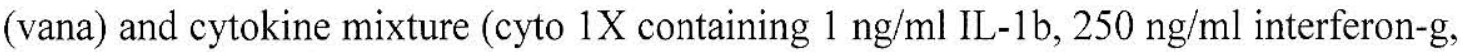
$4 \mathrm{ng} / \mathrm{ml} \mathrm{TNF}$-a) for 24 hours. Both islet morphology (A) and islet cell viability (B) were examined. Orthovanadate, the protein tyrosine phosphatases (PTPs) inhibitor, markedly reduced cytokine mediated islet cell death in MTNOD islets, indicating the sensentization to cytokine toxicity by MT transgene is relevant to the high activity of PTPs in MTNOD islets after cytokine treatment. Results came from 2 to 3 independent experiments with duplicates or triplicates in each experiment. ${ }^{*} \mathrm{P}<0.01$ for the indicated group vs. MTNOD islets treated with cytokines $1 \mathrm{X}$ by two-way ANOVA. Vertical bars indicate the standard error. 


\section{REFERENCES}

1. Guillausseau, P. J., Tielmans, D., Virally-Monod, M., and Assayag, M. (1997) Diabetes Metab 23 Suppl 2, 14-21

2. Lernmark, A., Moller, C., Kockum, I., and Sanjeevi, C. (1993) J.Intern.Med. 234, 361-369

3. Leslie, R. D. and Elliott, R. B. (1994) Diabetes 43, 843-850

4. Drash, A. L., Lipton, R. B., Dorman, J. S., Becker, D. J., LaPorte, R. E., Orchard, T. J., Riley, W. J., Trucco, M., and Kuller, L. H. (1991) Ann.Med. 23, 463-471

5. Dahlquist, G. (1993) Autoimmunity 15, 61-65

6. White, S. A., James, R. F., Swift, S. M., Kimber, R. M., and Nicholson, M. L. (2001) Diabet.Med. 18, 78-103

7. Ryan, E. A., Lakey, J. R., Paty, B. W., Imes, S., Korbutt, G. S., Kneteman, N. M., Bigam, D., Rajotte, R. V., and Shapiro, A. M. (2002) Diabetes 51, 21482157

8. Davalli, A. M., Scaglia, L., Zangen, D. H., Hollister, J., Bonner-Weir, S., and Weir, G. C. (1996) Diabetes 45, 1161-1167

9. Biarnes, M., Montolio, M., Nacher, V., Raurell, M., Soler, J., and Montanya, E. (2002) Diabetes 51, 66-72

10. Weir, G. C., Bonner-Weir, S., and Leahy, J. L. (1990) Diabetes 39, 401-405

11. Marquet, R. L., Bonthuis, F., van IJken, M., Bouwman, E., Wolvekamp, M. C., van Rooijen, N., Scheringa, M., and Ijzermans, J. N. (1994) Transpl.Int. 7 Suppl 1, S660-S662

12. Kroncke, K. D., Rodriguez, M. L., Kolb, H., and Kolb-Bachofen, V. (1993) Diabetologia 36, 17-24

13. Carlsson, P. O., Palm, F., Andersson, A., and Liss, P. (2001) Diabetes 50, 489495 
14. Petrowsky, H., Dippe, B., Geck, P., Lincke, M., Koenig, J., Bhatti, S., Wenisch, H. J., and Encke, A. (1995) Transplant.Proc. 27, 729-731

15. Land, W., Schneeberger, H., Schleibner, S., Illner, W. D., Abendroth, D., Rutili, G., Arfors, K. E., and Messmer, K. (1994) Transplantation 57, 211-217

16. Nakao, N., Frodl, E. M., Duan, W. M., Widner, H., and Brundin, P. (1994) Proc.Natl.Acad.Sci.U.S.A. 91, 12408-12412

17. Brenner, H. H., Burkart, V., Rothe, H., and Kolb, H. (1993) Autoimmunity. 15, 93-98

18. Suarez-Pinzon, W. L., Szabo, C., and Rabinovitch, A. (1997) Diabetes 46, $907-$ 911

19. Karsten, V., Sigrist, S., Moriscot, C., Sorg, T., Lemarchand, P., Belcourt, A., Benhamou, P. Y., Pinget, M., and Kessler, L. (2001) Transplant.Proc. 33, 575576

20. Stevens, R. B., Ansite, J. D., Mills, C. D., Lokeh, A., Rossini, T. J., Saxena, M., Brown, R. R., and Sutherland, D. E. (1996) Transplantation 61, 1740-1749

21. Mendola, J., Wright, J. R. J., and Lacy, P. E. (1989) Diabetes 38, 379-385

22. Hadjivassiliou, V., Green, M. H., James, R. F., Swift, S. M., Clayton, H. A., and Green, I. C. (1998) Nitric. Oxide. 2, 429-441

23. Malaisse, W. J., Malaisse-Lagae, F., Sener, A., and Pipeleers, D. G. (1982) Proc.Natl.Acad.Sci.U.S.A. 79, 927-930

24. Xu, B., Moritz, J. T., and Epstein, P. N. (1999) Free Radic.Biol.Med. 27, 830837

25. Zhang, H., Ollinger, K., and Brunk, U. (1995) Diabetologia 38, 635-641

26. Eizirik, D. L., Pipeleers, D. G., Ling, Z., Welsh, N., Hellerstrom, C., and Andersson, A. (1994) Proc.Natl.Acad.Sci.U.S.A. 91, 9253-9256

27. Lenzen, S., Drinkgern, J., and Tiedge, M. (1996) Free Radic.Biol.Med. 20, 463466

28. Gembal, M., Druzynska, J., Andrzejewska, S., Arendarczyk, W., and Wojcikowski, C. (1993) Endokrynol.Pol. 44, 147-150

29. Winter, D., Eich, T., Jahr, H., Brendel, M., and Bretzel, R. (2002) Transplant.Proc. 34, 2366 
30. Bertera, S., Crawford, M. L., Alexander, A. M., Papworth, G. D., Watkins, S. C., Robbins, P. D., and Trucco, M. (2003) Diabetes 52, 387-393

31. Xu, B., Moritz, J. T., and Epstein, P. N. (1999) Free Radic.Biol.Med. 27, 830837

32. Tiedge, M., Lortz, S., Munday, R., and Lenzen, S. (1998) Diabetes 47, 15781585

33. Tiedge, M., Lortz, S., Munday, R., and Lenzen, S. (1999) Diabetologia 42, 849 855

34. Uchigata, Y., Yamamoto, H., Kawamura, A., and Okamoto, H. (1982) J.Biol.Chem. 257, 6084-6088

35. Ohly, P., Dohle, C., Abel, J., Seissler, J., and Gleichmann, H. (2000) Diabetologia 43, 1020-1030

36. Yang, J. and Cherian, M. G. (1994) Life Sci. 55, 43-51

37. Chen, H., Carlson, E. C., Pellet, L., Moritz, J. T., and Epstein, P. N. (2001) Diabetes 50, 2040-2046

38. Thornalley, P. J. and Vasak, M. (1985) Biochim.Biophys.Acta 827, 36-44

39. Kumari, M. V., Hiramatsu, M., and Ebadi, M. (1998) Free Radic.Res 29, 93-101

40. Miura, T., Muraoka, S., and Ogiso, T. (1997) Life Sci. 60, L-9

41. Gotoh, M., Maki, T., Kiyoizumi, T., Satomi, S., and Monaco, A. P. (1985) Transplantation 40, 437-438

42. Appels, B., Burkart, V., Kantwerk-Funke, G., Funda, J., Kolb-Bachofen, V., and Kolb, H. (1989) J.Immunol. 142, 3803-3808

43. Ye, G., Metreveli, N. S., Ren, J., and Epstein, P. N. (2003) Diabetes 52, 777-783

44. Gonzalez, R. J. and Tarloff, J. B. (2001) Toxicol.In Vitro 15, 257-259

45. Byth, H. A., Mchunu, B. I., Dubery, I. A., and Bornman, L. (2001) Phytochem.Anal. 12, 340-346

46. Montana, E., Bonner-Weir, S., and Weir, G. C. (1993) J.Clin.Invest. 91, 780-787

47. Li, C. and Jackson, R. M. (2002) Am.J.Physiol Cell Physiol 282, C227-C241

48. Duranteau, J., Chandel, N. S., Kulisz, A., Shao, Z., and Schumacker, P. T. (1998) J.Biol.Chem. 273, 11619-11624 
49. Carlsson, P. O., Palm, F., Andersson, A., and Liss, P. (2000) Transplantation 69, 761-766

50. Jansson, L., Eizirik, D. L., Pipeleers, D. G., Borg, L. A., Hellerstrom, C., and Andersson, A. (1995) J.Clin.Invest. 96, 721-726

51. Lortz, S., Tiedge, M., Nachtwey, T., Karlsen, A. E., Nerup, J., and Lenzen, S. (2000) Diabetes 49, 1123-1130

52. Kennedy, M. C., Gan, T., Antholine, W. E., and Petering, D. H. (1993) Biochem.Biophys. Res. Commun. 196, 632-635

53. Hussain, S., Slikker, W., Jr., and Ali, S. F. (1996) Neurochem.Int. 29, 145-152

54. Cai, L., Klein, J. B., and Kang, Y. J. (2000) J.Biol.Chem. 275, 38957-38960

55. Ketchum, R. J., Deng, S., Weber, M., Jahr, H., and Brayman, K. L. (2000) Cell Transplant. 9, 453-462

56. Moritz, W., Meier, F., Stroka, D. M., Giuliani, M., Kugelmeier, P., Nett, P. C., Lehmann, R., Candinas, D., Gassmann, M., and Weber, M. (2002) FASEB J. 16, 745-747

57. Menger, M. D., Vajkoczy, P., Leiderer, R., Jager, S., and Messmer, K. (1992) J.Clin.Invest. 90, 1361-1369

58. Winter, D. T., Eich, T., Jahr, H., Brendel, M. D., and Bretzel, R. G. (2002) Transplant.Proc. 34, 2366-2368

59. Arita, S., Smith, C. V., Nagai, T., Sakamoto, Y., Maruyama, M., and Mullen, Y. (2000) Transplant.Proc. 32, 1667

60. Tajiri, Y. and Grill, V. E. (1999) Pancreas 18, 274-281

61. Vajkoczy, P., Lehr, H. A., Hubner, C., Arfors, K. E., and Menger, M. D. (1997) Am.J.Pathol. 150, 1487-1495

62. Adorini, L., Gregori, S., and Harrison, L. C. (2002) Trends Mol.Med. 8, 31-38

63. Mondino, A., Khoruts, A., and Jenkins, M. K. (1996) Proc.Natl.Acad.Sci.U.S.A $\mathbf{9 3}, 2245-2252$

64. Jansen, A., Homo-Delarche, F., Hooijkaas, H., Leenen, P. J., Dardenne, M., and Drexhage, H. A. (1994) Diabetes 43, 667-675

65. Charlton, B. and Mandel, T. E. (1989) Autoimmunity 4, 1-7

66. Gazda, L. S., Charlton, B., and Lafferty, K. J. (1997) J.Autoimmun. 10, 261-270 
67. Andre, I., Gonzalez, A., Wang, B., Katz, J., Benoist, C., and Mathis, D. (1996) Proc.Natl.Acad.Sci.U.S.A 93, 2260-2263

68. Gottlieb, P. A. and Eisenbarth, G. S. (1996) J.Autoimmun. 9, 277-281

69. Roep, B. O. (1996) Diabetes 45, 1147-1156

70. Harrison, L. C. (1994) Diabetes Care 17, 1220-1222

71. Nepom, G. T. (1995) Curr.Opin.Immunol. 7, 825-830

72. Gale, E. A. (1996) Eur.J.Endocrinol. 135, 643-644

73. Song, Y. H., Li, Y., and Maclaren, N. K. (1996) Immunol.Today 17, 232-238

74. Christie, M. R. (1996) Eur.J.Clin.Invest 26, 827-838

75. Tisch, R. and McDevitt, H. (1996) Cell 85, 291-297

76. Roll, U. and Ziegler, A. G. (1997) Exp.Clin.Endocrinol.Diabetes 105, 1-14

77. Bottazzo, G. F. (1984) Diabetologia 26, 241-249

78. Bottazzo, G. F., Genovese, S., Bosi, E., Dean, B. M., Christie, M. R., and Bonifacio, E. (1991) Ann.Med. 23, 453-461

79. Van de, W. M., Smets, G., Gepts, W., and Pipeleers, D. (1982) J.Clin.Invest 70, 41-49

80. Reddy, S., Wu, D., and Poole, C. A. (1996) J.Autoimmun. 9, 21-27

81. Hoek, A., Schoemaker, J., and Drexhage, H. A. (1997) Endocr.Rev. 18, 107-134

82. Schifter, T., Zahavi, I., and Moroz, C. (1996) Cardiology 87, 67-70

83. Leiter, E. H., Prochazka, M., and Coleman, D. L. (1987) Am.J.Pathol. 128, 380383

84. Serreze, D. V., Chapman, H. D., Varnum, D. S., Hanson, M. S., Reifsnyder, P. C., Richard, S. D., Fleming, S. A., Leiter, E. H., and Shultz, L. D. (1996) J.Exp.Med. 184, 2049-2053

85. Harada, M. and Makino, S. (1984) Diabetologia 27, 604-606

86. Yasunami, R. and Bach, J. F. (1988) Eur.J.Immunol. 18, 481-484

87. Kahn, S. E. (2000) Am.J.Med. 108 Suppl 6a, 2S-8S 
88. Pick, A., Clark, J., Kubstrup, C., Levisetti, M., Pugh, W., Bonner-Weir, S., and Polonsky, K. S. (1998) Diabetes 47, 358-364

89. Finegood, D. T., McArthur, M. D., Kojwang, D., Thomas, M. J., Topp, B. G., Leonard, T., and Buckingham, R. E. (2001) Diabetes 50, 1021-1029

90. Shimabukuro, M., Zhou, Y. T., Levi, M., and Unger, R. H. (1998) Proc.Natl.Acad.Sci.U.S.A 95, 2498-2502

91. Shimabukuro, M., Ohneda, M., Lee, Y., and Unger, R. H. (1997) J.Clin.Invest 100, 290-295

92. Efanova, I. B., Zaitsev, S. V., Zhivotovsky, B., Kohler, M., Efendic, S., Orrenius, S., and Berggren, P. O. (1998) J.Biol.Chem. 273, 33501-33507

93. Zhang, S., Liu, J., Saafi, E. L., and Cooper, G. J. (1999) FEBS Lett. 455, $315-$ 320

94. Wong, F. S., Visintin, I., Wen, L., Flavell, R. A., and Janeway, C. A., Jr. (1996) J.Exp.Med. 183, 67-76

95. Chervonsky, A. V., Wang, Y., Wong, F. S., Visintin, I., Flavell, R. A., Janeway, C. A. J., and Matis, L. A. (1997) Cell 89, 17-24

96. Nagata, M., Santamaria, P., Kawamura, T., Utsugi, T., and Yoon, J. W. (1994) J.Immunol. 152, 2042-2050

97. Kurrer, M. O., Pakala, S. V., Hanson, H. L., and Katz, J. D. (1997) Proc.Natl.Acad.Sci.U.S.A. 94, 213-218

98. Rabinovitch, A., Suarez, W. L., Thomas, P. D., Strynadka, K., and Simpson, I. (1992) Diabetologia 35, 409-413

99. Iwahashi, H., Hanafusa, T., Eguchi, Y., Nakajima, H., Miyagawa, J., Itoh, N., Tomita, K., Namba, M., Kuwajima, M., Noguchi, T., Tsujimoto, Y., and Matsuzawa, Y. (1996) Diabetologia 39, 530-536

100. Dunger, A., Augstein, P., Schmidt, S., and Fischer, U. (1996) J.Autoimmun. 9, 309-313

101. Wyllie, A. H., Kerr, J. F., and Currie, A. R. (1980) Int.Rev.Cytol. 68, 251-306

102. Ellis, R. E., Yuan, J. Y., and Horvitz, H. R. (1991) Annu.Rev.Cell Biol. 7, 663698

103. Thomas, H. E. and Kay, T. W. (2000) Diabetes Metab Res.Rev. 16, 251-261 
104. Delaney, C. A., Pavlovic, D., Hoorens, A., Pipeleers, D. G., and Eizirik, D. L. (1997) Endocrinology 138, 2610-2614

105. Moriwaki, M., Itoh, N., Miyagawa, J., Yamamoto, K., Imagawa, A., Yamagata, K., Iwahashi, H., Nakajima, H., Namba, M., Nagata, S., Hanafusa, T., and Matsuzawa, Y. (1999) Diabetologia 42, 1332-1340

106. Stassi, G., De Maria, R., Trucco, G., Rudert, W., Testi, R., Galluzzo, A., Giordano, C., and Trucco, M. (1997) J.Exp.Med. 186, 1193-1200

107. Moriwaki, M., Itoh, N., Miyagawa, J., Yamamoto, K., Imagawa, A., Yamagata, K., Iwahashi, H., Nakajima, H., Namba, M., Nagata, S., Hanafusa, T., and Matsuzawa, Y. (1999) Diabetologia 42, 1332-1340

108. Ferri, K. F. and Kroemer, G. (2001) Nat.Cell Biol. 3, E255-E263

109. Nicholson, D. W. and Thornberry, N. A. (1997) Trends Biochem.Sci. 22, 299306

110. Sakahira, H., Enari, M., and Nagata, S. (1998) Nature 391, 96-99

111. Kay, T. W., Chaplin, H. L., Parker, J. L., Stephens, L. A., and Thomas, H. E. (1997) Res.Immunol. 148, 320-327

112. Wong, F. S. and Janeway, C. A., Jr. (1999) J.Autoimmun. 13, 290-295

113. Wong, F. S., Dittel, B. N., and Janeway, C. A., Jr. (1999) Immunol.Rev. 169, 93104

114. Peterson, J. D., Pike, B., McDuffie, M., and Haskins, K. (1994) J.Immunol. 153, 2800-2806

115. Wang, Y., Pontesilli, O., Gill, R. G., La Rosa, F. G., and Lafferty, K. J. (1991) Proc.Natl.Acad.Sci.U.S.A 88, 527-531

116. Boitard, C., Yasunami, R., Dardenne, M., and Bach, J. F. (1989) J.Exp.Med. 169, $1669-1680$

117. Hutchings, P. R. and Cooke, A. (1990) J.Autoimmun. 3, 175-185

118. Cook, J. R., Solheim, J. C., Connolly, J. M., and Hansen, T. H. (1995) J.Immunol. 154, 47-57

119. Katz, J., Benoist, C., and Mathis, D. (1993) Eur.J.Immunol. 23, 3358-3360

120. Wicker, L. S., Leiter, E. H., Todd, J. A., Renjilian, R. J., Peterson, E., Fischer, P. A., Podolin, P. L., Zijlstra, M., Jaenisch, R., and Peterson, L. B. (1994) Diabetes 43, 500-504 
121. Serreze, D. V., Leiter, E. H., Christianson, G. J., Greiner, D., and Roopenian, D. C. (1994) Diabetes 43, 505-509

122. Sumida, T., Furukawa, M., Sakamoto, A., Namekawa, T., Maeda, T., Zijlstra, M., Iwamoto, I., Koike, T., Yoshida, S., Tomioka, H., and . (1994) Int.Immunol. 6, 1445-1449

123. Kagi, D., Odermatt, B., Seiler, P., Zinkernagel, R. M., Mak, T. W., and Hengartner, H. (1997) J.Exp.Med. 186, 989-997

124. Amrani, A., Verdaguer, J., Anderson, B., Utsugi, T., Bou, S., and Santamaria, P. (1999) J.Clin.Invest 103, 1201-1209

125. von Herrath, M. G. and Oldstone, M. B. (1997) J.Exp.Med. 185, 531-539

126. Ludewig, B., Odermatt, B., Landmann, S., Hengartner, H., and Zinkernagel, R. M. (1998) J.Exp.Med. 188, 1493-1501

127. Kreuwel, H. T., Morgan, D. J., Krahl, T., Ko, A., Sarvetnick, N., and Sherman, L. A. (1999) J.Immunol. 163, 4335-4341

128. Suda, T., Takahashi, T., Golstein, P., and Nagata, S. (1993) Cell 75, 1169-1178

129. Yamada, K., Takane-Gyotoku, N., Yuan, X., Ichikawa, F., Inada, C., and Nonaka, K. (1996) Diabetologia 39, 1306-1312

130. Loweth, A. C., Williams, G. T., James, R. F., Scarpello, J. H., and Morgan, N. G. (1998) Diabetes 47, 727-732

131. Suarez-Pinzon, W., Sorensen, O., Bleackley, R. C., Elliott, J. F., Rajotte, R. V., and Rabinovitch, A. (1999) Diabetes 48, 21-28

132. Itoh, N., Imagawa, A., Hanafusa, T., Waguri, M., Yamamoto, K., Iwahashi, H., Moriwaki, M., Nakajima, H., Miyagawa, J., Namba, M., Makino, S., Nagata, S., Kono, N., and Matsuzawa, Y. (1997) J.Exp.Med. 186, 613-618

133. Allison, J. and Strasser, A. (1998) Proc.Natl.Acad.Sci.U.S.A 95, 13818-13822

134. Kim, S., Kim, K. A., Hwang, D. Y., Lee, T. H., Kayagaki, N., Yagita, H., and Lee, M. S. (2000) J.Immunol. 164, 2931-2936

135. Jiang, Z. and Woda, B. A. (1991) J.Immunol. 146, 2990-2994

136. Toyoda, H., Formby, B., Magalong, D., Redford, A., Chan, E., Takei, S., and Charles, M. A. (1994) Immunol.Lett. 39, 283-288

137. Rabinovitch, A., Suarez-Pinzon, W. L., Sorensen, O., and Bleackley, R. C. (1996) Endocrinology 137, 2093-2099 
138. Held, W., MacDonald, H. R., Weissman, I. L., Hess, M. W., and Mueller, C. (1990) Proc.Natl.Acad.Sci.U.S.A 87, 2239-2243

139. Pilstrom, B., Bjork, L., and Bohme, J. (1997) J.Autoimmun. 10, 147-155

140. Rabinovitch, A., Suarez-Pinzon, W. L., Sorensen, O., Bleackley, R. C., and Power, R. F. (1995) J.Immunol. 154, 4874-4882

141. Pilstrom, B., Bjork, L., and Bohme, J. (1995) Cytokine 7, 806-814

142. Eizirik, D. L. and Mandrup-Poulsen, T. (2001) Diabetologia 44, 2115-2133

143. Mandrup-Poulsen, T. (1996) Diabetologia 39, 1005-1029

144. Grewal, I. S., Grewal, K. D., Wong, F. S., Picarella, D. E., Janeway, C. A., Jr., and Flavell, R. A. (1996) J.Exp.Med. 184, 1963-1974

145. Green, E. A., Eynon, E. E., and Flavell, R. A. (1998) Immunity. 9, 733-743

146. Steinman, L. (1997) J.Exp.Med. 185, 2039-2041

147. Dinarello, C. A. (1997) Cytokine Growth Factor Rev. 8, 253-265

148. Sims, J. E., Acres, R. B., Grubin, C. E., McMahan, C. J., Wignall, J. M., March, C. J., and Dower, S. K. (1989) Proc.Natl.Acad.Sci.U.S.A 86, 8946-8950

149. Stephanou, A., Brar, B. K., Scarabelli, T. M., Jonassen, A. K., Yellon, D. M., Marber, M. S., Knight, R. A., and Latchman, D. S. (2000) J.Biol.Chem. 275, $10002-10008$

150. Freeman, B. A. and Crapo, J. D. (1982) Lab Invest 47, 412-426

151. Finkel, T. (2001) IUBMB. Life 52, 3-6

152. Rhee, S. G. (1999) Exp.Mol.Med. 31, 53-59

153. Nathan, C. (1992) FASEB J. 6, 3051-3064

154. May, J. M. and de Haen, C. (1979) J.Biol.Chem. 254, 9017-9021

155. Meier, B., Radeke, H. H., Selle, S., Younes, M., Sies, H., Resch, K., and Habermehl, G. G. (1989) Biochem.J. 263, 539-545

156. Ohba, M., Shibanuma, M., Kuroki, T., and Nose, K. (1994) J.Cell Biol. 126, 1079-1088

157. Lo, Y. Y. and Cruz, T. F. (1995) J.Biol.Chem. 270, 11727-11730 
158. Sundaresan, M., Yu, Z. X., Ferrans, V. J., Irani, K., and Finkel, T. (1995) Science 270, 296-299

159. Bae, Y. S., Kang, S. W., Seo, M. S., Baines, I. C., Tekle, E., Chock, P. B., and Rhee, S. G. (1997) J.Biol.Chem. 272, 217-221

160. Krieger-Brauer, H. I. and Kather, H. (1992) J.Clin.Invest 89, 1006-1013

161. Griendling, K. K., Minieri, C. A., Ollerenshaw, J. D., and Alexander, R. W. (1994) Circ.Res. 74, 1141-1148

162. Boveris, A., Cadenas, E., and Stoppani, A. O. (1976) Biochem.J. 156, 435-444

163. Boveris, A. and Chance, B. (1973) Biochem.J. 134, 707-716

164. Cadenas, E., Boveris, A., Ragan, C. I., and Stoppani, A. O. (1977) Arch.Biochem. Biophys. 180, 248-257

165. Chandel, N. S. and Schumacker, P. T. (1999) FEBS Lett. 454, 173-176

166. Cai, J. and Jones, D. P. (1998) J.Biol.Chem. 273, 11401-11404

167. Cai, J. and Jones, D. P. (1999) J.Bioenerg.Biomembr. 31, 327-334

168. Banki, K., Hutter, E., Gonchoroff, N. J., and Perl, A. (1999) J.Immunol. 162, 1466-1479

169. Wissing, D., Mouritzen, H., and Jaattela, M. (1998) Free Radic.Biol.Med. 25, $57-65$

170. Singh, I., Pahan, K., Khan, M., and Singh, A. K. (1998) J.Biol.Chem. 273, 20354-20362

171. Sidoti-de Fraisse, C., Rincheval, V., Risler, Y., Mignotte, B., and Vayssiere, J. L. (1998) Oncogene 17, 1639-1651

172. Chandel, N. S., Maltepe, E., Goldwasser, E., Mathieu, C. E., Simon, M. C., and Schumacker, P. T. (1998) Proc.Natl.Acad.Sci.U.S.A 95, 11715-11720

173. Cross, A. R. and Jones, O. T. (1991) Biochim.Biophys.Acta 1057, 281-298

174. Bader, M., Muse, W., Ballou, D. P., Gassner, C., and Bardwell, J. C. (1999) Cell 98, 217-227

175. Bauskin, A. R., Alkalay, I., and Ben Neriah, Y. (1991) Cell 66, 685-696

176. Hwang, C., Sinskey, A. J., and Lodish, H. F. (1992) Science 257, 1496-1502 
177. Segal, A. W. and Shatwell, K. P. (1997) Ann.N.Y.Acad.Sci. 832, 215-222

178. Babior, B. M. (1999) Blood 93, 1464-1476

179. Bonizzi, G., Piette, J., Merville, M. P., and Bours, V. (2000) Biochem.Pharmacol. 59, 7-11

180. Tauber, A. I., Borregaard, N., Simons, E., and Wright, J. (1983) Medicine (Baltimore) 62, 286-309

181. Leusen, J. H., de Klein, A., Hilarius, P. M., Ahlin, A., Palmblad, J., Smith, C. I., Diekmann, D., Hall, A., Verhoeven, A. J., and Roos, D. (1996) J.Exp.Med. 184, 1243-1249

182. Krieger-Brauer, H. I. and Kather, H. (1995) Biochem.J. 307 (Pt 2), 549-556

183. Leseney, A. M., Deme, D., Legue, O., Ohayon, R., Chanson, P., Sales, J. P., Pires, d. C., Dupuy, C., and Virion, A. (1999) Biochimie 81, 373-380

184. Griendling, K. K., Sorescu, D., Lassegue, B., and Ushio-Fukai, M. (2000) Arterioscler.Thromb.Vasc.Biol. 20, 2175-2183

185. Jones, S. A., O'Donnell, V. B., Wood, J. D., Broughton, J. P., Hughes, E. J., and Jones, O. T. (1996) Am.J.Physiol 271, H1626-H1634

186. Jones, S. A., Wood, J. D., Coffey, M. J., and Jones, O. T. (1994) FEBS Lett. 355, 178-182

187. Jones, S. A., Hancock, J. T., Jones, O. T., Neubauer, A., and Topley, N. (1995) J.Am.Soc.Nephrol. 5, 1483-1491

188. Suzuki, Y. J. and Ford, G. D. (1999) J.Mol.Cell Cardiol. 31, 345-353

189. Thannickal, V. J., Day, R. M., Klinz, S. G., Bastien, M. C., Larios, J. M., and Fanburg, B. L. (2000) FASEB J. 14, 1741-1748

190. McKelvey, T. G., Hollwarth, M. E., Granger, D. N., Engerson, T. D., Landler, U., and Jones, H. P. (1988) Am.J.Physiol 254, G753-G760

191. Chance, B., Sies, H., and Boveris, A. (1979) Physiol Rev. 59, 527-605

192. Friedl, H. P., Till, G. O., Ryan, U. S., and Ward, P. A. (1989) FASEB J. 3, 2512 2518

193. Granger, D. N. (1988) Am.J.Physiol 255, H1269-H1275

194. Feng, L., Xia, Y., Garcia, G. E., Hwang, D., and Wilson, C. B. (1995) J.Clin. Invest 95, 1669-1675 
195. Sullivan, S. G., Chiu, D. T., Errasfa, M., Wang, J. M., Qi, J. S., and Stern, A. (1994) Free Radic.Biol.Med. 16, 399-403

196. Peters, G. H., Frimurer, T. M., and Olsen, O. H. (1998) Biochemistry 37, 53835393

197. Denu, J. M. and Tanner, K. G. (1998) Biochemistry 37, 5633-5642

198. Sattler, M., Verma, S., Shrikhande, G., Byrne, C. H., Pride, Y. B., Winkler, T., Greenfield, E. A., Salgia, R., and Griffin, J. D. (2000) J.Biol.Chem. 275, 24273 24278

199. Secrist, J. P., Burns, L. A., Karnitz, L., Koretzky, G. A., and Abraham, R. T. (1993) J.Biol.Chem. 268, 5886-5893

200. Cunnick, J. M., Dorsey, J. F., Mei, L., and Wu, J. (1998) Biochem.Mol.Biol.Int. 45, 887-894

201. Robinson, K. A., Stewart, C. A., Pye, Q., Floyd, R. A., and Hensley, K. (1999) Arch.Biochem.Biophys. 365, 211-215

202. Akhand, A. A., Pu, M., Senga, T., Kato, M., Suzuki, H., Miyata, T., Hamaguchi, M., and Nakashima, I. (1999) J.Biol.Chem. 274, 25821-25826

203. Minetti, M., Mallozzi, C., and Di Stasi, A. M. (2002) Free Radic.Biol.Med. 33, 744-754

204. Thomas, S. M. and Brugge, J. S. (1997) Annu.Rev.Cell Dev.Biol. 13, 513-609

205. Kamata, H. and Hirata, H. (1999) Cell Signal. 11, 1-14

206. Guyton, K. Z., Liu, Y., Gorospe, M., Xu, Q., and Holbrook, N. J. (1996) J.Biol.Chem. 271, 4138-4142

207. Wang, X., Martindale, J. L., Liu, Y., and Holbrook, N. J. (1998) Biochem.J. 333 ( Pt 2), 291-300

208. Lo, Y. Y., Wong, J. M., and Cruz, T. F. (1996) J.Biol.Chem. 271, 15703-15707

209. Abe, J., Takahashi, M., Ishida, M., Lee, J. D., and Berk, B. C. (1997) J.Biol.Chem. 272, 20389-20394

210. Abe, J., Kusuhara, M., Ulevitch, R. J., Berk, B. C., and Lee, J. D. (1996) J.Biol.Chem. 271, 16586-16590

211. Rao, G. N. (1996) Oncogene 13, 713-719 
212. Aikawa, R., Komuro, I., Yamazaki, T., Zou, Y., Kudoh, S., Tanaka, M., Shiojima, I., Hiroi, Y., and Yazaki, Y. (1997) J.Clin.Invest 100, 1813-1821

213. Lander, H. M., Ogiste, J. S., Teng, K. K., and Novogrodsky, A. (1995) J.Biol.Chem. 270, 21195-21198

214. Lander, H. M., Hajjar, D. P., Hempstead, B. L., Mirza, U. A., Chait, B. T., Campbell, S., and Quilliam, L. A. (1997) J.Biol.Chem. 272, 4323-4326

215. Lander, H. M., Milbank, A. J., Tauras, J. M., Hajjar, D. P., Hempstead, B. L., Schwartz, G. D., Kraemer, R. T., Mirza, U. A., Chait, B. T., Burk, S. C., and Quilliam, L. A. (1996) Nature 381, 380-381

216. Yoshizumi, M., Abe, J., Haendeler, J., Huang, Q., and Berk, B. C. (2000) J.Biol.Chem. 275, 11706-11712

217. Devary, Y., Gottlieb, R. A., Smeal, T., and Karin, M. (1992) Cell 71, 1081-1091

218. Suzaki, Y., Yoshizumi, M., Kagami, S., Koyama, A. H., Taketani, Y., Houchi, H., Tsuchiya, K., Takeda, E., and Tamaki, T. (2002) J.Biol.Chem. 277, 96149621

219. Saitoh, M., Nishitoh, H., Fujii, M., Takeda, K., Tobiume, K., Sawada, Y., Kawabata, M., Miyazono, K., and Ichijo, H. (1998) EMBO J. 17, 2596-2606

220. Tobiume, K., Matsuzawa, A., Takahashi, T., Nishitoh, H., Morita, K., Takeda, K., Minowa, O., Miyazono, K., Noda, T., and Ichijo, H. (2001) EMBO Rep. 2, 222-228

221. Konishi, H., Tanaka, M., Takemura, Y., Matsuzaki, H., Ono, Y., Kikkawa, U., and Nishizuka, Y. (1997) Proc.Natl.Acad.Sci.U.S.A 94, 11233-11237

222. Konishi, H., Matsuzaki, H., Tanaka, M., Takemura, Y., Kuroda, S., Ono, Y., and Kikkawa, U. (1997) FEBS Lett. 410, 493-498

223. Franke, T. F., Kaplan, D. R., and Cantley, L. C. (1997) Cell 88, 435-437

224. Marte, B. M. and Downward, J. (1997) Trends Biochem.Sci. 22, 355-358

225. Hemmings, B. A. (1997) Science 275, 628-630

226. Nishizuka, Y. (1992) Science 258, 607-614

227. Ono, Y., Fujii, T., Ogita, K., Kikkawa, U., Igarashi, K., and Nishizuka, Y. (1989) Proc.Natl.Acad.Sci.U.S.A 86, 3099-3103

228. Gopalakrishna, R. and Anderson, W. B. (1989) Proc.Natl.Acad.Sci.U.S.A 86, 6758-6762 
229. Gopalakrishna, R. and Anderson, W. B. (1987) FEBS Lett. 225, 233-237

230. Takekoshi, S., Kambayashi, Y., Nagata, H., Takagi, T., Yamamoto, Y., and Watanabe, K. (1995) Biochem. Biophys. Res. Commun. 217, 654-660

231. O'Brian, C. A., Ward, N. E., Weinstein, I. B., Bull, A. W., and Marnett, L. J. (1988) Biochem.Biophys. Res. Commun. 155, 1374-1380

232. Clapham, D. E. (1995) Cell 80, 259-268

233. Roveri, A., Coassin, M., Maiorino, M., Zamburlini, A., van Amsterdam, F. T., Ratti, E., and Ursini, F. (1992) Arch.Biochem.Biophys. 297, 265-270

234. Okabe, E., Kato, Y., Sasaki, H., Saito, G., Hess, M. L., and Ito, H. (1987) Arch.Biochem.Biophys. 255, 464-468

235. Okabe, E., Sugihara, M., Tanaka, K., Sasaki, H., and Ito, H. (1989) J.Pharmacol.Exp.Ther. 250, 286-292

236. Okabe, E., Kuse, K., Sekishita, T., Suyama, N., Tanaka, K., and Ito, H. (1991) J.Pharmacol.Exp.Ther. 256, 868-875

237. Doan, T. N., Gentry, D. L., Taylor, A. A., and Elliott, S. J. (1994) Biochem.J. 297 ( Pt 1), 209-215

238. Schieven, G. L., Kirihara, J. M., Burg, D. L., Geahlen, R. L., and Ledbetter, J. A. (1993) J.Biol.Chem. 268, 16688-16692

239. O'Shea, J. J., McVicar, D. W., Bailey, T. L., Burns, C., and Smyth, M. J. (1992) Proc.Natl.Acad.Sci.U.S.A 89, 10306-10310

240. Qin, S., Minami, Y., Hibi, M., Kurosaki, T., and Yamamura, H. (1997) J.Biol.Chem. 272, 2098-2103

241. Qin, S., Inazu, T., Takata, M., Kurosaki, T., Homma, Y., and Yamamura, H. (1996) Eur.J.Biochem. 236, 443-449

242. Klebanoff, S. J., Vadas, M. A., Harlan, J. M., Sparks, L. H., Gamble, J. R., Agosti, J. M., and Waltersdorph, A. M. (1986) J.Immunol. 136, 4220-4225

243. Maki, A., Berezesky, I. K., Fargnoli, J., Holbrook, N. J., and Trump, B. F. (1992) FASEB J. 6, 919-924

244. Amstad, P., Crawford, D., Muehlematter, D., Zbinden, I., Larsson, R., and Cerutti, P. (1990) Bull.Cancer 77, 501-502

245. Meyer, M., Schreck, R., and Baeuerle, P. A. (1993) EMBO J. 12, 2005-2015 
246. Schreck, R., Albermann, K., and Baeuerle, P. A. (1992) Free Radic.Res. Commun. 17, 221-237

247. Schreck, R., Rieber, P., and Baeuerle, P. A. (1991) EMBO J. 10, 2247-2258

248. Schoonbroodt, S., Ferreira, V., Best-Belpomme, M., Boelaert, J. R., LegrandPoels, S., Korner, M., and Piette, J. (2000) J.Immunol. 164, 4292-4300

249. Hehner, S. P., Breitkreutz, R., Shubinsky, G., Unsoeld, H., Schulze-Osthoff, K., Schmitz, M. L., and Droge, W. (2000) J.Immunol. 165, 4319-4328

250. Stein, B., Rahmsdorf, H. J., Steffen, A., Litfin, M., and Herrlich, P. (1989) Mol.Cell Biol. 9, 5169-5181

251. Angel, P. and Karin, M. (1991) Biochim.Biophys.Acta 1072, 129-157

252. Devary, Y., Gottlieb, R. A., Lau, L. F., and Karin, M. (1991) Mol.Cell Biol. 11, 2804-2811

253. Nose, K., Shibanuma, M., Kikuchi, K., Kageyama, H., Sakiyama, S., and Kuroki, T. (1991) Eur.J.Biochem. 201, 99-106

254. Okuno, H., Akahori, A., Sato, H., Xanthoudakis, S., Curran, T., and Iba, H. (1993) Oncogene 8, 695-701

255. Abate, C., Patel, L., Rauscher, F. J., III, and Curran, T. (1990) Science 249, 1157-1161

256. Xanthoudakis, S. and Curran, T. (1992) EMBO J. 11, 653-665

257. Myrset, A. H., Bostad, A., Jamin, N., Lirsac, P. N., Toma, F., and Gabrielsen, O. S. (1993) EMBO J. 12, 4625-4633

258. Rainwater, R., Parks, D., Anderson, M. E., Tegtmeyer, P., and Mann, K. (1995) Mol.Cell Biol. 15, 3892-3903

259. Wu, X., Bishopric, N. H., Discher, D. J., Murphy, B. J., and Webster, K. A. (1996) Mol.Cell Biol. 16, 1035-1046

260. Claiborne, A., Yeh, J. I., Mallett, T. C., Luba, J., Crane, E. J., III, Charrier, V., and Parsonage, D. (1999) Biochemistry 38, 15407-15416

261. Gilbert, H. F. (1982) J.Biol.Chem. 257, 12086-12091

262. Winterbourn, C. C. and Metodiewa, D. (1999) Free Radic. Biol.Med. 27, 322328 
263. Aslund, F., Zheng, M., Beckwith, J., and Storz, G. (1999)

Proc.Natl.Acad.Sci.U.S.A 96, 6161-6165

264. Zheng, M., Aslund, F., and Storz, G. (1998) Science 279, 1718-1721

265. Hirota, K., Nishiyama, A., and Yodoi, J. (1999) Tanpakushitsu Kakusan Koso 44, 2414-2419

266. Hirota, K., Murata, M., Sachi, Y., Nakamura, H., Takeuchi, J., Mori, K., and Yodoi, J. (1999) J.Biol.Chem. 274, 27891-27897

267. Schafer, F. Q. and Buettner, G. R. (2001) Free Radic.Biol.Med. 30, 1191-1212

268. Kuge, S. and Jones, N. (1994) EMBO J. 13, 655-664

269. Galter, D., Mihm, S., and Droge, W. (1994) Eur.J.Biochem. 221, 639-648

270. Lee, S. R., Bar-Noy, S., Kwon, J., Levine, R. L., Stadtman, T. C., and Rhee, S. G. (2000) Proc.Natl.Acad.Sci.U.S.A 97, 2521-2526

271. Luthman, M. and Holmgren, A. (1982) Biochemistry 21, 6628-6633

272. Azevedo-Martins, A. K., Lortz, S., Lenzen, S., Curi, R., Eizirik, D. L., and Tiedge, M. (2003) Diabetes 52, 93-101

273. Tiedge, M., Lortz, S., Drinkgern, J., and Lenzen, S. (1997) Diabetes 46, 1733 1742

274. McInerney, M. F., Seidel, M. J., Nguyen, J. M., Flynn, J. C., Sturm, N., Lee, H., Zhang, Z., Tillekeratne, L. M., and Hudson, R. A. (1996) Res.Commun.Mol.Pathol.Pharmacol. 94, 115-128

275. Piganelli, J. D., Flores, S. C., Cruz, C., Koepp, J., Batinic-Haberle, I., Crapo, J., Day, B., Kachadourian, R., Young, R., Bradley, B., and Haskins, K. (2002) Diabetes 51, 347-355

276. Sandstrom, J., Jonsson, L. M., Edlund, H., Holmberg, D., and Marklund, S. L. (2002) Free Radic.Biol.Med. 33, 71-75

277. Hotta, M., Tashiro, F., Ikegami, H., Niwa, H., Ogihara, T., Yodoi, J., and Miyazaki, J. (1998) J.Exp.Med. \%19;188, 1445-1451

278. Xu, B., Moritz, J. T., and Epstein, P. N. (1999) Free Radic.Biol.Med. 27, 830837

279. Li, X., Chen, H., and Epstein, P. N. (2004) J.Biol.Chem. 279, 765-771

280. Eizirik, D. L., Sandler, S., and Palmer, J. P. (1993) Diabetes 42, 1383-1391 
281. Chatenoud, L., Thervet, E., Primo, J., and Bach, J. F. (1994)

Proc.Natl.Acad.Sci.U.S.A 91, 123-127

282. Strandell, E., Eizirik, D. L., and Sandler, S. (1990) J.Clin.Invest 85, 1944-1950

283. Sreenan, S., Pick, A. J., Levisetti, M., Baldwin, A. C., Pugh, W., and Polonsky, K. S. (1999) Diabetes 48, 989-996

284. Raff, M. (1998) Nature 396, 119-122

285. Mauricio, D. and Mandrup-Poulsen, T. (1998) Diabetes 47, 1537-1543

286. Eizirik, D. L. and Darville, M. I. (2001) Diabetes 50 Suppl 1, S64-S69

287. Withers, D. J., Burks, D. J., Towery, H. H., Altamuro, S. L., Flint, C. L., and White, M. F. (1999) Nat.Genet. 23, 32-40

288. White, M. F. (2002) Am.J.Physiol Endocrinol.Metab 283, E413-E422

289. Hennige, A. M., Burks, D. J., Ozcan, U., Kulkarni, R. N., Ye, J., Park, S., Schubert, M., Fisher, T. L., Dow, M. A., Leshan, R., Zakaria, M., Mossa-Basha, M., and White, M. F. (2003) J.Clin.Invest 112, 1521-1532

290. Garofalo, R. S., Orena, S. J., Rafidi, K., Torchia, A. J., Stock, J. L., Hildebrandt, A. L., Coskran, T., Black, S. C., Brees, D. J., Wicks, J. R., McNeish, J. D., and Coleman, K. G. (2003) J.Clin.Invest 112, 197-208

291. Wrede, C. E., Dickson, L. M., Lingohr, M. K., Briaud, I., and Rhodes, C. J. (2002) J.Biol.Chem. 277, 49676-49684

292. Tuttle, R. L., Gill, N. S., Pugh, W., Lee, J. P., Koeberlein, B., Furth, E. E., Polonsky, K. S., Naji, A., and Birnbaum, M. J. (2001) Nat.Med. 7, 1133-1137

293. Aikin, R., Rosenberg, L., and Maysinger, D. (2000) Biochem. Biophys. Res.Commun. 277, 455-461

294. Giannoukakis, N., Mi, Z., Rudert, W. A., Gambotto, A., Trucco, M., and Robbins, P. (2000) Gene Ther. 7, 2015-2022

295. Chen, W., Salojin, K. V., Mi, Q. S., Grattan, M., Meagher, T. C., Zucker, P., and Delovitch, T. L. (2004) Endocrinology 145, 627-638

296. Kushner, J. A., Haj, F. G., Klaman, L. D., Dow, M. A., Kahn, B. B., Neel, B. G., and White, M. F. (2004) Diabetes 53, 61-66

297. Tao, J., Malbon, C. C., and Wang, H. Y. (2001) J.Biol.Chem. 276, 29520-29525 
298. Lee, S. R., Kwon, K. S., Kim, S. R., and Rhee, S. G. (1998) J.Biol.Chem. 273, $15366-15372$

299. Mahadev, K., Zilbering, A., Zhu, L., and Goldstein, B. J. (2001) J.Biol.Chem. 276, 21938-21942

300. Madge, L. A. and Pober, J. S. (2000) J.Biol.Chem. 275, 15458-15465

301. Pousset, F., Dantzer, R., Kelley, K. W., and Parnet, P. (2000) Eur.Cytokine Netw. $11,427-434$

302. Sizemore, N., Leung, S., and Stark, G. R. (1999) Mol.Cell Biol. 19, 4798-4805

303. Anneren, C. and Welsh, M. (2001) Mol.Med. 7, 301-310

304. Gotoh, M., Maki, T., Kiyoizumi, T., Satomi, S., and Monaco, A. P. (1985) Transplantation 40, 437-438

305. Paglia, D. E. and Valentine, W. N. (1967) J.Lab Clin.Med. 70, 158-169

306. Bonny, C., Oberson, A., Steinmann, M., Schorderet, D. F., Nicod, P., and Waeber, G. (2000) J.Biol.Chem. 275, 16466-16472

307. Bonny, C., Oberson, A., Negri, S., Sauser, C., and Schorderet, D. F. (2001) Diabetes 50, 77-82

308. Ling, Z., Van de, C. M., Dong, J., Heimberg, H., Haefliger, J. A., Waeber, G., Schuit, F., and Pipeleers, D. (2003) Diabetes 52, 2497-2502

309. Rabinovitch, A. and Suarez-Pinzon, W. L. (1998) Biochem.Pharmacol. 55, 1139-1149

310. Meng, T. C., Buckley, D. A., Galic, S., Tiganis, T., and Tonks, N. K. (2004) J.Biol.Chem.

311. Meng, T. C., Fukada, T., and Tonks, N. K. (2002) Mol.Cell 9, 387-399

312. Salmeen, A., Andersen, J. N., Myers, M. P., Meng, T. C., Hinks, J. A., Tonks, N. K., and Barford, D. (2003) Nature 423, 769-773

313. Altomare, D. A., Tanno, S., De Rienzo, A., Klein-Szanto, A. J., Tanno, S., Skele, K. L., Hoffman, J. P., and Testa, J. R. (2003) J.Cell Biochem. 88, 470-476

314. Burtscher, I., Compagni, A., Lamm, G. M., and Christofori, G. (1999) Cancer Res. 59, 3923-3926

315. Welsh, N., Margulis, B., Bendtzen, K., and Sandler, S. (1994) J.Endocrinol. 143, $151-156$ 
316. Chuang, S. M., Wang, I. C., Hwua, Y. S., and Yang, J. L. (2003) Carcinogenesis 24, 7-15

317. Kwon, Y. G., Min, J. K., Kim, K. M., Lee, D. J., Billiar, T. R., and Kim, Y. M. (2001) J.Biol.Chem. 276, 10627-10633

318. Sata, M., Kakoki, M., Nagata, D., Nishimatsu, H., Suzuki, E., Aoyagi, T., Sugiura, S., Kojima, H., Nagano, T., Kangawa, K., Matsuo, H., Omata, M., Nagai, R., and Hirata, Y. (2000) Hypertension 36, 83-88

319. Ozaki, M., Kawashima, S., Hirase, T., Yamashita, T., Namiki, M., Inoue, N., Hirata, K. K., and Yokoyama, M. (2002) Am.J.Pathol. 160, 1335-1344

320. Tejedo, J. R., Ramirez, R., Cahuana, G. M., Rincon, P., Sobrino, F., and Bedoya, F. J. (2001) Cell Signal. 13, 809-817

321. Tejedo, J. R., Cahuana, G. M., Ramirez, R., Esbert, M., Jimenez, J., Sobrino, F., and Bedoya, F. J. (2004) Endocrinology 145, 2319-2327

322. Hill, D. J., Petrik, J., Arany, E., McDonald, T. J., and Delovitch, T. L. (1999) J.Endocrinol. 161, 153-165

323. McClung, J. P., Roneker, C. A., Mu, W., Lisk, D. J., Langlais, P., Liu, F., and Lei, X. G. (2004) Proc.Natl.Acad.Sci.U.S.A 101, 8852-8857

324. Zhou, Z. and Kang, Y. J. (2000) J.Histochem.Cytochem. 48, 585-594

325. Goossens, V., Grooten, J., De Vos, K., and Fiers, W. (1995) Proc.Natl.Acad.Sci.U.S.A 92, 8115-8119

326. Besselsen, D. G., Wagner, A. M., and Loganbill, J. K. (2000) Comp Med. 50, 498-502

327. Jacoby, R. O., Ball-Goodrich, L. J., Besselsen, D. G., McKisic, M. D., Riley, L. K., and Smith, A. L. (1996) Lab Anim Sci. 46, 370-380

328. Jacoby, R. O., Johnson, E. A., Ball-Goodrich, L., Smith, A. L., and McKisic, M. D. (1995) J.Virol. 69, 3915-3919

329. McKisic, M. D., Paturzo, F. X., and Smith, A. L. (1996) Transplantation 61, 292-299

330. Ball-Goodrich, L. J., Leland, S. E., Johnson, E. A., Paturzo, F. X., and Jacoby, R. O. (1998) J.Virol. 72, 3289-3299

331. Nicklas, W. (1999) Berl Munch Tierarztl.Wochenschr. 112, 201-210 


\title{
CURRICULUM VITAE
}

\author{
Xiaoyan (Nina) Li
}

\section{PERSONAL}

Address:

101 Nob Hill Lane, \#8, Louisville, Kentucky 40206

Telephone:

Home: (502)-895-1782

Work: (502)-852-2632

Fax: (502)-852-5634

E-mail:

x0li0005@gwise.louisville.edu

\section{RESEARCH EXPERIENCE}

08/2000-08/2004 Graduate Research Assistant, Department of Pharmacology and Toxicology, University of Louisville, Kentucky

Advisor: Paul N. Epstein

Ph.D. project "Pancreatic beta cell antioxidant transgenes in diabetes and islet transplantation", supported by NIH grants RO1-DK 52309 and RO1-DK58100

09/1992-01/2000 Research Assistant and Lecturer, Department of Neurobiology, Shanghai Medical University, Shanghai, P.R. China

Worked on three projects:

- Depressive disorders concerning biochemical mechanisms and treatment of animal model, funded by Shanghai Municipal Health Bureau, No. 95 (A) 1117, 1996-1999 
- Roles of opioid peptides and receptors in antinociception, funded by the National Natural Science Foundation of China, No. 39670901, 19921997

- Roles of dopamine agonists/antagonists and receptor subtypes in pain modulation, funded by the National Natural Science Foundation of China, No. 39230360, 1993-1995

01/1997-08/1999

Neurobiology,

Graduate Research Assistant, Department of

Shanghai Medical University, Shanghai, P.R. China

M.S. in Neurobiology

Advisor: Shaofen $\mathrm{Xu}$

M.S. project "Role of serotoninergic system on analgesia"

10/1991-07/1992 Undergraduate student, Department of Neurobiology, Shanghai Medical University, Shanghai, P.R. China

Thesis work "C-Fos expression during electroacupuncture analgesia in rats."

\section{$\underline{\text { EDUCATION }}$}

01/2003-08/2004 University of Louisville, Louisville, KY 40202

Ph.D. in Pharmacology and Toxicology

01/2001-12/2002 University of Louisville, Louisville, KY 40202

M.S. in Pharmacology and Toxicology

08/2000-01/2001 University of North Dakota, Grand Forks, ND 58202

Ph.D. student in Pharmacology and Toxicology program

01/1997-08/1999 Shanghai Medical University, Shanghai, P.R. China

M.S. in Neurobiology

09/1987-07/1992 Shanghai Medical University, Shanghai, P.R. China

B.S. in Pharmacology 


\section{TEACHING ACTIVITIES}

In China: Neurobiology to Undergraduate students and Graduate students, including both laboratory tutoring and large group lecturing

\section{HONORS AND AWARDS}

1. $\quad 3^{\text {rd }}$ Place Award for Graduate Student Division, 2002, Research Louisville 2002

2. Honorable Mention for Graduate Student Division, 2001, Research Louisville 2001

3. IPIBS Fellowship: 2001-2002, University of Louisville

4. One of the winners of the Second Prize for Scientific Technological Development by the National Education Commission for the research on opioid receptor and its molecular mechanism during acupuncture analgesia, 1999, National Education Commission, China

5. One of the winners of the First Prize for Scientific Technological Development by the National Education Commission for the research on relationship between opioidnergic and dopaminergic system during electroacupuncture combined with drugs. 1997, National Education Commission, China

6. First Prize for the Best Research Manuscript from the Third East-West Panin Conference, XiAn, China, 1994.

Title: "The mechanism during electroacupuncture analgesia enhanced by fenfluramine"

7. Outstanding Student Fellowship from Shanghai Medical University, China in 1988, 1990, 1992

\section{PUBLICATIONS}


1. Xiaoyan Li, Hainan Chen, Patricia Kralik, Paul N. Epstein. Overexpression of cytoplasmic antioxidant proteins in pancreatic beta cells unexpectedly sensitizes NOD mice to type 1 diabetes by diminishing reactive oxygen species mediated beta cell self-protection. (Manuscript in preparation)

2. Hainan Chen, Xiaoyan Li, Paul N. Epstein. Overexpression of MnSOD and Catalase synergistically protects transgenic mouse beta cells from oxidative damage but not from cytokine-induced cytotoxicity. (to be submitted to The Journal of Clinical Investigation)

3. Xiaoyan Li, Hainan Chen, Paul N. Epstein. Metallothionein protects islets from hypoxia and extends islet graft survival by scavenging most kinds of reactive oxygen species. J. Biol. Chem. (2004) 279 (1): 765-771

4. Xiaoyan Li, Chong-Bin Zhu, Hainan Chen, Yan-Hua Zhu, Gen-Cheng Wu, Shao-Fen Xu. Effects of fenfluramine combined with electroacupuncture on monoamine release in periaqueductual gray of rat brain. Acta Pharmacol Sin (1999) 20 (7): 597-600

5. Xiaoyan $\mathbf{L i}$, Jin $\mathrm{Yu}$, Gengcheng Wu: Sucrose preference is restored by electroacupuncture combined with chlorimipramine in the depressive rats induced by chronic mild stress. Caps News Communication 1998, 17(Suppl 1): $113-114$

6. Xiu Gao, Xiaoyan Li, Shaofen Xu: Changes of central D1 and D5 receptor messenger RNA after electro-acupuncture in rat. Chin J Neurosci $1998 ; 14(1): 46-49$

7. Xianyan Li, Jin Yu, Gengcheng Wu: Reduction of immobility in a mouse forced swimming test by antidepressant combined with electroacupuncture. Chinese Journal of Neuroanatomy 1997, 13(suppl): 139-140

8. Chongbin Zhu, Xiaoyan Li, Yanhua Zhu, Shaofen Xu: Function and expression of centrol dopamine receptor in electroacupuncture analgesia. Chinese Journal of Neuroanatomy 1997, 13(suppl): 107-108

9. Chongbin Zhu, Xiaoyan Li, Yanhua Zhu, Shaofen Xu: Alterations of monoamine content in perfusate of rat brain following droperidol enhanced electroacupuncture analgesia. Acta Physiol Sin 1997, 49(4): 382-388

10. Chongbin Zhu, Xiaoyan Li, Yanhua Zhu, Shaofen Xu: Preproopiomalanocoutin (POMC) and preprodynorphin (PPD) mRNA expression following combination of electroacupuncture with droperidol. Acta Pharmacol Sin 1997, 18(1):54-7

11. Xiaoyan Li, Chongbin Zhu, Yanhua Zhu, Shaofen Xu: Expressions of 
preproenkephalin mRNA during electroacupuncture analgesia enhanced by fenfluramine. Acta Pharmacol Sin 1995;16(5): 431-4

12. Chongbin Zhu, Xiaoyan Li, Yanhua Zhu, Shaofen Xu: Binding sites of mu receptor increased when acupuncture analgesia was enhanced by droperidol: an autoradiographic study. Acta Pharmacol Sin 1995; 16(4); 311-4

13. Xiaoyan Li, Yanhua Zhu, Shaofen Xu: A free-floating method for in situ hybridization histochemistry using DIG labelled RNA probes. Acta Acad Med Shanghai $1995 ; 22(1): 79-82$

14. Chongbin Zhu, Xiaoyan Li, Yanhua Zhu, Shaofen Xu: Alterations of central delta and Kappa opioid receptor binding sites in droperidol enhanced acupuncture analgesia. Acta Acad Med Shanghai 1994; 21(suppl): 14-8

15. Xiaoyan Li, Chongbin Zhu, Yanhua Zhu, Shaofen Xu: Changes of opioid receptor in rat brain during electroacupuncture analgesia potentiated by fenfluramine. Acta Acad Med Shanghai 1994; 21(suppl):50-5

16. Jiale Dai, Yanhua Zhu, Xiaoyan Li, Shaofen Xu: C-Fos expression during electroacupuncture analgesia in rats--an immunohistochemical study. Acupuncture \& Electro-Therapeutics Res, INT.J. 1992; 17:165-176

\section{ABSTRACTS AND MEETING PRESENTATIONS}

1. Xiaoyan Li, Hainan Chen, Patricia Kralik, Paul N. Epstein. Overexpression of beta cell cytoplasmic antioxidants reduced ROS mediated beta cell survival and unexpectedly sensitized Type 1 diabetes and beta cell apoptosis in NOD mice. Presented as a late breaking abstract at American Diabetes Association's $64^{\text {th }}$ Scientific Sessions, Orlando, Florida 2004

2. Xiaoyan Li, Hainan Chen, Patricia Kralik, Paul N. Epstein. Unexpected susceptibility to cyclophosphamide accelerated Type 1 diabetes and beta cell apoptosis in NOD mice due to beta cell overexpression of antioxidant transgenes. Presented at Research Louisville, University of Louisville, Kentucky, November 2003

3. Xiaoyan Li, Hainan Chen, Patricia Kralik, Paul N. Epstein. Unexpected susceptibility to cyclophosphamide accelerated Type 1 diabetes and beta cell apoptosis in NOD mice due to beta cell overexpression of antioxidant transgenes. Presented as a late breaking abstract at American Diabetes Association's $63^{\text {rd }}$ Scientific Sessions, New Orleans, Louisiana, 2003 
4. Xiaoyan Li, Hainan Chen, Paul N. Epstein. Metallothionein overexpression improves graft function during the early phase of pancreatic islet transplantation. Accepted as an abstract publication at American Diabetes Association's $63^{\text {rd }}$ Scientific Sessions, New Orleans, Louisiana, 2003

5. Hainan Chen, Xiaoyan Li, Paul N. Epstein. Overexpression of MnSOD and Catalase synergistically protects transgenic mouse beta cells from oxidative damage but not from cytokine-induced cytotoxicity. Presented at American Diabetes Association's $63^{\text {rd }}$ Scientific Sessions, New Orleans, Louisiana, 2003

6. Hainan Chen, Xiaoyan Li, Paul N. Epstein. Complimentary protection of MnSOD and catalase transgenes against reactive oxygen species and streptozotocin induced pancreatic beta cell destruction. Presented at Ohio Valley Society of Toxicology Meeting, Louisville, Kentucky, 2002

7. Xiaoyan Li, Hainan Chen, Paul N. Epstein. Metallothionein protects islets from hypoxia and extends islet graft survival by scavenging most kinds of reactive oxygen species. Presented at Ohio Valley Society of Toxicology Meeting, Louisville, Kentucky, 2002

8. Hainan Chen, Xiaoyan Li, Paul N. Epstein. Synergistic protection on pancreatic islets by beta cell specific overexpression of MnSOD and catalase in transgenic mice. Presented at Research Louisville, University of Louisville, Kentucky, November 2002

9. Xiaoyan Li, Hainan Chen, Paul N. Epstein. Metallothionein protects islets from hypoxia and extends islets graft survival by scavenging most kinds of reactive oxygen species. Presented at Research Louisville, University of Louisville, Kentucky, November 2001

10. Xiaoyan Li, Jin $\mathrm{Yu}$ and Gengcheng $\mathrm{Wu}$. Reduction of immobility in a mouse forced swimming test by antidepressant combined with electroacupuncture. Presented at The Chinese Society for Neuroscience, the Second Biennial Meeting, Xi'an China, 1997

11. Xiaoyan Li, Chongbin Zhu, Yanhua Zhu and Shaofen Xu. The mechanism during electroacupuncture analgesia enhanced by fenfluramine. Presented at The Third Standford International Neuroscience Symposium, Shanghai China, 1995

12. Xiaoyan Li, Chongbin Zhu, Yanhua Zhu and Shaofen Xu. Effects of fenfluramine combined with electroacupuncture on monoamine release in periaqueductal gray of rat brain. Presented at The Chinese Society for Neuroscience, the First Biennial Meeting, Shanghai China, 1995 
13. Xiaoyan Li, Chongbin Zhu, Yanhua Zhu and Shaofen Xu. The mechanism during electroacupuncture analgesia enhanced by fenfluramine. Presented at The Third East-West Pain Conference, Xi'an China, 1995

14. Xiaoyan Li, Chongbin Zhu, Yanhua Zhu and Shaofen Xu. Changes of opioid receptor in rat brain during electroacupuncture analgesia potentiated by fenfluramine. Presented at The fifth Chinese electroacupuncture Anesthesia and Analgesia Symposium, Wuhan China,. 1994 